Life Sciences Division

and Center for Human Genome Studies

1994

Compiled by

L. Scott Cram

Carolyn Stafford 



\section{DISCLAIMER}

This report was prepared as an account of work sponsored by an agency of the United States Government. Neither the United States Government nor any agency thereof, nor any of their employees, make any warranty, express or implied, or assumes any legal liability or responsibility for the accuracy, completeness, or usefulness of any information, apparatus, product, or process disclosed, or represents that its use would not infringe privately owned rights. Reference herein to any specific commercial product, process, or service by trade name, trademark, manufacturer, or otherwise does not necessarily constitute or imply its endorsement, recommendation, or favoring by the United States Government or any agency thereof. The views and opinions of authors expressed herein do not necessarily state or reflect those of the United States Government or any agency thereof. 


\section{DISCLAIMER}

Portions of this document may be illegible electronic image products. Images are produced from the best available original document. 


\section{ACKNOWLEDGMENTS}

We wish to thank all those who participated in the preparation of this document for their valuable assistance; in particular, Monica Fink, Fawn Gore, Ruby Archuleta, Dusty

DeAguero, Tricia Lewis, Josie Gutierrez, and the Life Sciences principal investigators.

This document was produced by Group CIC-1. Editors were Linda K. Wood of Bethco, Inc., for Group CIC-1 and Virginia Cleary of Group CIC-1. Photocomposition was accomplished by Deidre' A. Plumlee of Ray Rashkin Associates, Inc., for Group CIC-1. Printing coordinator was Guadalupe Archuleta of Group CIC-17. 
Overview

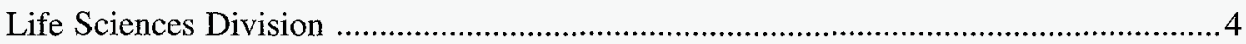

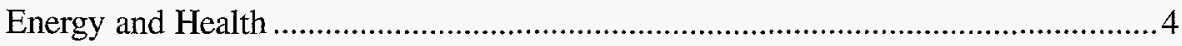

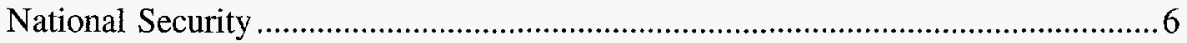

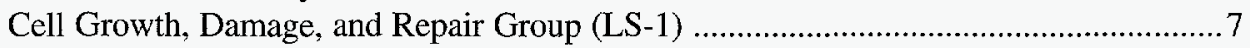

Genomics and Structural Biology Group (LS-2) ......................................................... 10

Selected Research Highlights

Construction of an Integrated Map of Human Chromosome 16 (DOE) ......................... 16

Rapid Kinetics Flow Cytometry (LDRD) ………..................................................21

Loss of the Catalytic Subunit of the DNA-Dependent Protein Kinase in scid Mouse and Chinese Hamster Ovary V3 Cells (DOE) ..........................................................2 24

Biological Implications of the Hairpin Structures Formed by the Single Strands of

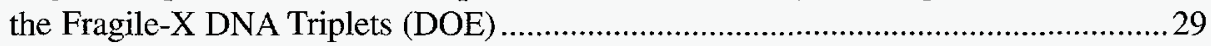

Research Projects

Genomics

Human Recombinant DNA Library (DOE)

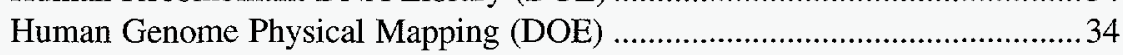

Genome Organization and Function (DOE) .................................................... 35

Directly Labeled Fluorescent DNA Probes for Chromosome

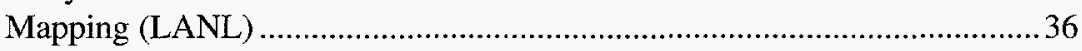

Sequence-Tagged Site Generation and Yeast Artificial Chromosome Contig Assembly on Human Chromosome 5 (DOE) ............................................... 36

Molecular Genetics (DOE) …………………….......................................... 37

Molecular Microbial Ecology-Soil Microbial Communities in Stressed

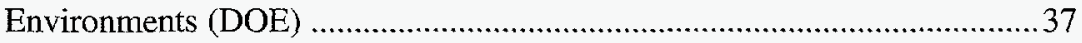

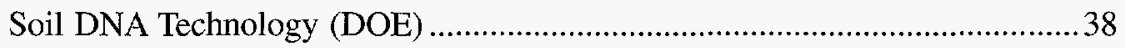

Plant Gene Expression (Southwest Consortium for Plant Genetics and

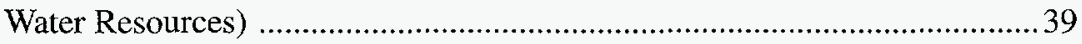

Development of Methods That Detect and Monitor Environmental Munitions

Contaminants Using Plant Sentinels and Molecular Probes (U.S. Army) ....39

Development and Testing of Biosensors That Quantitatively and Specifically

Detect Organic Contaminants (LANL) ......................................................40

Chelation of Metal Ions by Cell Wall Components (DOE) …………………......41

Genomics Accomplishments ......................................................................42

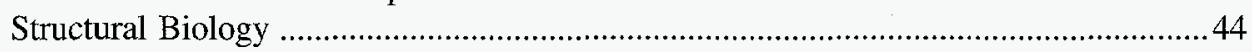

Engineering Sequence-Specific Ribonucleic Acid and Single-Stranded DNA

Binding Proteins (LANL) .........................................................................4

Folding and Stability of the Gene V Protein of Phage f1 (NIH) …..................44

The Use of Spallation Neutron Sources for Structural Biology ........................45

Dynamic Studies of Protein Hydration .............................................................4

Neutron Diffraction Studies of Myoglobins .......................................................46

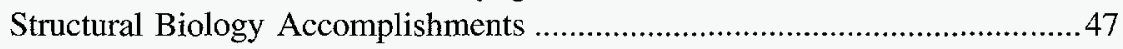

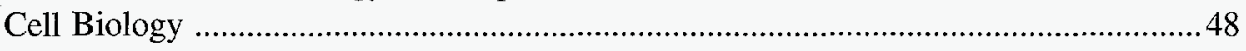

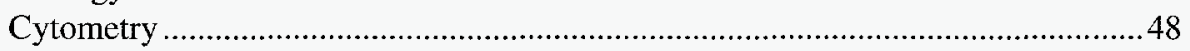

National Flow Cytometry Resource (NIH) ...................................................4 48

Advanced Flow Cytometric Development (DOE) ......................................... 49

Flow Cytometer for Quantifying Fluorescence Lifetime (NIH) .......................49 
Flow Cytometric Analysis of Multiple DNA Fluorochromes (NIH) ..............50

Normalization of Immunophenotyping Data (NIH) .....................................51

Rapid Mix Flow Cytometer (LANL) ………….........................................52

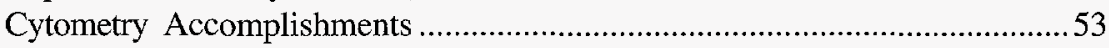

Cell Growth and Differentiation .............................................................................5

Optimization and Monitoring of Hollow-Fiber Bioreactors (LANL) ...............54

Regulation of Cellular Growth in Multicellular Spheroids (NIH) ...................54

Nuclear Magnetic Resonance Spectroscopy and Imaging of Tumor

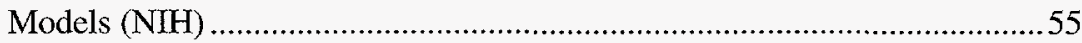

Molecular Biology of Cell-Cycle-Dependent Genomic Structure (DOE) .......56

Mechanisms of Pulmonary Damage (DOE) ..................................................56

Latent Expression of Genetic Damage in Human Lung Cells Caused by

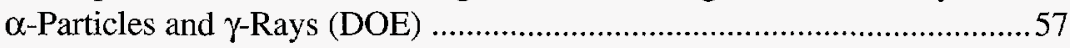

Cell Growth and Differentiation Accomplishments .........................................58

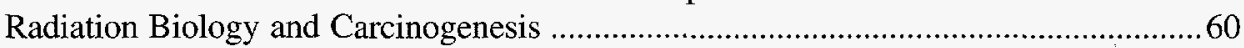

Mechanisms of Radiation and Chemical Genetic Toxicology (DOE) .............60

Molecular Genetics of Human Radiation Repair Genes (DOE) ........................60

Cell-Cycle Regulation after $\alpha$-Particle Exposure (NIH) .................................61

Molecular Cloning of a Human Radiation Repair Gene (NIH) .....................61

Radiation-Induced Mutation Spectra at the Human HPRT Locus (NIH) ........62

Transgenic Cell and Animal Models of Human Radiation

Sensitivity (DOE)

Chromosomal Damage in the 1-Rad Region: Cytogenetic Detection

Following Ultralow Doses and Dose Rate (DOE) .64

Applications of Strand-Specific In-Situ Hybridization (LANL) .....................64

Repair of Bifilar DNA Damage Induced by Radiation (NIH) ........................65

Radiation Responses of S-Phase Cells (DOE) ..............................................65

Development of an Ultrasensitive and Rapid DNA Repair

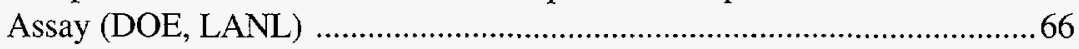

Competency Development in Antibody Production for Cancer

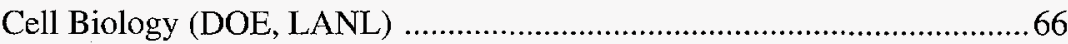

Karyotype Instability and Neoplasia (DOE, LANL) ...................................67

Radiation Biology and Carcinogensis Accomplishments ..................................68

Facilities and Support Services

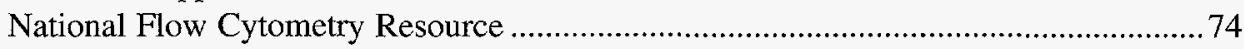

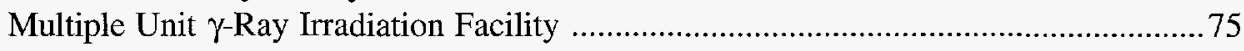

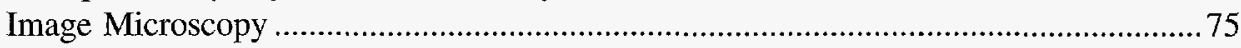

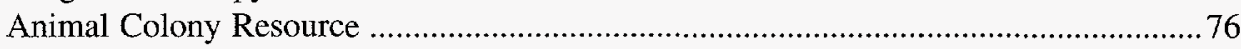

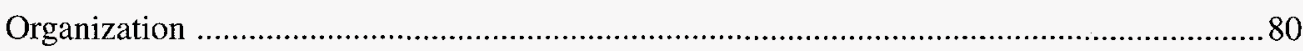

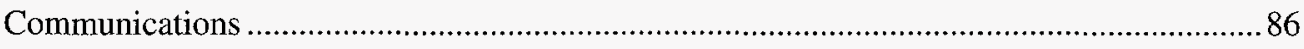

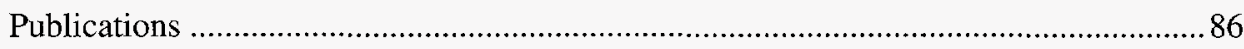

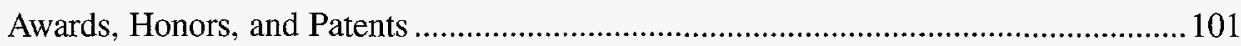




\title{
Life Sciences Division and Center for Human Genome Studies
}

\author{
1994 \\ Compiled by \\ L. Scott Cram and Carolyn Stafford
}

\begin{abstract}
This report summarizes the research and development activities of the Los Alamos National Laboratory's Life Sciences Division and the biological aspects of the Center for Human Genome Studies for the calendar year 1994.

The technical portion of the report is divided into two parts, (1) selected research highlights and (2) research projects and accomplishments. The research highlights provide a more detailed description of a select set of projects. A technical description of all projects is presented in sufficient detail so that the informed reader will be able to assess the scope and significance of each project. Summaries useful to the casual reader desiring general information have been prepared by the group leaders and appear in each group overview. Investigators on the staff of the Life Sciences Division will be pleased to provide further information.
\end{abstract}




\section{Overview}




\section{LIFE SCIENCES DIVISION}

The mission of the Life Sciences (LS) Division at Los Alamos National Laboratory (LANL) is to serve the nation's needs in health, energy, and national security by addressing a broad range of biological problems at the molecular, cellular, physiological, and whole-organism levels. The Division develops and uses the most advanced biological technologies and, whenever appropriate, exploits unique resources in the physical, chemical, and theoretical sciences found throughout Los Alamos National Laboratory.

Life Sciences Division consists of two technical groups: Cell Growth, Damage, and Repair (LS-1), and Genomics and Structural Biology (LS-2). The Center for Human Genome Studies (CHGS) is closely integrated with the Life Sciences Division. These three organizations are responsible for approximately 90 projects. Support for the Division's projects originates largely from the Department of Energy's Office of Health and Environmental Research (OHER). A significant portion also is derived from National Institutes of Health (NIH) and the Department of Defense (DoD). Laboratory-Directed Research and Development (LDRD) funds are also used to support new initiatives. Projects funded by all of these sources are included in this report because they are integrated into the Division's strategic plan and serve to strengthen and complement the core OHER effort.

\section{Energy and Health}

The primary mission of the Department of Energy (DOE) is to ensure the energy needs of the nation. Major sources of energy are from nuclear fission and fossil fuel. Both processes generate byproducts that can affect health through the induction of carcinogenesis caused by DNA damage. As a consequence of these concerns, a major objective of the Life Sciences Division is to understand the health effects of different types of radiation and chemicals. The basic biological principles will apply irrespective of whether the radiation and chemicals are artificially produced or originate from natural sources. Research projects in the Division address the molecular mechanisms of mutagenesis, DNA repair, and regulation of gene expression. Because carcinogenesis is characterized by genetic instability and aberrant cell growth, research projects are further directed toward an understanding of cell cycle controls, cell metabolism and differentiation, and the processes of tumor growth and tumor rejection. These projects are being developed with the intention of pursuing a new program in cancer risk assessment biology. This program has as its ultimate goal the ability to predict an individual's risk based on an understanding of susceptibility genes and external carcinogenic factors. These projects use the latest technologies of molecular and cellular biology; recombinant DNA technology, tissue culture, DNA sequencing, oligonucleotide synthesis, cytogenetic analysis, cell synchronization, flow cytometry (FCM); and pulsed-field electrophoresis and high-performance liquid chromatography. The National Flow Cytometry Resource (NFCR), located in the Division, provides unique FCM instrumentation for biomedical research programs and chromosome sorting for the Human Genome Project. All efforts are made 
to keep the FCM instrumentation at the highest level of performance by incorporating advances made in new data acquisition systems, new optical techniques, cutting edge electronics, and computer and programming techniques.

The Human Genome Project is part of a nationwide effort to physically map the 100,000 or more human genes and eventually to sequence human genomes. The project will provide the DNA sequence database for biomedical research concerned with DNA damage from radiation and chemicals and with human susceptibilities to genetic diseases. Major research activities in LS Division are directed to chromosome sorting, to development of human chromosome libraries, and to the physical mapping of chromosomes 16 and 5. In collaboration with the Chemical Science and Technology (CST) Division, a major effort is underway to develop advanced DNA sequencing methods based on single molecular detection. This venture has the potential to revolutionize DNA sequencing methods.

Whereas radiation-induced DNA damage is largely a random hit mechanism, this is not the case for chemically induced DNA damage that is determined in part by the accessibility of the DNA substrate to the chemicals. Thus, an understanding of chemical damage to DNA will require an understanding of the packaging of DNA in chromosomes and changes in chromosome structure through the cell cycle. It is remarkable that, although chromosomes have been central to biology since they were first observed almost two centuries ago, surprisingly little is known at the molecular level of their organization, structure, and functions. Such understanding is central to basic questions in biology, e.g., developmental cell biology, as well as to the mission of DOE. Major projects in LS Division are concerned with the organization of chromosomes, particularly with the functions of repetitive DNA sequences.

The DNA sequence database from the Human Genome Project is important for two major goals in structural biology. The first is to clarify the DNA organization, structure, and functions of chromosomes at all levels down to the nucleosome. The second goal is to gain the capability of going from linear DNA gene-coding sequences to three-dimensional protein structures and their functions. The latter effort will require an enlarged protein sequence-conformation database. To approach these long-term problems, DOE is developing a structural biology initiative that will utilize the unique facilities in the national laboratories, such as high-flux neutron and x-ray scattering and high-resolution nuclear magnetic resonance (NMR) spectroscopy that will complement the high-flux neutron and $x$-ray sources. Because we lack even lowresolution solutions to many of the structural questions concerning the folding path and packaging of DNA in chromosomes, we must evaluate imaging techniques that have the potential to image hydrated states of nucleoproteins. Such techniques employ scanning tunneling microscopy (STM) and atomic force microscopy (AFM).

The radiation biology program in the Life Sciences Division focuses on determining the molecular mechanisms of radiation damage in living organisms and the limits and consequences of low levels of radiation exposure. Projects concerned with the mutagenicity of low doses of ionizing radiation address the problems of identifying the primary genetic lesions of radiation damage. Projects concerned with the 
effects of radiation on chromatin structure address issues involving the role of protein-DNA interactions in radiation damage. The mechanisms of radiation damage are also studied at the cellular and molecular levels. These programs on low-level radiation effects provide an important database for the assessment of national concerns about nuclear reactor accidents, such as those that occurred at Three Mile Island and Chernobyl, and fulfill the need to understand the consequences of radiation exposure resulting from national defense activities.

Mechanisms by which human airway epithelial cells respond to radon ( $\alpha$-particles) are being studied to determine the biochemical, cytogenetic, and cellular targets of these particles. The role of reactive oxygen species (such as are found in the lung) and the importance of the latent expression of damage will provide guidance for designing safe energy production processes. These studies will also provide a knowledge base for assessing the impact of energy production on the environment.

Other environmental concerns are also addressed by the Division's programs that examine plant stress. The reclamation of land disturbed by energy production activities will require understanding of chronic effects of toxicity on vegetation. An example of basic research having spin-off into the problems of environmental cleanup is provided by plant genetics and molecular biology studies of plants and associated microflora that survive in stressed environments. An understanding of microbial ecology in the area surrounding naturally stressed environments will help us understand and predict how ecosystem components respond to different maninduced environmental changes.

\section{National Security}

Life Sciences Division provides the nation with a technological base for several national security programs in the life sciences. Pulmonary programs have provided an understanding of the mechanisms of pulmonary injury by toxic inhalants, which is critical to understanding effects on soldiers in the field. These programs use the latest advances in cell biology, genetics, and flow and image cytometry to provide insight into problems facing U.S. national security.

The Division's genetics program strengthens national security with plant genetics projects that use cell culture and recombinant DNA technology genetically to engineer plants tolerant to arid regions. These projects aid national security by providing the technological base for developing food production under adverse agricultural conditions and for maintaining American competitiveness in the agricultural sector.

In conclusion, the Life Sciences Division uses its biomedical technology base to support the mission of both the DOE and LANL, which is to conduct basic and applied research of importance to the nation's security, with emphasis on defense science, technology, and energy needs. 


\section{CELL GROWTH, DAMAGE, AND REPAIR GROUP (LS-1)}

The Cell Growth, Damage, and Repair Group (LS-1) comprises research and development operations in three areas: cell biology, molecular and cellular radiobiology, and flow cytometry. The Group's programmatic efforts are directed toward a mechanistic understanding of biological processes involved in the regulation of cellular growth, differentiation, senescence, and apoptosis (programmed cell death), and of how imbalances in these processes mediate genetic and epigenetic effects of radiation and energy-related chemicals. Our programmatic research utilizes sophisticated techniques in somatic cell genetics and molecular biology, coupled with stateof-the-art instrumentation, to understand the complex series of biochemical events associated with the regulation of cellular proliferation and the processes of DNA repair in the preservation of genetic information.

Research in cell biology is directed toward understanding the interrelationships among various genes and gene products (e.g., kinases, cyclin-dependent kinases) in controlling the cell cycle and how imbalances in these processes can result in cell transformation leading to the neoplastic state. Chromosome instability resulting in the rearrangement or deletion of critical genes, including those involved in cell cycle control, is suspect in the transformation process leading to neoplasia. We are attempting to identify, isolate, and characterize genes and gene products that directly influence karyotype instability and cellular immortalization. Our model system employs human cells expressing the SV40 large T-antigen, a process known to promote chromosome instability. In collaboration with the Human Genome Center at Los Alamos, recently we have isolated several yeast artificial chromosome (YAC) clones in order to define the breakpoint region on human chromosome 6, position q21.

During the past year, we proposed in our cell biology program a new initiative designed to identify biomarkers capable of predicting cancer risk. The basis of this "cancer risk assessment" program is (1) to identify and understand various genes and gene products that regulate cell division and control the processes of repair of DNA damage and (2) to use these putative "cancer susceptibility genes" as biomarkers for predicting risk to individuals exposed to carcinogenic agents. This new initiative is supported in FY95 with Laboratory-Directed Research and (Programmatic) Development (LDRD) funds and is the thematic focus of other ongoing cell biology programs within the Group. Using a combination of experimental resources and advanced instrumentation at LANL, coupled with the ever-increasing genetic information emerging from the Human Genome Program, we propose (1) to identify and isolate various candidate cancer susceptibility genes; (2) to develop functional assays for selected candidate genes; (3) to establish the predictive nature for cancer risk for selected genes; and (4) to develop rapid and reliable bioassays for cancer risk assessment for ultimate commercialization with industrial partners.

In another study, we are developing a model system employing multicellular tumor cell spheroids to clarify the mechanisms controlling the proliferation of malignant cells in solid tumors. State-of-the-art nuclear magnetic resonance (NMR) 
spectroscopy and imaging techniques are being employed to investigate the regulation of tumor cell metabolism and viability using the in vitro spheroid tumor model system.

The underlying mission of our research programs, which primarily are supported by DOE's Office of Health and Environmental Research (OHER), is to provide a fundamental understanding of the long-term health and environmental risks associated with energy and national security activities and to develop approaches and methodologies that mediate the response to potentially hazardous agents. For example, a considerable controversy continues in the U.S. regarding public exposure to radon and its decay products (radon progeny). The major uncertainty underlying this conflicting issue is that of the health effects resulting from low-level radon exposure. It is known that chromosome aberrations represent radiation-induced genetic damage and are sensitive indicators of low-level radiation exposure. We are applying the method of premature chromosome condensation to compare radiation-induced chromosome breaks induced by densely ionizing, radon-like $\alpha$-particles to those generated by low linear-energy transfer (LET) $\gamma$-rays. Current efforts are directed towards the development of a flow cytometric assay for the detection of genetic damage. This automated approach will enable the rapid screening for rare events induced by low-level radiation exposure $(<1 \mathrm{rad})$. The relevance of this work will be in the generation of new, comparative experimental data obtained under conditions mimicking actual human environmental exposures.

Within the Group, we have a team research effort that is focused on understanding the interaction of radiation and energy-associated chemicals with DNA and the metabolic processes involved with the recognition, processing, and/or fixation of resultant DNA damage. Major areas of interest are the mapping of radiation repair genes in the human genome and the development of molecular/cellular genetic strategies to isolate human DNA repair genes. Over the past two years, in collaboration with the Human Genome Center, we have mapped the following repair-related genes: XRCC5, XRCC4L, MutS, SCID, and the human RAD52 homolog to human chromosomes $2 q 35,5 q 14,2 p 16,8 q 11$ and $12 p 12.2-13$, respectively. Our more recent efforts on the excision repair gene ERCC5, now referred to as XP-G since it is the gene defective in xeroderma pigmentosum complementation group $\mathrm{G}$, have resulted in the identification of naturally occurring mutations in XP-G patients, overproduction of the XP-G protein in a baculovirus expression system, and immunocharacterization of the intracellular localization of the XP-G protein.

Ultimately, our molecular/cellular results must be related to phenomena at the whole-organism level. A long-term goal is to understand the genetic basis of cancer susceptibility in a relevant mammalian model system, i.e., the mouse, to determine the contribution of DNA repair pathways to cancer risk in humans. We are currently engineering null ("knockout") mutations in several murine DNA repair-related genes (AP-endonuclease, XP-G, and FEN-1) in order to ascertain the biochemical, genetic, and developmental consequences associated with deficiencies in these genes. Our objective is to develop genetically controlled embryonic cell lines with targeted gene replacements for breeding to germ line. 
A significant effort within Group LS-1 is being devoted to the development, refinement, and application of laser-based analytical techniques, primarily those involving flow cytometry (FCM). Central to this effort is the National Institutes of Health (NIH)-sponsored National Flow Cytometry (NFCR). The NFCR is currently in its 12th year of support by the NIH. Its programmatic objectives are those of research and development (R\&D) in advanced FCM techniques; collaborative research utilizing unique capabilities at Los Alamos; and service projects, training, and information dissemination. Three projects constitute its core R\&D: (1) application of new approaches to multivariate data analysis in further refinement of clustering techniques in the classification and analyses of clinical immunophenotyping data; (2) development of a high-speed optical sorting FCM based on a "photophysical chromosome inactivation" approach; and (3) implementation of a digital data acquisition and analysis system to upgrade and improve the capabilities of our NFCR instrumentation. An associated NIH-funded program is directed toward the development and application of a flow cytometric method capable of separating fluorescent emission signals based on differences in fluorescence lifetimes (phasesensitive FCM).

In addition, we have an ongoing effort in the development of a stopped-flow FCM that allows mixing and delivering of biological samples and acquisition of sample data within a time frame of a few hundred milliseconds. This design will offer a new approach to examine ligand-receptor interactions in living cells, especially in those cases where the binding affinities are so low as to be undetected by conventional methods.

The NFCR provides these advanced flow cytometric capabilities to the biomedical community through research collaborations, consultations, and sabbaticals; training that includes workshops, invited speakers, and visiting scientists; undergraduate, graduate, and postdoctoral fellowship programs; and co-sponsorship, organization, and presentation of an annual flow cytometry course. Information pertaining to various NFCR activities is disseminated quarterly in our NFCR Newsletter.

The National Laboratory Gene Library Project is also located within Group LS-1. The goals of this DOE-funded project are (1) to construct various recombinant DNA libraries for each of the human chromosomes and (2) to distribute these libraries to researchers worldwide through a contract with the American Type Culture Collection in Rockville, Maryland. Coupled closely with this project is an ongoing effort that provides an image microscopy resource for mapping unique DNA sequences (probes) to specific human chromosomes. We have an image microscopy facility dedicated to the development of improved fluorescence in situ hybridization (FISH) methods and the application of computer-assisted digital imaging microscopy to facilitate the speed and accuracy of the chromosome physical mapping. FISH techniques are effective tools for mapping DNA sequences to their corresponding chromosomal locations. We have developed and are employing a variation of this technique referred to as chromosomal orientation FISH, or CO-FISH, that results in defining the 
relative orientation of targeted sequences on a chromosome. This approach is being applied to our gene mapping effort and provides a new physical approach to examine altered gene expression. The identification and characterization of unique, chromosome-specific human DNA probes will be invaluable tools in the physical and genetic mapping efforts of the Human Genome Initiative, as well as in genetic disease diagnosis.

At the time of this writing, Group LS-1 has 23 staff members, 15 technicians, and 15 postdoctoral fellows. In addition we employ 19 LANL-sponsored Graduate Research Associates (GRAs), seven of whom are actively enrolled in an M.S. or Ph.D. degree program through a cooperative arrangement with the University of New Mexico (UNM) School of Medicine in Albuquerque and the UNM North Campus at Los Alamos. We regularly participate in various LANL minority programs, including the DOE-sponsored Historically Black Colleges and Universities (HBCU) program. Currently, four HBCU GRA students are assigned to LS-1. We also have several students with appointments in the LANL-sponsored University Cooperative Program, which provides limited-term laboratory work experiences for third- and fourth-year college undergraduate students. We provide short-term, research employment opportunities for undergraduate students in the LANL-sponsored Undergraduate Student (UGS) program and High School Education Cooperative Program (HS Co-Op). On the average, we employ between 15 and 20 highly qualified students (GRAs and UGSs), who participate in ongoing research projects during their summer break. We also sponsor employment opportunities in the Laboratory's Science and Engineering Research Semester (SERS) program, Teacher's Summer Employment Program (TSEP), and University of California Personnel Assignment Programs. In addition, several of our staff members participate in the New Mexico Academy of Science Visiting Science Program.

\section{GENOMICS AND STRUCTURAL BIOLOGY GROUP (LS-2)}

The Genomics and Structural Biology Group (LS-2) conducts basic research in two major areas-genomics and structural biology. In the genomics research programs, studies are conducted to understand the organization, replication, and regulation of complex genomes, with an emphasis on the human genome. In the structural biology research programs, advanced biophysical techniques are employed to study the structure, function, and interactions of biological macromolecules. The genomics and structural biology programs are highly interactive. For example, one result of the Human Genome Project is a continually increasing database of DNA sequence data, which is important for two of the major problems in structural biology. The first problem is that of understanding the organization and structure of DNA at all levels of organization, from chromosomes down to nucleosomes. The second problem is the protein-folding problem, in which three-dimensional protein structures, and eventually their functions, can be predicted from the linear DNA gene-coding sequences. Both genomics and structural biology are major programmatic areas in the research program of the DOE's Office of Health and Environmental Research (OHER). 
The goal of all of our genomics research programs is to understand the organization, structure, and function of complex genomes. Accordingly, these efforts focus on gaining fundamental knowledge concerning the evolution of DNA as a self-replicating, information-encoding molecule; on elucidating the mechanisms underlying the regulation of gene expression; and on understanding the responses of complex genomes to environmental insults. Addressing these problems requires the development and implementation of state-of-the-art capabilities in molecular biology, cell biology, biochemistry, genetics, and recombinant DNA technology, as well as computerized approaches to data acquisition, data analysis, data management, and communication. These research efforts address the DOE's mission to understand the molecular basis for heritable biological effects of materials related to energy production and are multidisciplinary and highly interactive within the Laboratory. The genomics programs interact closely with the Los Alamos Center for Human Genome Studies as well as with collaborators in the Cell Growth, Damage and Repair Group (LS-1); Theoretical (T) Division; Engineering Sciences and Applications (ESA) Division; Computing, Information, and Communications (CIC) Division; and Chemical Sciences and Technology (CST) Division.

The genomics research activities cover two main areas. The first area involves studies of the organization, replication, and regulation of complex genomes. These studies focus on the identification, isolation, and understanding of specific DNA sequences or features that are involved in modulating chromosome structure and/or in the regulation of differential gene expression. In this area, the identification, cloning, and characterization of the human telomere have provided the basic tools for exploring the structural and functional behavior of this region of the vertebrate genome. Our efforts in the National Laboratory Gene Library Project have concentrated on the construction of recombinant DNA libraries from individual human chromosomes isolated by fluorescence-activated flow sorting. Of particular interest to us is the development and application of large DNA fragment cloning methodology, such as yeast artificial chromosomes (YACs). One of the goals of the Human Genome Project at Los Alamos is to develop technology for genomic physical mapping and to construct a physical map of chromosome 16, as well as to accomplish collaborative evaluation of the physical mapping of other human chromosomes using new mapping technology. In this initiative, bacteriophage, cosmid, and YAC cloning vectors are being employed to produce an ordered set of overlapping DNA fragments that will encompass the chromosome. Partial sequencing of the ends of selected DNA fragments is providing information on potential sequence-tagged sites (STSs).

The second area of genomics research focuses on the regulation of gene expression. While previous studies have investigated both model mammalian and plant cell systems, our current experiments are focused on the genetic systems responsible for the induction of resistance to or tolerance of plant cells to heavy metals. These studies are elucidating the biochemical details of the mechanisms by which plant cells protect themselves against heavy metal toxicity, and researchers are investigat- 
ing the regulation of the expression of the putative metallothionein gene in response to metal ions. As a result of these studies, environmental applications of metal ion binding to plant cells and metabolism of organic compounds by plant cells are being pursued.

The common goal of our structural biology programs is to understand the structure, function, and interactions of biological macromolecules. Some of the advanced biophysical techniques employed in these studies are small-angle neutron scattering, small-angle x-ray scattering, circular dichroism, x-ray diffraction, NMR spectroscopy, scanning tunneling microscopy (STM), and atomic force microscopy (AFM). One general area of interest in our structural biology programs is that of DNA structure at its various levels of organization, from chromosomes to nucleosomes. The second general area of interest is that of protein structure and structural descriptions of protein-protein interactions and protein-DNA interactions. This knowledge of the structure of DNA-protein complexes should provide us with a deeper understanding of the molecular mechanisms by which chemicals react with DNA in cells.

Small-angle neutron scattering and small-angle $\mathrm{x}$-ray scattering measurements provide low-resolution information concerning the shapes of biological macromolecules in solution. Our neutron scattering experiments are conducted at the Manuel T. Lujan, Jr., Neutron Scattering Center (LANSCE) at Los Alamos, a highflux, pulsed-neutron source. Proteins and DNA have intrinsic differences in their neutron scattering densities. As a result, their scattering density can be matched to the scattering density of the solvent using different $\mathrm{H}_{2} \mathrm{O}: \mathrm{D}_{2} \mathrm{O}$ ratios, and thus do not contribute to the neutron scattering pattern. In this technique of contrast variation with neutron scattering, varying the $\mathrm{H}_{2} \mathrm{O}_{2} \mathrm{D}_{2} \mathrm{O}$ solvent composition in a solution of a DNA-protein complex allows one to observe independently the scattering from the DNA component, the protein component, and the DNA-protein complex itself. This technique has proven quite valuable in continuing studies on nucleosomes.

High-resolution information about biological macromolecules can also be obtained by other techniques, such as x-ray diffraction, nuclear magnetic resonance (NMR) spectroscopy, and scanning probe microscopy (SPM). NMR and x-ray crystallography are complementary techniques for studying the structure of biological macromolecules. The X-ray crystallography technique, which gives a detailed description of the atomic coordinates in a molecule, is being employed to study the structure, stability, and function of proteins and will also be applied to protein-DNA complexes. NMR spectroscopy, which can be used to study the structures of molecules in solution, is being used to investigate unusual DNA structures and the binding domains of protein-DNA complexes, such as DNA repair enzyme complexes. The SPM techniques of STM, which probes for changes in surface conductivity, and scanning force microscopy (SFM), which probes forces between the scanning stylus and the surface, are being investigated for the imaging of biological macromolecules. Because these techniques are subject to sample preparation artifacts, the current focus of this program is on the development of well-defined, reproducible methods for the binding of nucleic acids to surfaces. 
Additional areas of research in the group are related to our core structural biology program. One area of interest is understanding the modifications that occur to nuclear proteins as a result of exposure to chemical insults or ionizing radiation and how these modifications affect chromatin structure. These studies employ both highperformance liquid chromatography (HPLC) and high-performance capillary electrophoresis (HPCE) to analyze histones and high-mobility group nuclear proteins. These same analytical techniques are also being applied to studies to identify protein changes associated with chromosome instability and studies to describe the changes in proteins found in the lung following exposure to contaminants. A second area of interest is the chelation of actinide elements by extracellular chelating materials produced by soil microorganisms, which may contribute significantly to their environmental mobility. The chelation of $\mathrm{Pu}+4$ by an iron-complexing siderophore is being studied to address this question. Additional studies are being conducted to determine the structure of the siderophore, which was isolated near the proposed Yucca Mountain nuclear waste repository site in Nevada. 

Selected Research Highlights 


\title{
CONSTRUCTION OF AN INTEGRATED MAP OF HUMAN CHROMOSOME 16 (DOE)
}

\author{
Norman A. Doggett, Lynne A. Goodwin, Judy G. Tesmer, Linda J. Meincke, \\ Michael R. Altherr, Amanda A. Ford, Cleo M. Naranjo, David C. Bruce, David C. Torney,* \\ Robert D. Sutherland, ** Michael G. Lowenstein, Emanual H. Knill,**Larry L. Deaven, \\ David F. Callen, ${ }^{\dagger}$ Grant R. Sutherland, ${ }^{\dagger}$ and Robert K. Moyzis
}

A physical map of a human chromosome should allow rapid access to cloned material covering any chromosomal band or any region between markers on the genetic map. The map should also provide cloned materials necessary for rapid gene identification via "exon amplification" or "direct selection" approaches. Ideally, all available genes and DNA markers should be integrated into this map to provide the widest variety of reference points for entry into all levels of mapping resolution. The map should also provide a high-resolution set of overlapping clones to serve as a template for DNA sequencing.

We have constructed an integrated physical/genetic/cytogenetic map of human chromosome 16 that meets these needs (Fig. 1). The framework for constructing this map is a high-resolution cytogenetic breakpoint map derived from 78 mouse/human somatic cell hybrids and 4 fragile sites that divide chromosome 16 into 90 intervals of average size $1 \mathrm{Mb}$. The physical map consists of both a low-resolution yeast artificial chromosome (YAC) contig map and a high-resolution cosmid contig map. The low-resolution YAC contig map comprises 650 Centre d'Etude du Polymorphisme Humain (CEPH) mega-YACs and 220 flow-sorted, chromosome 16-specific YACs that are localized to and ordered within the breakpoint intervals with 400 sequence-tagged sites (STSs). This YAC map provides $98 \%$ coverage of the euchromatic arms of the chromosome and has an average resolution of $250 \mathrm{~kb}$ between STS markers.

A high-resolution, "sequence ready" cosmid contig map, consisting of 4000 fingerprinted cosmids assembled into contigs covering $60 \%$ of the chromosome, is anchored to the YAC and cytogenetic breakpoint maps via STSs developed from cosmid contigs and by hybridizations between YACs and cosmids. To date, 300 of these contigs, containing greater than 1600 cosmids, have been merged with the integrated physical/genetic/cytogenetic map and thus are regionally localized along the chromosome. This cosmid contig map has an average resolution of $5 \mathrm{kbp}$ between partially ordered restriction sites.

*Theoretical Division

**Computing, Information, and Communications Division

${ }^{\dagger}$ Adelaide Children's Hospital, Adelaide, South Australia, Australia 
A highly informative microsatellite-based genetic map (developed at the Adelaide Children's Hospital) consisting of 78 polymerase chain reaction (PCR) typable markers and having a $2.6 \mathrm{cM}$ median ( 3.2 average) distance between markers is tightly integrated with the physical map because most of these GT/CA markers were developed from localized cosmids or screened against the YAC map, and by regional localization of all markers to the cytogenetic breakpoint map. A total of 193 polymorphic genetic markers have been integrated with the physical map, providing an average resolution of $0.8 \mathrm{~cm}$ between available genetic markers.

To integrate a transcription map of chromosome 16 with the existing physical/ genetic/cytogenetic map, we have subjected 14,000 chromosome 16 cosmids to exon amplification, isolated 5000 exon clones, and sequenced 500 of these clones. More than 500 genes, anonymous DNA markers, and microsatellite repeats have also been incorporated as part of an ongoing effort to integrate all available loci in the genome database with the chromosome 16 map. An STS map with an average resolution of $160 \mathrm{kbp}$ has been achieved by integrating 570 STSs into the physical map. The current state of this integrated map now exceeds the five-year goals of the Human Genome Project. This integrated map is providing a major impact on the cloning of various disease genes and fragile sites on chromosome 16. 


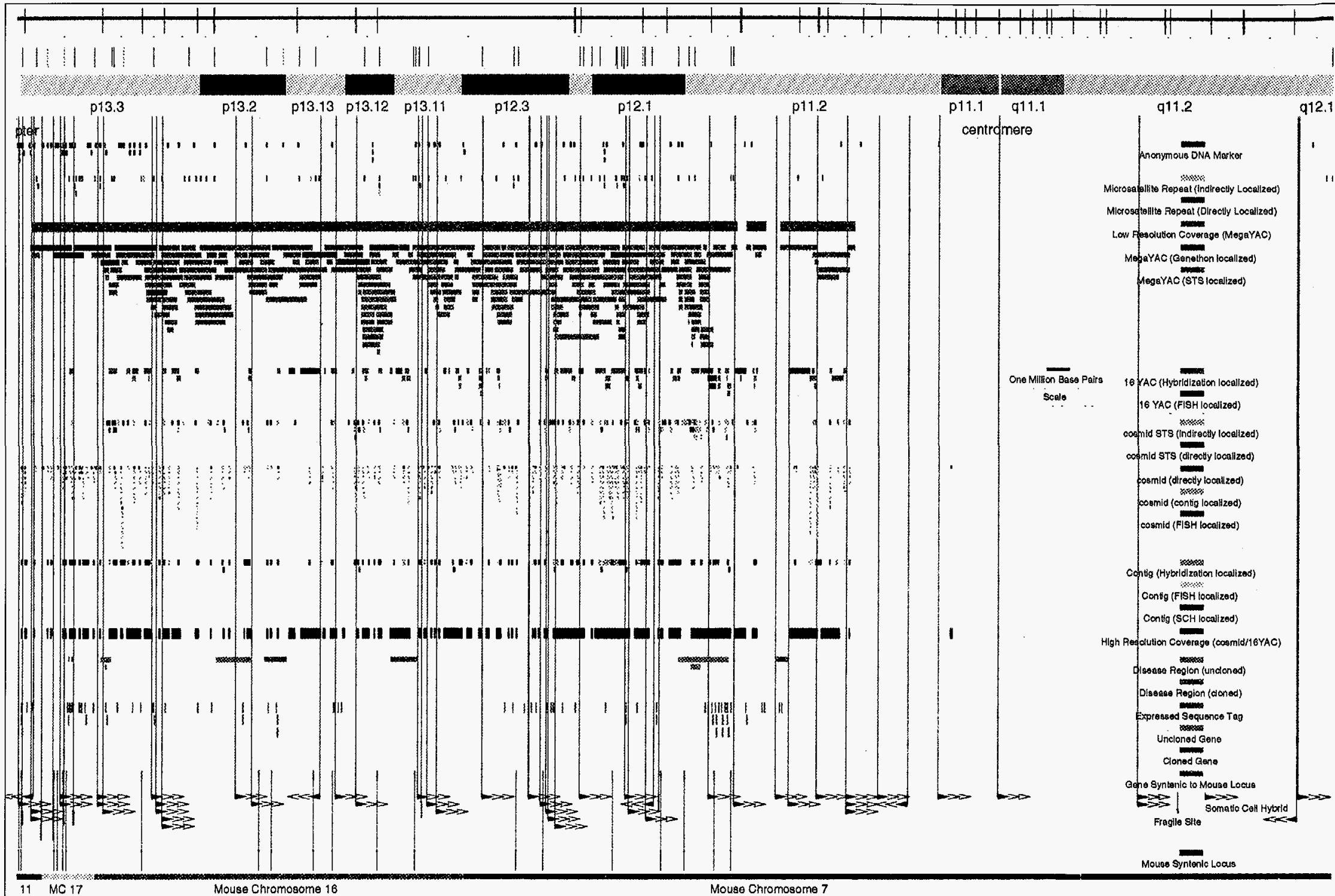

Fig. 1. Graphical representation of the integrated map of human chromosome 16, showing clonal coverage and integration of various map types. Clone names have been removed to allow reproduction on two pages. Typically the map is printed at a size of $3 \mathrm{ft}$ by $15 \mathrm{ft}$ to permit viewing of the most detail. This page contains the $p$ arm of the chromosome, and the following page contains the q arm. Various coloring shades are provided for clarity in reading. 


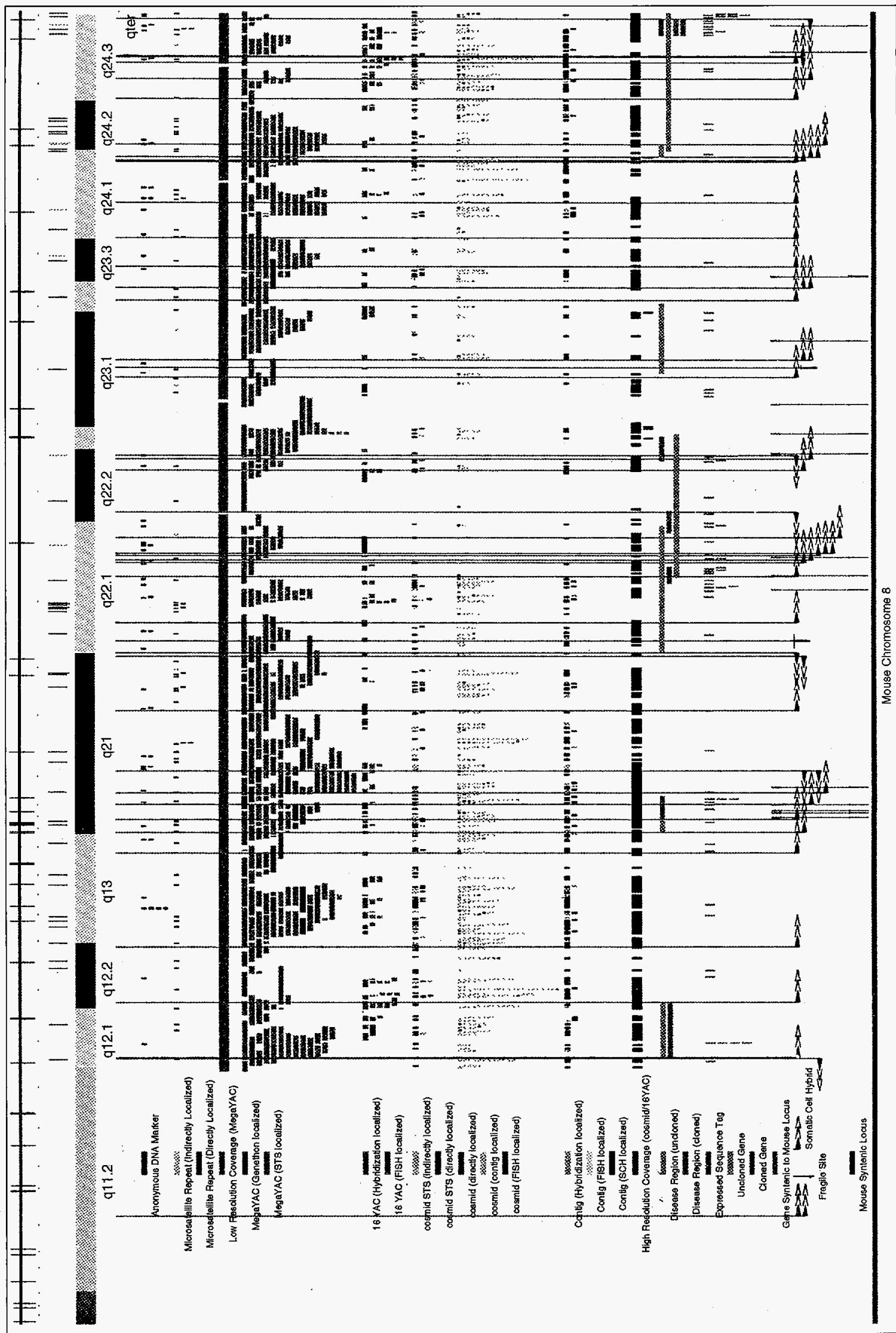




\section{REFERENCES}

1. N. A. Doggett, D. F. Callen, L. A. Duesing, J. G. Tesmer, L. J. Meincke, D. C. Bruce, M. R. Altherr, A. A. Ford, D. C. Torney, R. D. Sutherland, M. G. Lowenstein, M. O. Mundt, W. J. Bruno, E. H. Knill, L. L. Deaven, G. R. Sutherland, R. I. Richards, and R. K. Sutherland, "An Integrated Map of Human Chromosome 16" (to be published in Hum. Mol. Genet., 1995).

2. N. A. Doggett and D. F. Callen, "Report of the Third International Workshop of Human Chromosome 16 Mapping," Cytogenet. Cell Genet. 68, 165-184 (1995).

3. N. A. Doggett, D. F. Callen, L. A. Duesing, J. G. Tesmer, L. J. Meincke, D. C. Bruce, M. R. Altherr, A. A. Ford, D. C. Torney, R. D. Sutherland, M. G. Lowenstein, M. O. Mundt, W. J. Bruno, E. H. Knill, L. L. Deaven, G. R. Sutherland, R. I. Richards, and R. K. Sutherland, "An Integrated Physical/Genetic/Cytogenetic Map of Human Chromosome 16," Am. J. Hum. Genet. 55, Suppl. 1505 (1994).

4. Y. Shen, H. M. Kozman, A. Thompson, H. A. Phillips, K. Holman, J. Nancarrow, S. Lane, Z. L. Chen, S. Apostolou, N. A. Doggett, D. F. Callen, J. C. Mulley, G. R. Sutherland, and R. I.

Richards, "A PCR-based Genetic Linkage Map of Human Chromosome 16," Genomics 22, 6876 (1994).

5. N. A. Doggett, R. L. Stallings, C. E. Hildebrand, and R. K. Moyzis, "The Mapping of Chromosome 16," LA Science 20, 182-215 (1992).

6. R. L. Stallings, N. A. Doggett, D. F. Callen, S. Apostolou, P. Harris, H. Michison, M. Breuning, J. Sarich, C. E. Hildebrand, and R. K. Moyzis, "Evaluation of a Cosmid Contig Physical Map of Human Chromosome 16," Genomics 13, 1031-1039 (1992).

7. R. L. Stallings, D. C. Torney, C. E. Hildebrand, J. L. Longmire, L. L. Deaven, J. H. Jett, N. A. Doggett, and R. K. Moyzis, "Physical Mapping of Human Chromosomes by Repetitive Sequence Fingerprinting," Proc. Natl. Acad. Sci. U.S.A. 8, 6218-6222 (1990). 


\title{
RAPID KINETICS FLOW CYTOMETRY
}

\author{
Larry A. Sklar, * John P. Nolan, Robert C. Habbersett, and John C. Martin
}

Overview. Among the most powerful and least exploited capabilities of flow cytometry is the ability of cytometers to discriminate free and cell-bound ligand without a wash step. Ligand-receptor binding can be monitored with a sensitivity improved by three to six orders of magnitude over static cuvette methods. Kinetic methods based on these principles have already been useful in examining ligand-receptor binding interactions with time constants in the range of seconds. However, if the technology were extended into the subsecond time frame, the power of flow analysis could be applied to ligands with affinities as low as $1 \infty 10^{6} / \mathrm{M}$. These ligands would include hormones, peptides, and peptidomimetics. Since binding events occur on cells in subsecond time domains and precede cell activation, such assembly and activation events would be accessible to real-time analysis. Many other biological questions (cell activation, enzyme activities, and others) also demand subsecond kinetic analysis. In the ongoing investigations, kinetic capabilities are being systematically introduced into flow cytometry through the development of a rapid mix flow cytometer. The performance of the device is being evaluated by physical and biological criteria. The instrumentation will be applied to biological questions involving model peptide receptor systems. We anticipate that the instrumentation will be suitable for patenting and commercialization.

Approach. A flow system offers the possibility of characterizing a low-affinity ligand-receptor interaction in a homogeneous assay system before ligand has a possibility to dissociate as it might in a heterogeneous radioligand assay system. Consider the example of a ligand with an affinity of $1 \infty 10^{6} / \mathrm{M}$. If the ligand is a small molecule like a peptide hormone, the association rate constant would approach a limit of $\sim 1 \infty 10^{7} / \mathrm{Msec}$ and the off rate constant would be $\sim 10 / \mathrm{sec}$. This ligand would exhibit a dissociation halftime $\sim 100 \mathrm{msec}$, a time inconsistent with analysis in a heterogeneous assay system. In order to examine such interactions where equilibration is occurring in the subsecond time domain, it would be necessary to mix and deliver sample in a flowing system in a subsecond time frame. Since flow cytometry provides the capability of single cell analysis in cell populations with the receptors present at natural abundance, this approach makes it possible to examine ligands and receptors on living cells that are actually transducing signals. To be useful in the most general range of applications, a "fast" cytometer should possess the following capabilities: (1) sample mixing and delivery in a time frame of hundreds of milliseconds; (2) accurate and reproducible mixing volumes so that information pertaining to the concentrations of the reagents is known; (3) integration of sample delivery into the cytometer fluidics system so that the sample flow is stable to retain the advantage of flow analysis to discriminate free and bound ligand.

Brief Summary of Progress and Results to Date. In first year of the project, concepts to modify a commercial mixer and add a fast valve between mixer and cytometer solved a crucial problem in sample delivery, allowing the output of the mixer (several hundred microliters of sample mixed in a few milliseconds) to be delivered into the flow cytometer at an appropriate rate of $\sim 1 \mu \mathrm{l} / \mathrm{sec}$.

*University of New Mexico, School of Medicine, Albuquerque, New Mexico 
In the second year of the project, we (1) succeeded in modifying the mixing and delivery system and tested the mixer independent of the flow cytometer; (2) integrated the mixing device with the flow cytometer and achieved mixing and delivery times in the range of 500-1000 msecs; and (3) established data acquisition capabilities to collect data vs. time and to display the data.

In the third year (FY94), (1) we mounted the biologic mixing device on a FACS 2 optical bench, which provides pressure-driven fluidics and stream-in-air sample measurement, as well as conventional "slow" sample delivery and two-channel fluorescence detection plus forward angle light scatter signal (FALS); (2) reduced the dead volume between exit valve and the sheath stream via a custom-made sample nozzle; (3) modified sample lines for ease of sample handling by incorporating sample injection loops, allowing reduction in the amount of sample needed per experiment and greatly decreasing the time needed between experiments to flush lines and change reagents; (4) configured computer-triggered time ramps for short (10-30 sec) and longer (1-10 $\mathrm{min})$ experiments. These changes established a stable and robust instrument configuration for routine testing. We extensively tested the ability of the instrument quantitatively to proportion reagents and efficiently to mix sample, achieving delivery times of under $300 \mathrm{~ms}$ for fluorescent microspheres (Fig. 1).

Biological Applications. Initial emphasis will be placed on biological applications using the formyl peptide receptor of the neutrophil. The receptor is involved in host defense and binds ligands of the type CHO-met-leu-phe. Neutrophils express $\sim 100,000$ of these receptors, and the affinities of the ligands can be $1 \infty 10^{9} / \mathrm{M}$ and higher. Several biological preparations (transfected cells) of the formyl peptide receptors which permit complementary cytometric and spectrofluorometric analysis of ligand-receptor interactions are available, as are peptide ligands with affinities ranging from $\sim 1 \infty 10^{5}$ to $\sim 1 \infty$ $10^{10} / \mathrm{M}$. Analysis of the kinetics of association and dissociation of these ligands with their receptors provides mechanistic information about cell signaling, including interactions of receptors with guanine nucleotide binding proteins ( $\mathrm{G}$ proteins), receptor desensitization, and receptor internalization and recycling. An example of the use of the rapid mix flow cytometer to make high-resolution kinetic measurements of receptor-ligand interactions is shown in Fig. 2, where transfected mouse fibroblasts expressing the formyl peptide receptor were mixed with three different concentrations of fluorescein isothiocyanate (FITC)-labeled formyl peptide.

Future Applications and Development. Analysis of ligand association and dissociation with receptor as a function of time provides information about rates and extent of receptor coupling with $\mathrm{G}$ proteins, as well as receptor desensitization. Further information on the initial events in cell activation will be obtained by measuring rapid $\mathrm{Ca}^{++}$fluxes in response to ligand binding. Discussions with external collaborators concerning fluorescent RGD peptides for platelets are ongoing. The presence of sample loops has the added advantage of permitting two sequential mixing operations which will allow analysis of complex time-dependent biological processes that occur during the activation of living cells. This will be made possible since each syringe may be used to push and mix two sample loops. Protocols for such two-step mixes are being developed and tested. The successful completion of these steps should lead to a significant demand for the technology by investigators outside the laboratory. 

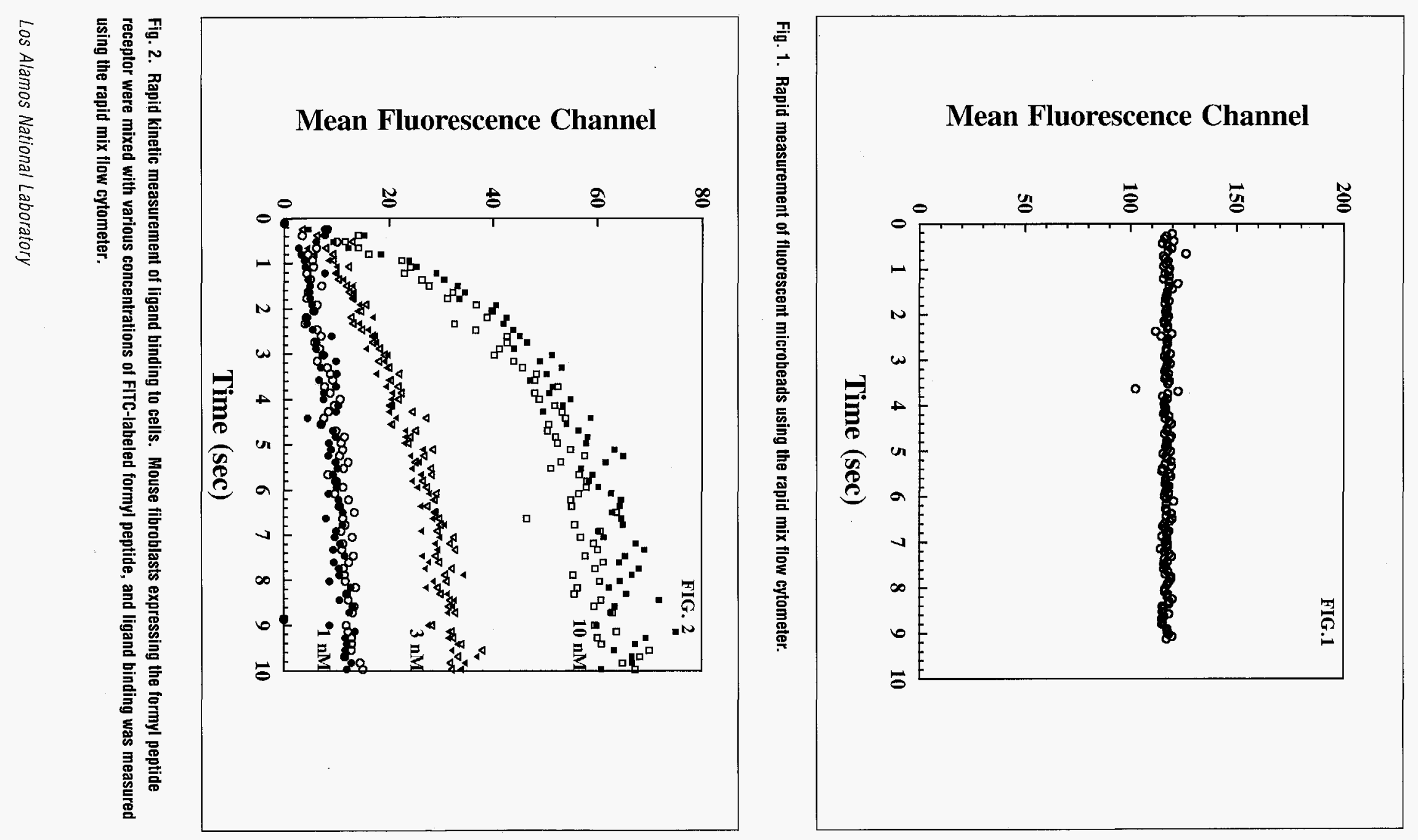


\title{
LOSS OF THE CATALYTIC SUBUNIT OF THE DNA-DEPENDENT PROTEIN KINASE IN SCID MOUSE AND CHINESE HAMSTER OVARY V3 CELLS
}

\author{
Scott R. Peterson, Akihiro Kurimasa, ${ }^{*}$ Mitsuo Oshimura, * William S. Dynan, ** \\ E. Morton Bradbury, and David J. Chen
}

Protein kinases modulate many aspects of cellular metabolism including the transduction of signals from the cell surface to the nucleus and regulation of cell growth and division cycles. Recently, our research has shown that a protein kinase called the DNA-dependent protein kinase (DNA-PK), may be a key component of both DNA double-stranded break (DSB) repair and the genetic recombination pathway required for the generation of a functional immune system. DNA-PK is unique among protein kinases in that it requires DNA as a cofactor for enzymatic activity. The DNA-PK holoenzyme consists of two subunits: a heterodimeric DNAbinding component called $\mathrm{Ku}$ protein and a $350 \mathrm{kd}$ catalytic subunit. In the presence of double-stranded DNA, the catalytic subunit binds to the Ku protein to form an active kinase complex on the DNA molecule. This property has led to the suggestion that this enzyme may function in DNA metabolism, such as gene transcription or DNA repair.

The ability of cells to detect and repair damaged DNA is critical for maintaining genetic stability. The study of mammalian DNA-repair processes has been aided by the identification of a number of cell lines that are defective in different repair activities. Mutant Chinese hamster ovary $(\mathrm{CHO})$ cell lines that have been demonstrated to be deficient in DSB repair lack a DNA end-binding activity that was recently shown to be dependent on the Ku protein. In the absence of a functional $\mathrm{Ku}$ protein, the capacity of the DNA-PK catalytic subunit to bind to DNA is abolished. Interestingly, these same mutant cells are also incapable of performing variable diversity joining $[\mathrm{V}(\mathrm{D}) \mathrm{J}]$ recombination, a necessary step involved in the generation of both antibody and T-cell receptor diversity. These data indicated to us that mutation of the gene encoding the catalytic subunit of DNA-PK would likely result in similar DNA-repair and [V(D)J] recombination phenotypes. We tested this idea by examining the CHO cell line V3 and cells derived from the severe-combined-immunodeficiency ( $s c i d$ ) mouse, both of which have been shown to share a common genetic defect that disrupts both DNA DSB repair and [V(D)J] recombination pathways. Using monoclonal antibodies specific for the catalytic and $\mathrm{Ku}$ components of DNA-PK, we screened protein extracts from these cells and found that the p350 protein was absent in extracts prepared from both the V3 and scid cells (Fig. 1), whereas the expression of the $\mathrm{Ku} 70$ protein in these cells was identical to that of wild-type $\mathrm{CHO}$ and mouse cells. However, a scid cell hybrid that contains a centromeric fragment from human chromosome 8 that complements the DNA repair

\footnotetext{
*Department of Molecular and Cell Genetics, School of Life Science, Faculty of Medicine, Tottori University, Yonago, Tottori, Japan

**Department of Chemistry, University of Colorado, Boulder, Colorado
} 


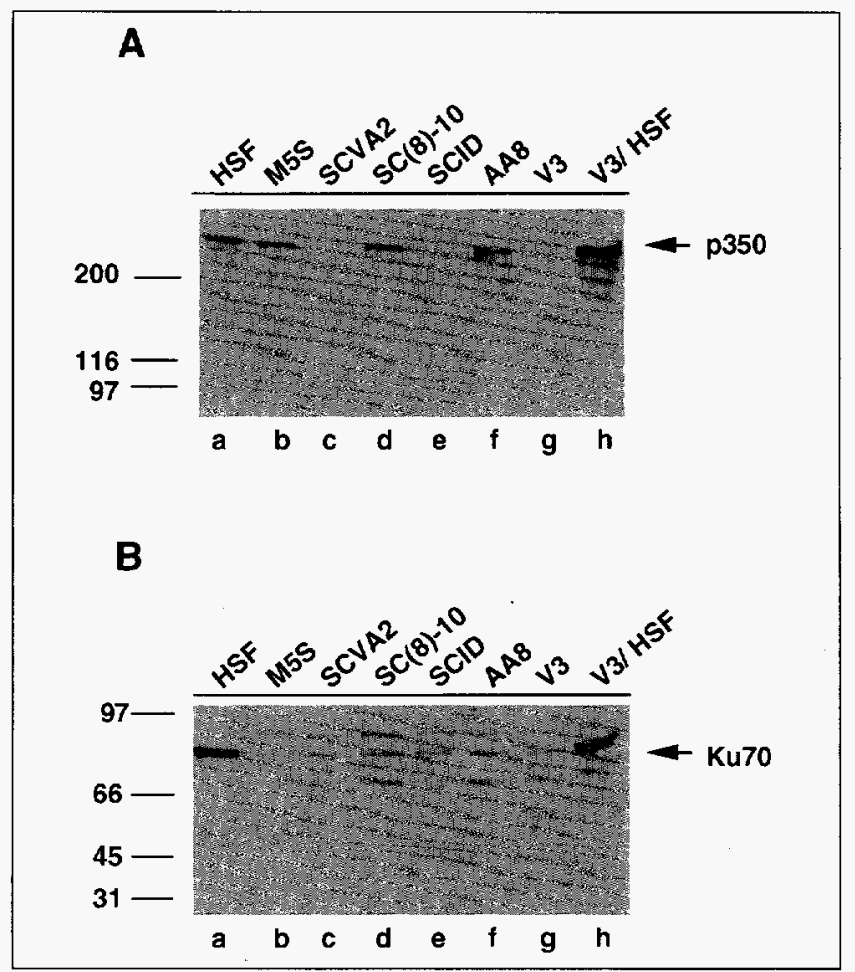

Fig. 1: Immunoblot analysis of p350 and Ku70. Hypotonic cell extracts of the human diploid fibroblast HSF55 (a), wild-type mouse M5S (b), scid mutant mouse SCVA2 (c), scid mouse/ human chromosome 8 hybrid SC(8)-10 (d), primary scid tibroblast (e) wild-type CHO AA8 (f), CHO mutant V-3 (g), and a V-3/ HSF55 hybrid (h) were resolved by SDS-PAGE and transferred to nitrocellulose. (A) The p350 protein was detected by immunoblotting immobilized proteins with an equal mixture of the anti-p350 monoclonal antibodies 18-2 and 42-26. The total amount of protein analyzed for the HSF55, SC(8)-10, and V-3/HSF extracts was $20 \mu \mathrm{g}$. For the other cell extracts, $80 \mu \mathrm{g}$ was used. The arrow indicates the position of the p350 protein. The position of prestained molecular weight markers is indicated in kilodaltons. (B) Ku70 protein was detected by immunoblotting with the anti-Ku70 monoclonal antibody NH310. Twenty $\mu \mathrm{g}$ of material was analyzed from the HSF55 and V-3/HSF extracis. For the other cell extracts, $80 \mu \mathrm{g}$ of material was used. The arrow indicates the position of Ku70. The position of prestained protein molecular weight markers is indicated in kilodaltons.

deficiency in the scid cells expresses the p350 protein. With help from our collaborator from Japan, Dr. Mitsuo Oshimura, we screened several more scid mouse cell lines that contain DNA from various regions of human chromosome 8. Some of these chromosomal fragments contain the human gene that complements the scid radiosensitivity defect. We compared the expression of the $\mathrm{p} 350$ protein in these cells and found that it correlated with the presence of DNA from human chromosome 8 that spans the centromere (Fig. 2). The human gene that complements the scid mouse mutation maps to this same region. These data support the idea that the $\mathrm{p} 350$ protein is either encoded by the scid gene or that the scid gene regulates the expression of p350. We are currently working to map the p350 gene to this region.

Our observation that the catalytic subunit of DNA-PK is absent in the scid and V3 mutant cells suggests that the integrity of the DNA-PK enzyme is also disrupted. 


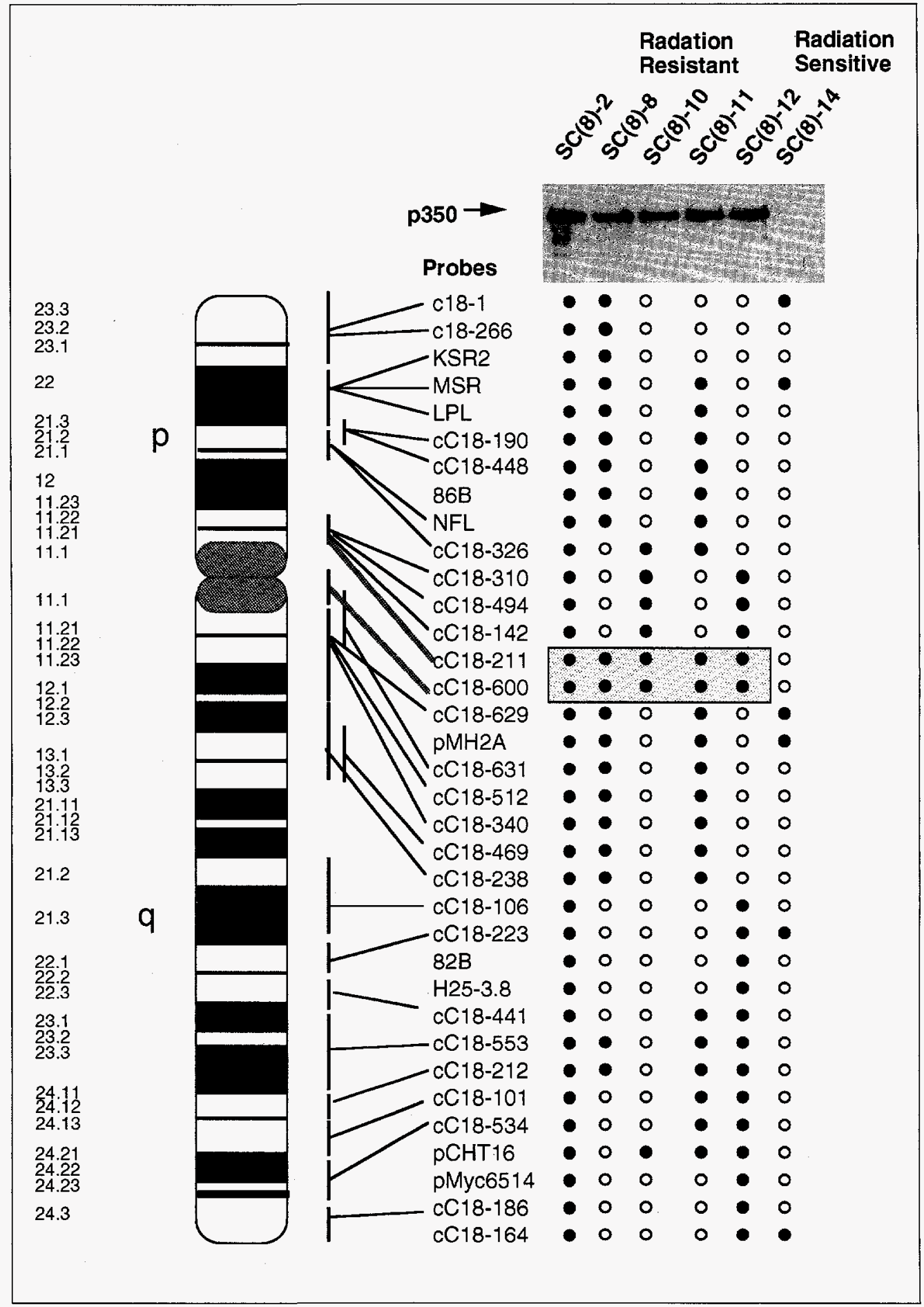

Fig. 2: Expression of the catalytic subunit of DNA-PK is correlated with radioresistance complementation of murine scid cells. Whole cell protein extracts were prepared from the radioresistant scid cells SC(8)-2, $\operatorname{SC}(8)-8$, $\operatorname{SC}(8)-10, S C(8)-11, S C(8)-12$, and $S C(8)-14$, which contain fragments of human chromosome 8 , as indicated by cosmid mapping. The presence of the p350 protein in these extracts was determined by immunoblot analysis, as described in Fig. 1. 
However, since the monoclonal antibodies we used to detect this protein only recognize a specific epitope, it was also possible that the $\mathrm{p} 350$ protein was still present and functional in these cells. To determine whether the immunoblot data signified that the activity of the DNA-PK enzyme was indeed missing, we compared the DNAstimulated kinase activity present in the wild-type and scid mutant mouse cells (Fig. 3). These data demonstrate that the DNA-PK activity is absent in the scid mutant cells, but it is restored in the scid cells containing the centromeric section of human chromosome 8 .

The phenotype of both the scid and the V3 cells suggests that the DNA-PK enzyme is essential for both DSB repair and $[\mathrm{V}(\mathrm{D}) \mathrm{J}]$ recombination. Since the rejoining of broken DNA is common to both of these processes, it seems logical to suggest that the kinase activity of this enzyme functions in some way to activate the rejoining of double-stranded DNA. It is possible that this is mediated via the phosphorylative activation of repair proteins such as ligases or helicases. Interestingly, the $\mathrm{Ku}$ protein has recently been shown to be an adenosine triphosphate (ATP)-dependent DNA helicase and is itself phosphorylated by the p350 kinase. It may be that the helicase activity of the $\mathrm{Ku}$ protein is regulated by phosphorylation by the $\mathrm{p} 350$ kinase subunit. In addition, p350 may serve to target a multimeric repair complex that is

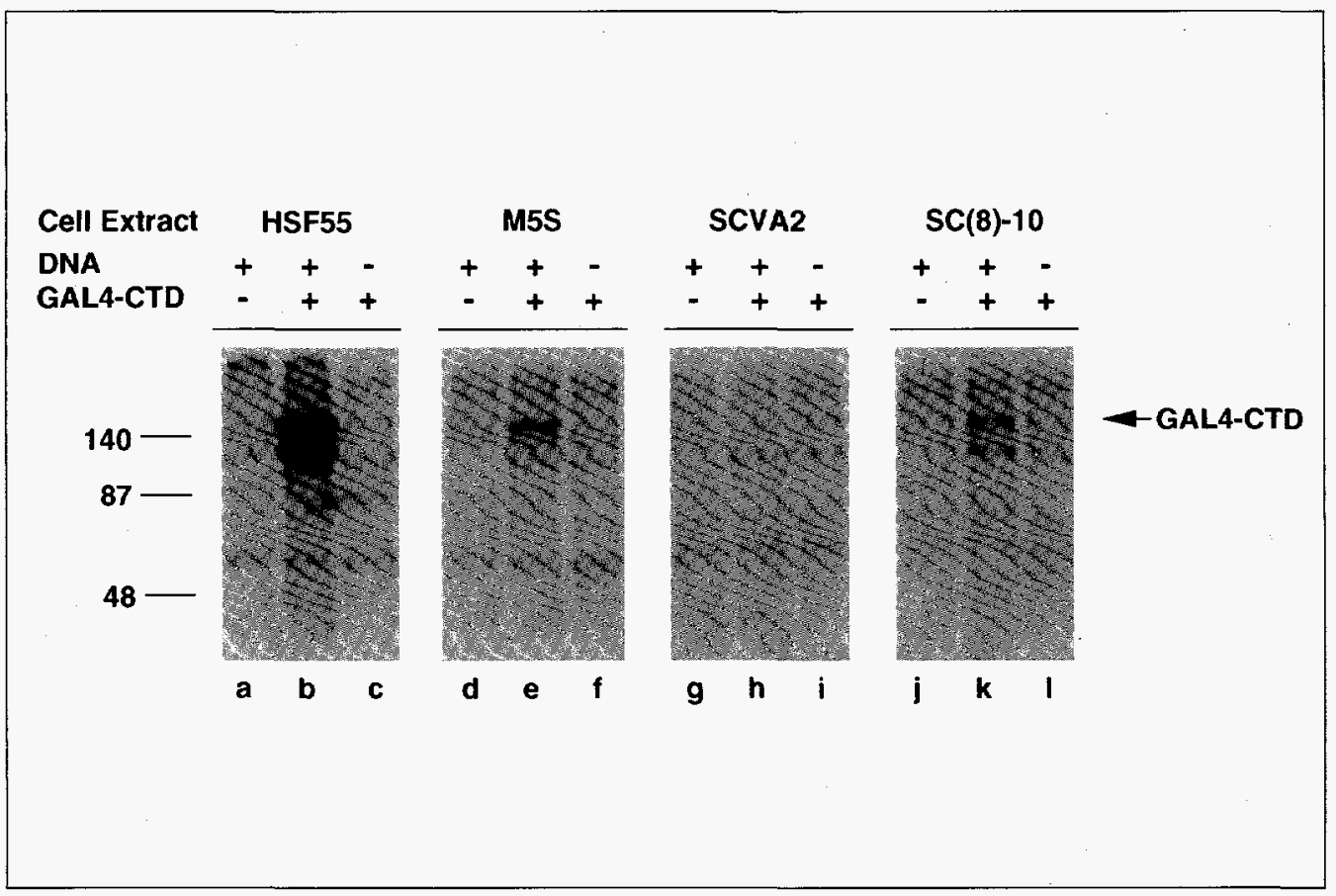

Fig. 3: Determination of DNA-PK activity in wild-type and scid mutant cell extracts. Phosphorylation of a GAL4-CTD fusion protein substrate was determined for cell extracts prepared from human diploid fibroblast HSF55 cells, wild-lype mouse M5S cells, scid mutant mouse cells SCVA2, and the scid mouse/ human chromosome 8 hybrid cells SC(8)-10. Reactions were performed with or without DNA and GAL4-CTD substrate, as indicated, and products of the reactions were analyzed by $7.5 \%$ SDS-PAGE and visualized by autoradiography. The arrow indicates the position of the hyperphosphorylated form of the CTD-fusion substrate. The position of protein molecular weight markers is indicated in kilodaltons. 
recruited to the DNA through the Ku protein. In the absence of either the Ku or p350 components, targeting of this putative complex to double-stranded breaks would be disrupted.

Additionally DNA-PK may function to initiate a biochemical cascade in response to double-stranded DNA breaks that signals to the cell that damage has occurred. In this scenario, DNA-PK binds to double-stranded breaks in the DNA and relays this information to other cell regulatory machinery by phosphorylation of DNA-bound reporter proteins. One way in which DNA-PK may function in this capacity is via the phosphorylation of the cell-cycle regulatory factor p53. In response to DNA damage, p53 activates the transcription of genes that, in turn, cause the cell to arrest in the G1 phase of the cell cycle. It has been proposed that this G1 arrest allows for the repair of damaged DNA before the onset of DNA replication or that the arrest initiates cellular programs leading to senescence or cell death in response to DNA damage. DNA-PK phosphorylates p53 in vitro, and it has been proposed that this phosphorylation step may signal p53 to initiate the cell G1 arrest pathway. This model indicates that mutant cells lacking DNA-PK would be unable to signal to the cell cycle machinery that DNA damage has been incurred. We are currently engaged in testing this model using primary embryonic fibroblasts isolated from normal and scid mice.

With the identification of cells mutated in both the catalytic and Ku subunits of DNA-PK, we have an excellent opportunity to determine the role played by this enzyme in both DNA repair and in other cellular activities. In addition, by examining the phosphorylation targets of DNA-PK in response to DNA damage, we may be able to identify other components of this DNA repair pathway and begin to assemble more accurate models of this biochemical process. 


\title{
Biological Implications of the Hairpin Structures Formed by the Single Strands of the Fragile-X DNA Triplets
}

\author{
Xian Chen, * S. V. Santhana Mariappan, * Paolo Catasti, * Robert L. Ratliff, Robert L. K. Moyzis, \\ Ali Laayoun, ** Steven S. Smith, ** E. Morton Bradbury, and Goutam Gupta*
}

Human fragile- $\mathrm{X}$ syndrome is a major cause of inherited mental retardation and is associated with expansion of the trinucleotide repeat GGC/GCC. The fragile-X syndrome is associated with (1) site-specific fragility, (2) amplification of the repeat, and (3) hypermethylation of the CpG island adjacent to the fragile-X gene, FMR-1.

Inordinate expansion and hypermethylation of the fragile-X DNA triplet repeat (GGC)n-(GCC)n have been correlated with the ability of the individual G- and C-rich single strands to form hairpin structures. Two-dimensional nuclear magnetic resonance (NMR) and gel electrophoresis studies show that both the G- and C-rich single strands form hairpins under physiological conditions. We found that the propensity of hairpin formation is more pronounced for the C-rich strand than for the G-rich strand. This observation predicts that the C-rich strand is more likely to form hairpin or "slippage" structure and show asymmetric strand expansion during replication. Figure 1 shows the stereo-pair of a representative energy-minimized structure of the GCC hairpin. As indicated in Fig. 1, the hairpins formed by the C-rich strands fold such that the cytosine at the $\mathrm{CpG}$ step of the stem is $\mathrm{C} \cdot \mathrm{C}$ paired. We then studied the methylation of the G-rich and $\mathrm{C}$-rich strands by the human methyltransferase under conditions in which unimolecular hairpins were the primary species. The enzymatic activity of the human methyltransferase is dramatically stimulated when C-rich strands form hairpins; the presence of a $\mathrm{C} \cdot \mathrm{C}$ mismatch at the $\mathrm{CpG}$ site provides local flexibility that is utilized to reach the transition state by the human methyltransferase. In other words, the hairpins of the C-rich strand can act as better substrates for the human methyltransferase than can the Watson-Crick duplex or the G-rich strand. Therefore, these structural and enzymological data lead to two major conclusions regarding the nature of expansion and methylation of the fragile-X triplet repeats (GGC)n-(GCC)n. (1) Both the C- and G-rich strands can independently form hairpins under physiological conditions. However, the C-rich strand has a much higher tendency to form hairpins and, therefore, is more likely to form slippage structure and be preferentially expanded during replication. (2) The hairpins of the C-rich strands display exceptionally high substrate efficiency for the human methyl transferase (six times higher than that of the Watson-Crick duplex). This observation provides a molecular mechanism of the methylation of the $\mathrm{CpG}$ island inside the fragile$\mathrm{X}$ repeat that inactivates the FMR-1 gene and causes the disease.

Based on these data, we propose a slippage model (Fig. 2) to explain how hairpin formation by the $\mathrm{C}$-rich strand gives rise to slippage during replication. This slippage leads to both expansion and methylation of the C-rich strand. Finally, the maintenance methylation step causes late replication, which may result in defective DNA condensation and fragility.

\footnotetext{
*Theoretical Division

**Department of Cell and Tumor Biology, City of Hope National Medical Center, Duarte, California
} 


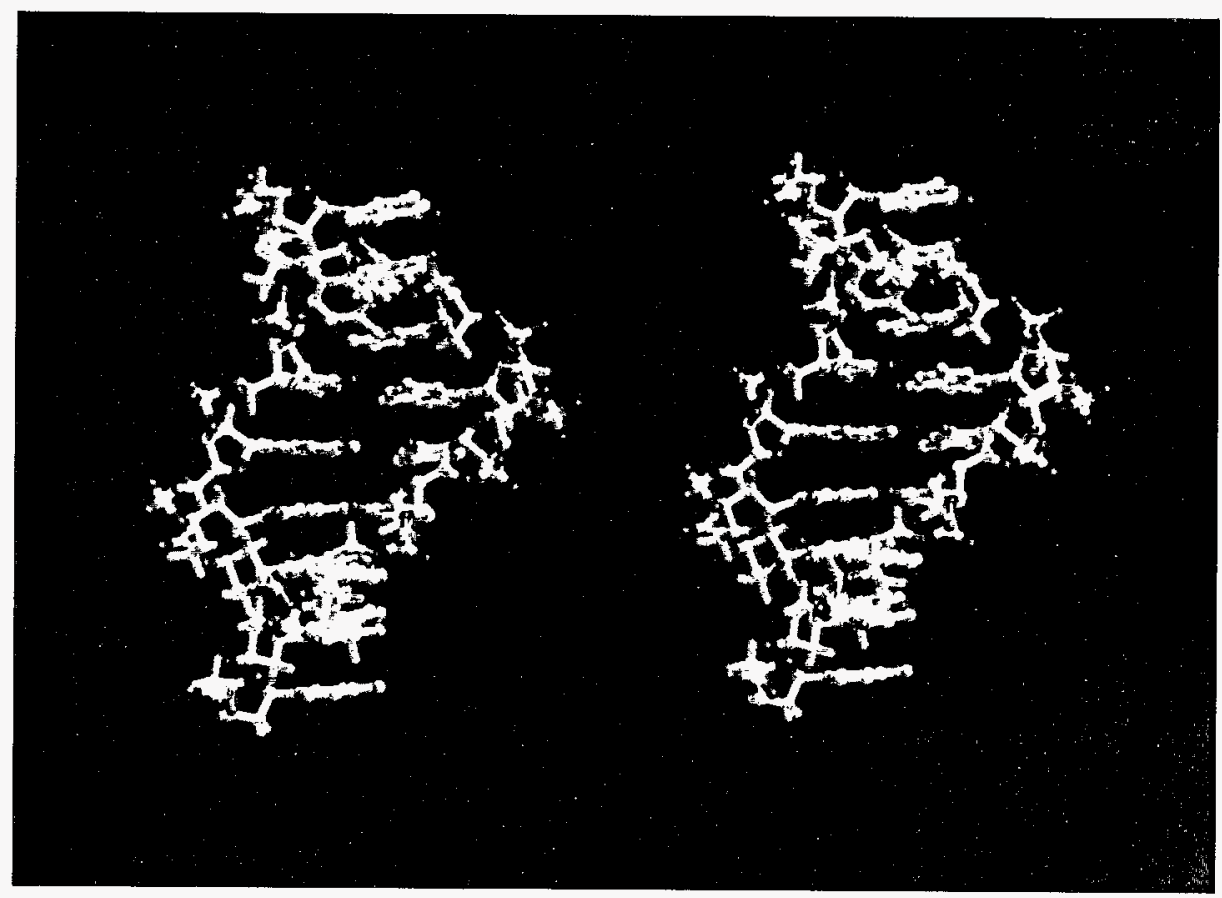

Fig. 1a. A stereo pair of the hairpin model of (GGC) in which the stem satisfies the NMR constraints of the $\left[(G G C)_{4}\right]_{2}$ duplex. Analysis of nuclear Overhauser enhancement spectroscopy (NOESY) data (200- and 500-ms mixing time) of [(GGC) $]_{2}$, with the aid of full-matrix NOESY simulation, resulted in a set of 163 average interproton distances for the 12-base-pair-long duplex. In both Figs. 1a and $1 \mathrm{~b}$, oxygen is indicated by red, phosphate by yellow, carbon by white, and nitrogen by blue.

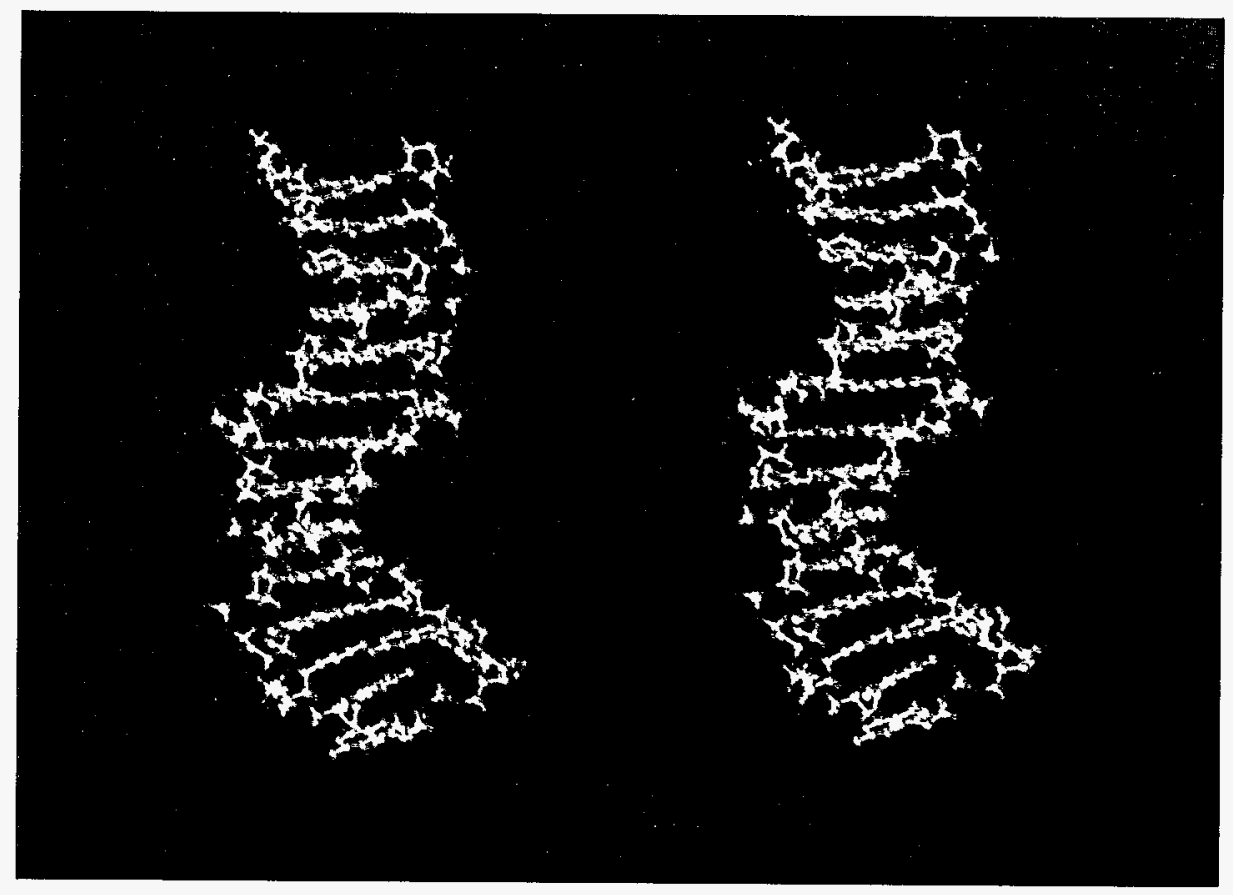

Fig. 1b. A stereo pair of representative energy-minimized structure of the (GCC) $)_{5}$ hairpin consistent with the NMR data. Analysis of NOESY data (200- and 500-ms mixing time) of (GCC) $)_{5}$, with the aid of full-matrix NOESY simulation, resulted in a set of 135 distance constraints. 


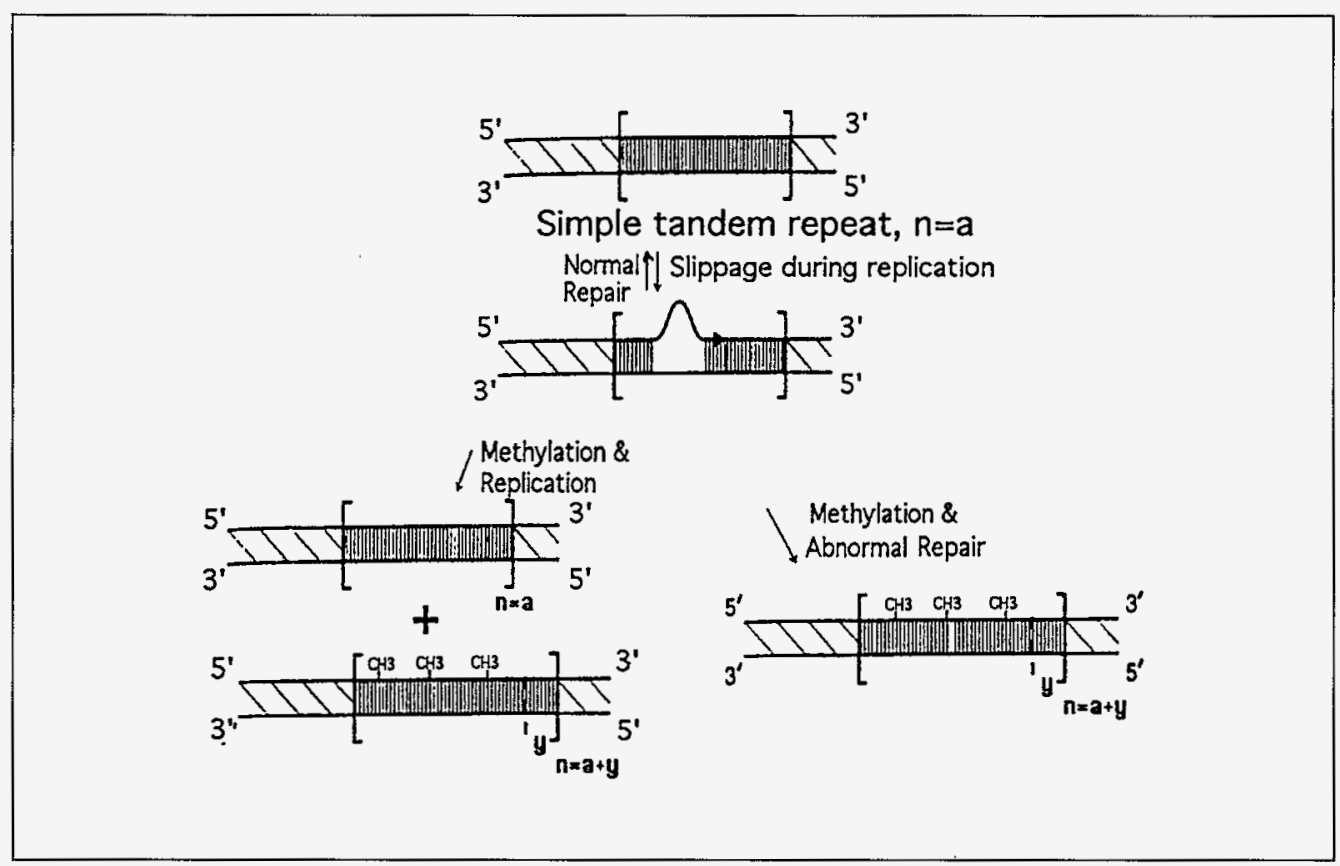

Fig. 2. Slippage during replication is proposed. The slippage is due to the formation of the hairpins by the G-and C-rich strands. The amount of expansion, which can occur due to abnormal repair of a second round of replication, depends on the size of the hairpin; i.e., the Ionger the size of hairpin (or the slippage), the longer the size (v) of expansion. From our studies, it appears that the $\mathrm{C}$-rich strand of the fragile $\mathrm{X}$ repeat is most likely to get methylated first. Then in the next round of replication, the complementary G-rich strand will also be methylated by the mechanism of maintenance or methyl-directed methylation.

\section{REFERENCES}

YAC Data and Incorporation into an Existing Genomic Database, Third International Workshop on Human Chromosome 16 (Pittsburgh, Pennsylvania, 1994), p. 20.

S. T. Winokur, U. Bengtsson, J. Feddersen, K. D. Matthews, B. Weiffenbach, H. Bailey, R. P. Markovich, J. C. Murray, J. J. Wasmuth, M. R. Altherr, and B. C. Schutte, "The DNA Rearrangement Associated with Facioscapulohumeral Muscular Dystrophy Involves a Heterochromatin-Associated Repetitive Element: Implications for a Role for Chromatin Structure in the Pathogenesis of the Disease," Chromosome Research 2(3), 225-234 (1994). 


\section{Research Projects}




\title{
GENOMICS
}

\section{Human Recombinant DNA Library (DOE)}

\author{
Principal Investigator: L. L. Deaven
}

\section{Co-Investigator: J. L. Longmire}

The goals of the National Laboratory Gene Library project are the construction of recombinant DNA libraries for each of the human chromosomal types and the distribution of these libraries to user groups throughout the world. We have constructed a series of DNA libraries from flow-sorted chromosomes. Small insert, complete digest libraries cloned into the EcoRI insertion site of Charon $21 \mathrm{~A}$ are available from the American Type Culture Collection, Rockville, Maryland. Partial digest libraries cloned into cosmid ( $\mathrm{s} \operatorname{Cos} 1$ ) or phage (Charon 40 ) vectors have been constructed for chromosomes 4, 5, 6, 8, 10,11, 13, 14, 16, 17, 20, and X. Purity estimates by in situ analysis of sorted chromosomes, flow karyotype analysis, and plaque or colony hybridization indicate that most of these libraries are $90-95 \%$ pure. Additional cosmid library constructions, 5-10X arrays of libraries into microtiter plates, and high-density membrane arrays of libraries are in progress.

Recently, we have constructed Yeast Artificial Chromosome (YAC) libaries for chromosomes 5, 9, 16, and 21. These libraries are made from complete DNA digests, using the rare cutters ClaI, SacII, EagI, or NotI/NheI. The average insert size is $\sim 200$ $\mathrm{kb}$, and chimera frequencies are low (1-10\%).

Libraries have also been constructed using M13 or bluescript vectors (chromosomes 5, 7, and 17) to generate sequence-tagged site (STS) markers for the selection of chromosome-specific inserts from total genomic YAC libraries.

Because of the advantages of insert size and stability associated with bacterial artificial chromosome (BAC) and P1-derived artificial chromosome (PAC) cloning systems, we are currently attempting to adapt $\mathrm{pBAC} 108 \mathrm{~L}$ and $\mathrm{pCYPAC} 1$ vectors for use with flow-sorted chromosomal DNA.

\section{Human Genome Physical Mapping (DOE)}

Principal Investigator: $R$. K. Moyzis

Co-Investigators: R. L. Stallings, C. E. Hildebrand, L. L. Deaven, J. H. Jett, N. A. Doggett, and M. K. McCormick

The Los Alamos Center for Human Genome Studies provides coordination, technical oversight, and direction for the following interdisciplinary elements of the 
Human Genome Program at Los Alamos: physical mapping, new technology development, and informatics. The center also develops collaborative research and development programs with the private sector and with other centers for human genome research.

The goals of this project are as follows: (1) to develop concepts and to advance technology for genomic physical mapping, (2) to construct a contig physical map of human chromosome 16 that will include an ordered set of overlapping DNA fragments and STS markers encompassing the chromosome, and (3) to apply novel technology to the construction of physical maps of other chromosomes. Currently, collaborations with outside investigators on chromosomes 5, 7, and 21 are in progress. The significance of this work lies in the immediate application of the knowledge (1) to understand human genetic disease; (2) to clarify the molecular bases for genetic disease susceptibility, especially in regard to energy-related chemical or radiation exposures; and (3) to reveal the molecular details underlying longrange chromosome architecture and dynamics.

\section{Genome Organization and Function (DOE)}

\section{Principal Investigator: $R$. K. Moyzis}

\section{Co-Investigators: J. Meyne, R. L. Ratliff, and D. L. Grady}

The ultimate objective of this program is to determine the molecular mechanisms by which higher organisms organize and express their genetic information. Applications of these basic investigations will include the development of novel approaches for (1) the detection of human genetic diseases and (2) the measurement of the effects of low-level ionizing radiation and/or of carcinogen exposure. A combination of biochemical, biophysical, and recombinant DNA techniques are being used to identify, isolate, and determine the roles of DNA sequences involved in long-range genomic order. Currently, major efforts are focused on determining the organization and function of human repetitive DNA sequences. Major findings in the last year included (1) the demonstration that the human telomere sequence (TTAGGG) identified and isolated by our laboratory, is the vertebrate telomere and (2) the cloning of 100- to 250-kb human telomere fragments as yeast artificial chromosomes (YACs). Future studies will be directed toward the further definition and isolation of "functional" repetitive DNA regions such as centromeres. Defining the mechanisms responsible for organizing the mammalian genome and those responsible for the genetic and nonmutational alterations accompanying abnormal phenotypic change is an important aspect of defining the effects of energy-related technologies. Determining the genetic variability in these mechanisms provides a rational basis for establishing thresholds for toxic substances, for making valid cross-species extrapolations, and ultimately, for identifying individuals at risk. 


\title{
Directly Labeled Fluorescent DNA Probes for Chromosome Mapping (LANL)
}

\author{
Principal Investigator: B. L. Marrone
}

Co-Investigators: C. L. Potter, G. C. Salzman, J. A. Gonzales, S. H. Pendergrass, and L. L. Deaven

This project supports technology development for human chromosome mapping using the methods of fluorescence in situ hybridization (FISH) and digital imaging microscopy. In FISH, a probe made from a DNA sequence is labeled with a fluorescent tag and then bound, or hybridized, to its complementary sequence on normal human metaphase chromosomes spread on a microscope slide. The fluorescence seen by fluorescence microscopy gives the location of the DNA sequence, which is then quantitated by computer analysis of a digitized image of the labeled chromosome. The quantitation of probe location is called the fractional length measurement. The goals are (1) to improve methods for labeling DNA sequence probes with fluorescent tags in order to facilitate the speed and accuracy of chromosome physical mapping efforts and (2) to implement and automate procedures for analysis and quantitation of fluorescently labeled DNA probes on chromosomes using computer-assisted digital imaging microscopy.

\section{Sequence-Tagged Sites Generation and Yeast Artificial Chro- mosome Contig Assembly on Human Chromosome 5 (DOE)}

\author{
Principal Investigator: D. L. Grady
}

\section{Co-Investigators: E. Peterson, D. Robinson, L. Chasteen}

The generation of sequence-tagged sites (STSs) is an integral part of strategies designed to produce low-resolution yeast artificial chromosome (YAC) contig maps of human chromosomes. Three hundred and six new human chromosome 5-specific STS markers have been systematically generated and regionally ordered. Chromosome 5 DNA prepared from flow-sorted chromosomes was digested with restriction enzymes BamHI and HindIII and cloned in bacteriophage M13mp18. Random clones were sequenced, and following computer analysis to identify common human repetitive sequences and putative coding regions, appropriate polymerase chain reaction (PCR) deoxyoligomers were synthesized in unique regions. An acceptable STS-PCR assay yielded the appropriate size amplification product from both total human DNA and hybrid cell line DNA containing only human chromosome 5. Each STS has been regionally localized by breakpoint analysis using a set of hybrid panels consisting of natural deletions or translocations of human chromosome 5. This hybrid panel allows localization of STSs to one of 50 bins on the short arm and one of 15 bins on the long arm. The STS markers appear to be randomly distributed along the length of this 
194-Mb chromosome. The current overall density of markers (approximately 1 STS/ $650 \mathrm{~kb}$ ) is sufficient to provide a framework map for YAC contig assembly in any region of human chromosome 5. Special emphasis for contig assembly is being concentrated on the critical regions defined for cri du chat syndrome, the most common human terminal deletion syndrome, which is localized to the short arm of human chromosome 5 .

\title{
Molecular Genetics (DOE)
}

\section{Principal Investigator: $M . R$. Altherr}

The motivating focus of this project is to understand the molecular basis of human genetic disease. This project provides a variety of services including (1) localization of small DNA fragments sequence-tagged sites (STSs) to specific subregions of chromosomes 4 and 16 using a panel of somatic cell hybrids containing a collection of natural rearrangements of these chromosomes; (2) development and implementation of techniques to generate a "sequence-ready" collection of DNA clones; and (3) development of an expressed sequence map using the strategy of exon trapping. In addition, the molecular basis of a number of distinct human maladies including the Wolf-Hirschhorn syndrome (WHS) and facioscapulohumeral muscular dystrophy (FSHD) are being investigated. Both of these diseases exhibit structural disruptions of the chromatin that may contribute to the phenotype. In the case of WHS, the end of the short arm of chromosome 4 is deleted; and in the case of FSHD, the deletion of a mildly repetitive sequence is correlated with the defect although no coding sequences have been identified in the region. Finally, transgenic mice are being used to examine the biology of suspected chromosomal structural elements (i.e., centromeres and telomeres) and the effects of these elements on development and gene expression.

\section{Molecular Microbial Ecology-Soil Microbial Communities in Stressed Environments (DOE)}

\author{
Principal Investigator: C. R. Kuske \\ Co-Investigator: P. J. Jackson
}

The eruption of Sunset Crater, Arizona, in 1064 A.D. covered a $2000-\mathrm{km}^{2}$ area with ash and cinders, greatly affecting the geologic conditions and exterminating the biosystem present at that time. Plants and their associated soil microflora have recolonized this hotter, dryer, nutrient-poor environment. Studying the mechanisms by which piñon pine and its microflora have adjusted to this stressed environment may help us understand and predict how ecosystem components respond to current man-induced environmental changes. We are combining microbial plating assays 
with ribosomal ribonucleic acid (RNA) gene-based molecular analyses to characterize the soil microflora associated with piñon pine in stressed and unstressed environments. Soil samples collected from the piñon rhizosphere are plated on a matrix of selective media to count and characterize the bacteria, fungi, and actinomycetes present. For the molecular analysis, total DNA is extracted directly from soil. Polymerase chain reaction (PCR)-amplified DNA fragments are used to generate cloned libraries, which are then sequenced to determine the community composition represented by different rDNA sequences.

Comparisons of the rhizosphere microbial community associated with piñon growing in cinders and an adjacent soil site indicate dramatic differences in numbers and composition of soil fungi, bacteria, and actinomycetes. Differences in microbial numbers and composition are also apparent between piñon rhizospheres and interspace (between tree) areas at each site. At two sampling times in 1994, greater numbers of bacteria and actinomycetes were found in the rhizosphere of piñon growing in soil than on cinders. In both soil environments, bacteria and actinomycete numbers were higher in piñon rhizospheres than in interspaces. Numbers of fungi were higher in piñon rhizospheres than in interspaces, but were not different between piñon growing on the two soil sites.

\title{
Soil DNA Technology (DOE)
}

\author{
Principal Investigator: C. R. Kuske
}

\section{Co-Investigator: P. J. Jackson}

We are developing methods to extract and purify DNA from environmental samples to detect target microorganisms or communities of microorganisms using polymerase chain reaction (PCR) amplification. From a soil or water sample, total DNA that represent DNA from the microorganisms living in that sample, including DNA from resistant spore structures, can be extracted. DNA from environmental samples must be purified to remove polyphenolic compounds and other inhibitors typically present in environmental samples. Oligonucleotides are selected to PCRamplify DNA fragments unique to a specific target microorganism or portions of the ribosomal RNA region from related microorganisms. Determination of detection limits is currently under investigation for certain target microorganisms (Bacillus sp., Fusarium sp., and Phytophthora sp.) in different soil types, by seeding known numbers of vegetative cells or spores into soil samples before DNA extraction and PCR analysis. 


\title{
Plant Gene Expression (Southwest Consortium for Plant Genetics and Water Resources)
}

\author{
Principal Investigator: C. R. Kuske \\ Co-Investigator: K. Taylor*
}

We are investigating a decline disorder of unknown etiology that affects citrus grown in the desert Southwest. This disorder, known as Macrophylla decline, is characterized by dysfunction of the vasculature, severe zinc deficiency, twig and branch dieback, and eventual death of the tree. In decline-affected citrus, zinc is redistributed and sequestered in the phloem tissues. We are comparing the vasculature of healthy and decline-affected citrus, decline-resistant and susceptible citrus rootstocks, and decline-susceptible citrus grown under different conditions of zinc availability to identify changes in microscopic anatomy (Taylor lab), tissue physiology (Taylor lab), and tissue gene expression (Kuske lab). Arbitrarily primed polymerase chain reaction (PCR) fingerprinting of ribonucleic acid (RNA) from healthy and decline-affected citrus tissue is being used to detect differences in expressed genes. Differentially expressed sequences are excised from display gels, reamplified by PCR, cloned, and sequenced. Selected sequences will then be used in Northern blot analysis to further characterize their expression in decline-affected and healthy citrus cultivars. This information will detect metabolic and/or structural changes that contribute to decline symptoms and will help identify factors important to the development of this disorder.

\section{Development of Methods That Detect and Monitor Environmental Munitions Contaminants Using Plant Sentinels and Molecular Probes (U.S. Army)}

Principal Investigator: $P$. J. Jackson

\section{Co-Investigator: C. R. Kuske}

The objective of the project is to determine the feasibility of monitoring gene expression in plants exposed to toxic compounds (including munitions contaminants) as a means of determining the presence and mobility of these compounds in soils. Plants accumulate trinitrotoluene (TNT) and similar compounds from soil. Their sessile nature requires that plants adapt to environmental changes by biochemical and molecular means. In principle, it should be possible to develop a monitoring capability based on expression of any gene that is activated by specific environmental conditions. We have identified plant genes activated upon exposure to TNT and

*University of Arizona, Tucson, Arizona 
cloned portions of these genes. Partial gene sequences have been determined. While several of these genes are activated by exposure to several different sources of environmental stress, several also appear to be specific to TNT exposure. Gene sequences will be used to design DNA probes that measure TNT-induced gene activity in exposed plants. These probes will be the basis of sensitive assays that monitor gene expression in plants growing in environments possibly contaminated with explosives. By monitoring expression of TNT-induced genes, we may be able to determine whether the plant is growing in soils containing this compound.

\title{
Development and Testing of Biosensors That Quantitatively and Specifically Detect Organic Contaminants (LANL)
}

\author{
Principal Investigator: P. J. Jackson
}

\section{Co-Investigators: C. R. Kuske and P. S. Keim*}

Application of different environmental remediation technologies is dependent on the type and extent of contamination. Removal or treatment of surface deposits may suffice in some cases whereas flushing an aquifer may be required in others. Site restoration has not succeeded in some notable cases, despite expenditure of billions of dollars. Before remediation can proceed, a site must first be characterized to determine types and concentrations of contaminants. Assaying for organic compounds in complex environmental samples is a costly ( $\$ 200-\$ 2000$ per assay) and labor-intensive process. We have demonstrated that it is feasible to develop biosensors that are very sensitive and specific for particular organic molecules. These sensors take advantage of bacterial regulatory systems that sense minute quantities of particular organic compounds in their environment and then respond by activating genes-encoding enzymes that degrade these molecules. Genes-encoding enzymes responsible for metabolizing these compounds are tightly regulated because production of these proteins in the absence of substrate is often detrimental to the cells. We have genetically engineered the promoters and regulatory proteins from two such systems to act as specific biological monitors of two common environmental contaminants, benzoate and toluene. We have clearly demonstrated that the benzoic acid biosensor does function and that it can readily detect benzoate concentrations characteristic of contaminated environmental samples. Successful development of these and other biosensors will reduce or eliminate the necessity to purify contaminants from complex mixtures before their identification. Our benzoate biosensor demonstrates sensitivity equivalent to current technology, and it may be possible to increase this sensitivity at least tenfold. We estimate costs of $\$ 0.30$ to $\$ 1.00$ per assay.

*Northern Arizona University, Flagstaff, Arizona 


\title{
Chelation of Metal Ions by Cell Wall Components (DOE)
}

\author{
Principal Investigator: P. J. Jackson
}

\section{Co-Investigators: J. G. DeWitt and G. Rayson*}

Certain plant species and their corresponding cell suspension cultures hyperaccumulate metal ions from soils. Many ions, including necessary micronutrients, bind tightly to different components of the primary cell wall. Cell viability is not required for metal chelation to the extracellular matrix, and biopolymers purified from these cells can be used selectively to remove metal ions from waste streams. Binding of normally toxic metal ions to the primary plant cell wall significantly reduces their toxicity. Chemical and metal luminescence methods have generated information about metal binding and cell wall components responsible for these bindings. Many metal binding sites have very high-binding affinities for particular metal ions. The chemical groups within these sites that are responsible for binding have been identified, and high-binding affinities are not simply the result of the ion exchange properties of the binding domains. Structural aspects of the sites play an important role by increasing binding affinities significantly. Relative binding affinities have been determined for several sites. This information is being used to determine the feasibility of developing metal-binding resins that contain nonviable plant cells. 


\section{Genomics Accomplishments}

- We have constructed the first integrated chromosome 16 physical-genetic-cytogenetic map, which includes the following: a low-resolution yeast artificial chromosome (YAC) contig map providing nearly complete coverage of euchromatin; a map consisting of 350 sequence-tagged sites (STSs), 600 Centre d'Etude du Polymorphisme Humain (CEPH) mega-YACs and 220 flow-sorted chromosome 16specific YACS that are localized to and ordered within a somatic cell hybrid breakpoint map (1-Mb average resolution); and a high-resolution, sequence-ready, fingerprinted cosmid contig map covering $60 \%$ of chromosome 16 and anchored to YAC and breakpoint maps via STSs, as developed from cosmid contigs and by hybridizations between YACs and cosmids.

- We successfully constructed a human chromosome 5 framework STS map, which consists of 306 markers. Of these, 60 were assigned regionally on the $\mathrm{p}$ arm at a 1 $\mathrm{Mb}$ resolution, ${ }^{*}$ and 100 were assigned regionally on the $\mathrm{q}$ arm at a $1.5-\mathrm{Mb}$ resolution.**

- Biological developments include the following: (1) identification and cloning of the human telomere; (2) determination of an unusual three-dimensional structure of telomeric DNA ${ }^{\dagger}$; (3) identification and cloning of highly conserved centromeric repetitive DNA regions that are likely to be human centromere components; and (4) development of a fluorescent in situ hybridization (FISH) technique that enables physical orientation of probes.

- New technologies were developed, including the following: (1) National Laboratory Gene Library Project (NLGLP) chromosome-specific libraries (over 2600 DNA libraries sent to research and production laboratories worldwide, including complete digest libraries for each human chromosome; partial-digest phase and cosmid libraries for human chromozomes $4,5,6,8,10,11,13,14,15,16,17,20, \mathrm{X}$, and $\mathrm{Y}$; and complete digest low-chimeric YAC libraries for human chromosome, partialdigest phase and cosmid libraries for human chromosomes 5, 9, 16, and 21); (2) flow-cytometry techniques for DNA fragment sizing and detecting single DNA molecules, resulting in a Cooperative Research and Development Agreement (CRADA) with Life Technologies, Inc. (LTI) for codevelopment of rapid DNAsequencing technology; (3) a robot capable of high-density cosmid-YAC array replication and distribution; and (4) a parallel primer walking directly off cosmid contig clones.

- New cytometric tools were developed (1) to semiautomate the assignment of FISH signals to chromosome bands; and (2) to resolve the order of two-color FISH signals on metaphase chromosomes.

\footnotetext{
*Research conducted with John Wasmuth, University of Califomia-Irvine, Irvine, California **Research conducted with Joan Overthauser. Thomas Jefferson University, Philadelphia, Pennsylvania 'Research conducted with Alex Rich, Massachusetts Institute of Technology, Cambridge, Massachusetts Research conducted with the Lawrence Livermore National Laboratory, Livermore, California
} 
- Comparisons were made of the rhizosphere microbial community of piñon growing in cinders (stressed environment) and of piñon growing on an adjacent soil site (unstressed). Findings indicate the following. (1) Numbers of soil fungi, bacteria, and actinomycetes are dramatically different between piñon at the two sites. Greater numbers of bacteria and actinomycetes were found in the rhizospheres of piñon growing in soil than in piñon growing on cinders. (2) Microbial numbers and composition also differ between piñon rhizospheres and interspace (between tree) areas at each site. In both soil environments, bacteria and actinomycete numbers were higher in piñon rhizospheres than in the interspaces. (3) Numbers of fungi were higher in piñon rhizospheres than in the interspaces but were not different between piñon growing on the two soil sites. (4) Microbial numbers and compositions varied seasonally.

- New methods of extracting and purifying DNA directly from soil samples have been developed. These procedures successfully extract DNA from microbial spore structures, as well as from vegetative cells present in the sample. DNA has been extracted and purified from soils of different textural classes that vary in amounts of clay and organic matter. Oligonucleotides from the rDNA region have been used to amplify by polymerase chain reaction (PCR) certain phylogenetic groups of microorganisms (specifically eubacteria, fungi, and actinomycetes) to generate microbial libraries. Specific bacterial target microorganisms have been detected by PCR, using specific primers in complex environmental samples, with detection limits as low as four cells per gram sample.

- Differences in gene expression between healthy and decline-affected Macrophylla rootstock plants have been identified, using arbitrarily primed PCR fingerprinting of ribonucleic acid (RNA). Thirty-two differentially expressed sequences have been excised from display gels, have been reamplified by PCR, and are being cloned for sequencing.

- We have identified genes that are induced in trinitrotoluene (TNT)-induced plant cells. While some of these genes encode general stress-response proteins, others previously were undescribed and may be specific to TNT-exposed plants. These may be useful in developing plant biomonitors that sense munitions in contaminated soils.

- Bacterial biosensors that detect specific organic compounds in complex solutions have been developed. These microbes respond to contaminant exposure by producing luciferase. Assays of this enzyme in microbial suspension exposed to polluted samples provide information about the concentration of selected compounds in the mixture. These biosensors will form the basis of bioassays that detect xylenes, polyaromatic hydrocarbons (PAHs), and certain other chemicals that commonly pollute environmental sites.

- Plant cell wall metal binding sites have been chemically characterized, and their relative affinities for different metal ions have been determined under a variety of conditions (e.g., changes in $\mathrm{pH}$, temperature, and metal ion concentrations). The structure of these sites plays a significant role in the binding process. 


\title{
STRUCTURAL BIOLOGY
}

\section{Engineering Sequence-Specific Ribonucluic Acid and Single- Stranded DNA Binding Proteins (LANL)}

\author{
Principal Investigator: $T$. C. Terwilliger
}

\section{Co-Investigators: G. Borgstahl-Kramer and R. G. Nanni}

We are using the special properties of the gene V protein from bacteriophage f1, along with our experience in protein engineering, to create a set of proteins that will bind to any desired sequence of ribonucleic acid (RNA) or single-stranded DNA. We will first construct a group of protein modules, each of which recognizes a specific four-nucleotide sequence of RNA or single-stranded DNA. We will then develop the technology to link four or more of these modules in any order, so as to generate proteins that bind specifically to any 16 or more nucleotide sequence of RNA or single-stranded DNA.

The technology to design a protein that would bind to any given RNA or singlestranded DNA sequence would have major applications in areas ranging from treatment of diseases to sequencing of DNA. Additionally, in the process of constructing sequence-specific RNA and single-stranded DNA binding proteins, we expect to develop an understanding of the interactions between single-stranded nucleic acids and proteins that define this specificity.

\section{Folding and Stability of the Gene V Protein of Phage f1 (NIH)}

Principal Investigator: T. C. Terwilliger

\section{Co-Investigators: M. M. Skinner, D. H. Leschnitzer, and C. J. Tape}

The aims of this project are to determine the structure of the gene $\mathrm{V}$ protein; to use this structure to interpret our previous experimental observations on the stabilities of variant gene $V$ proteins with amino acid substitutions; to determine the structures of gene $V$ proteins with substitutions that change the polarity of a side chain (valine $\rightarrow$ threonine substitution); to use these structures to estimate the effective polarity of a protein interior; and to determine the structures of variant gene $\mathrm{V}$ proteins that have amino acid substitutions that lead to altered stability; and to use these structures to identify interactions that are important in determining the stability of a protein. 


\title{
The Use of Spallation Neutron Sources for Structural Biology
}

\author{
Principal Investigator: $B . P$. Schoenborn
}

This project is intended to study the use of the pulsed neutron source at the Manuel T. Lujan, Jr., Neutron Scattering Center (LANSCE) for the study of proteins and membranes and to develop plans to establish facilities at LANSCE for structural biology.

Theoretical analysis of the properties of pulsed neutron sources show that such radiation sources are ideal for the study of ordered biological complexes like protein crystals, membranes, or viruses.

The time (wavelength)-dependent nature of neutrons from spallation processes produces Laue-like diffraction, but without the problems associated with Laue patterns produced by white radiation.

The major effort expanded over the last year was that of the analysis of moderator characteristics to design experimental facilities with maximum available flux in the useful energy region. In addition to moderator behavior, detailed examination of beam line component behavior was initiated to maximize the effective flux on the target crystals. This involves the use of choppers to select the appropriate wavelength region and protect the detectors from the initial high-energy neutrons and gamma radiation. To increase data collection efficiency, focusing devices like toroid mirrors and large position-sensitive detectors will be used.

In addition to the development plans to use LANSCE for structural biology, studies were made to investigate the use of so-called long-pulse neutron sources. The linear accelerator (LINAC) of the Los Alamos Meson Physics Facility (LAMPF) is just such a high-intensity neutron source with about 10 times the flux of LANSCE, but with a much longer pulse structure. Such a longer pulse system produces neutrons with less energy resolution. Calculations have shown that pulses up to .5-ms duration at a current of $1 \mathrm{~mA}$ produce neutrons with an energy resolution ideal for protein crystallography with a flux increase of at least 10 times the flux of the LANSCE system, running at a maximum current of $.1 \mathrm{~mA}$.

Long pulse neutron sources, such as the LAMPF LINAC, are ideal for structural biology. 


\title{
Dynamic Studies of Protein Hydration
}

\author{
Principal Investigator: B. P. Schoenborn
}

\author{
Co-Investigators: W. Gu and A. Garcia
}

The evaluation of solvent structure by $x$-ray, neutron and nuclear magnetic resonance (NMR) techniques initially produced controversial results, with the diffraction techniques identifying a large number of water molecules bound to proteins while NMR investigations show only a few such bound water molecules. Molecular dynamics simulations, using data from neutron studies, were carried out to investigate this controversy and showed that diffraction studies emphasize the average solvent structure, which depicts water molecules that constantly make and break hydrogen bonds. NMR techniques only show water molecules with a higher binding energy that do not move from their binding sites. Diffraction and NMR techniques produce data showing different aspects of solvent behavior important to protein function.

\section{Neutron Diffraction Studies of Myoglobins}

\section{Principal Investigator: B. P. Schoenborn}

\section{Co-Investigators: F. Shu* and V. Ramakrishnan**}

In order to improve neutron data resolution and accuracy, myoglobin was deuterated completely, using the $\mathrm{T} 7$ expression vector. Deuterated protein produced by this vector, using E. Coli for expression, was isolated and purified and after addition of the heme group was shown to be identical to the native form.

This predeuterated metmyoglobin was crystallized and used for a preliminary investigation of solvent interactions and for a study of possible structural changes caused by the exchange of $\mathrm{H}$ by $\mathrm{D}$.

This x-ray diffraction investigation revealed no differences between the native and the predeuterated myoglobins. However, because $\mathrm{x}$-rays do not allow the elucidation of $\mathrm{H}$ atoms in proteins, a neutron diffraction study was initiated using the reactor at Brookhaven National Laboratory.

*State University of New York, at Stony Brook, Stony Brook, New York

**Brookhaven National Laboratory, Upton, New York 


\section{Structural Biology Accomplishments}

- The structures of 10 mutants of gene $\mathrm{V}$ protein with amino acid substitutions in the protein core have been determined by x-ray crystallographic means.

- We found that the effects of an amino acid substitution on protein structure depend strongly on the location within the protein where it is made.

- We demonstrated that the structural changes in a protein that result from two mutations made in the same molecule are very nearly equal to the sum of the changes that result from the changes when made one at a time.

- We constructed an engineered protein that binds to single-stranded DNA in much the same way as does the natural gene $V$ protein, except that the engineered protein is twice as large and binds twice as much DNA. This protein will be the starting point for an engineered protein that has specificity for particular DNA sequences.

- We have completed the conceptual design for a neutron protein crystallographic station at the Manuel T. Lujan, Jr., Neutron Scattering Center (LANSCE). Theoretical studies showed that the use of a "linear accelerator (LINAC) only neutron source" is ideal for the study of proteins, with an expected reduction of data collection time by an order of magnitude.

- A dynamic simulation based on structural neutron data of myoglobin has shown that the apparent controversy between nuclear magnetic resonance (NMR) and neutron results in regard to the number of bound solvent molecules was due to time averaged versus instantaneous measurements of solvent location.

- Fully predeuterated myoglobin has been made, using a high-level expression vector in sufficient quantities to grow the large protein crystals needed for protein neutron crystallography. These crystals were analyzed by optical and $\mathrm{x}$-ray diffraction techniques and shown to be identical to the native myoglobin. 


\title{
CELL BIOLOGY
}

\section{CYTOMETRY}

\section{National Flow Cytometry Resource (NIH)}

\author{
Principal Investigator: J. H. Jett
}

Co-Investigators: R. Beckman,* C. Bell-Prince, L. S. Cram, H. A. Crissman, J. J. Fawcett, R. C. Habbersett, J. C. Martin, J. P. Nolan, J. D. Parson, M. Roslaniec, G. C. Salzman, L. A. Sklar, ** J. A. Steinkamp, M. E. Wilder, and C. Wistrom

The National Flow Cytometry Resource (NFCR) is very active in all five program areas that constitute a National Institutes of Health $(\mathrm{NIH})$ Research Resource: technology research and development, collaborative research, service projects, training, and dissemination. The NFCR has now completed its twelfth year and is well into the second renewal period, which will carry it through June 1997.

Currently, three projects make up the core research and development activities of the NFCR. They are (1) development of new approaches to multivariate data analysis; (2) development of a new approach to chromosome sorting; and (3) development of a modern data acquisition, analysis, and sort control system for flow cytometers. In addition, several technologies, such as the phase-sensitive flow cytometer and the fastkinetics cytometer, are part of the instrumental base that is available to NFCR collaborators. At the present time, the NFCR has a variety of collaborative and service projects in the following areas: data analysis, chromosome analysis and sorting, cell cycle analysis, cell physiology, ligand-receptor interaction, spectroscopy, and clinical applications. Several of the collaborative projects are brought to the Resource by Dr. Larry Sklar, codirector of the NCFR, through his affiliation with the University of New Mexico School of Medicine.

In the near future we will add two important instrumental capabilities to the list of facilities that are available to NFCR collaborators. The multi-laser system will be modified to add modulated excitation and phase-sensitive detection for one laser beam. This three-laser instrument will then be capable of performing a number of "routine" measurements in combination with phase-sensitive measurements.

Experience gained in the development of the DNA fragment-sizing capabilities will be implemented in a new instrument. We will take the present state of the art and construct an instrument that will be available for routine fragment-sizing experiments, while the technology development is performed on another apparatus. The phase-sensitive flow cytometer has demonstrated the capability for measuring fluorescence lifetimes. This capability can be used as a spectroscopic tool to quantify physiological parameters of cells, or the system can be operated in a mode in which undesired fluorescence is rejected and thus the detection system is "tuned" to the desired fluorescent species.

* Analysis and Assessment Division

**University of New Mexico School of Medicine, Albuquerque, New Mexico 


\title{
Advanced Flow Cytometric Development (DOE)
}

\author{
Principal Investigator: J. H. Jett \\ Co-Investigators: R. C. Habberset, J. C. Martin, M. Navier, J. A. Steinkamp, \\ J. D. Parson, and M. E. Wilder
}

The goal of this program has been to advance the state of the art in flowcytometry instrumentation for the analysis and sorting of biological particles. Developments are providing new measurement techniques at three levels: cellular, chromosomal, and molecular. Analysis at the molecular level has been advanced by the development of the ability to measure the size of DNA fragments. Sizing of DNA fragments between 1.5 and $150 \mathrm{~kb}$ has been demonstrated. Experience gained in the development of the DNA fragment-sizing capabilities to date will be implemented in a new instrument. With the current state of the art, we will construct an instrument that will be available for routine fragment-sizing experiments while the technology development is carried out on another apparatus. This new instrument will be used to help characterize recombinant libraries and to analyze cosmid fingerprints. Future directions will include the application of conventional flow-cytometry sorting techniques to "plating" of bacteria that are infected with recombinant phage.

A new digital data acquisition system (DiDAC) is being developed for smallfragment DNA sizing and other cytometry applications. One of the operational characteristics of the DiDAC being developed is that the analog signal from the photodetector is continuously digitized with a minimum of intervening analog electronics. The stream of digital information is processed by custom circuits to calculate the desired parameters from the input signal. Initially, the pulse-processing circuitry was designed to extract the height, width, and area of the input pulse. A preliminary design has been completed to extract the phase and lifetime information from the modulated signals of the phase-sensitive flow cytometer. When the new pulse processor is constructed, it will be compatible with the DiDAC system and use all its capabilities for data display, storage, and sort control.

\section{Flow Cytometer for Quantifying Fluorescence Lifetime (NIH)}

\author{
Principal Investigator: J. A. Steinkamp \\ Co-Investigators: H. A. Crissman, C. Deka, B. E. Lehnert, J. C. Martin, and \\ L. A. Sklar
}

The goals of this project are to develop a flow-cytometric method for (1) separating fluorescence emission signals-based differences in their lifetimes (phase shifts) and (2) quantifying lifetime(s) directly in fluorochrome-labeled cells and chromosomes. Our specific aims in accomplishing these goals are (1) to characterize the instrument in terms of measurement precision, sensitivity, dynamic range, and accuracy of lifetime measurement by phase shift and amplitude demodulation, i.e., 
frequency domain measurements; (2) to evaluate the instrument's ability to separate the emission signals from spectrally overlapping fluorochromes and its effectiveness in suppressing background interferences caused by cellular autofluorescence, unbound/nonspecific dye-binding, and Raman-Rayleigh scattering; (3) to utilize the instrument as a spectroscopic tool for probing the interactions of fluorochromes with cells and chromosomes (structural information); and (4) to develop a more advanced instrument for use by the biomedical research community, based on technological development/evaluation of the prototype system.

A first-generation, phase-sensitive flow cytometer has been developed that combines flow cytometry and frequency-domain fluorescence lifetime spectroscopymeasurement principles to provide unique capabilities for making phase-resolved measurements on fluorochrome-labeled cells and chromosomes. No other instrument can resolve and measure fluorescent probe emissions based on differences in their lifetimes and quantify lifetimes directly in real time, while maintaining the capability to make conventional flow-cytometric measurements. Several biological applications that take advantage of the unique capabilities of this new technology are underway.

\section{Flow Cytometric Analysis of Multiple DNA Fluorochromes (NIH)}

\section{Principal Investigator: $H$. A. Crissman}

\section{Co-Investigators: G. T. Hirons, L. D. Bustos, J. A. Dixon, and A. Nastasi}

The specific aims of this project are to develop new, multiparameter flowcytometric (FCM) techniques utilizing multiple DNA-specific fluorochromes for studying cell-cycle-related and other physiology-related changes in chromatin structure. The approach used takes advantage of the differential in DNA accessibility and fluorescence spectra of dyes with different DNA-binding properties. Changes in the relative binding of the various fluorochromes are assessed by FCM fluorescenceratio analysis of the multiple fluorochromes applied for cell staining. Alterations in the binding patterns by different fluorochromes will be compared to the changes in the nucleoprotein modifications reported in the literature. To achieve these goals, we must (1) perform detailed spectral studies on various DNA fluorochromes bound to DNA and to chromatin, (2) optimize FCM applications of these fluorochromes when applied as single or multiple staining agents, and (3) correlate differences in accessibility of DNA to different fluorochromes with changes in chromatin structure in viable and fixed cells from culture of highly synchronized cells and differentiating cells. From these studies, we will relate the potential changes in accessibility of DNA to different fluorochromes to the cell-cycle-related modifications in the nucleoprotein composition in chromatin. 


\title{
Normalization of Immunophenotyping Data (NIH)
}

\author{
Principal Investigator: G. C. Salzman

\section{Co-Investigators: S. J. Stewart and C. C. Stewart*}

Immunophenotyping has become the major use of flow cytometry in the clinical laboratory. When a laboratory obtains a new batch of a monoclonal antibody, it is often the case that the fluorescence intensity of a reference population, such as peripheral blood monocytes, is different from that obtained from a previous batch. To compare data obtained before and after the batch change, one dataset must be normalized to the other. We have developed a method for bringing the two datasets into registration and have written MacNormalize, a Macintosh computer program to implement the method.

The normalization method requires that the user locate the mean of a common cell population before and after the batch change. For each event (data for one cell) in the patient's dataset, the fluorescence channel number is converted from its logarithmic value to a linear value. A linear correction is applied, and the value is converted back to its logarithmic channel number (Fig. 1).
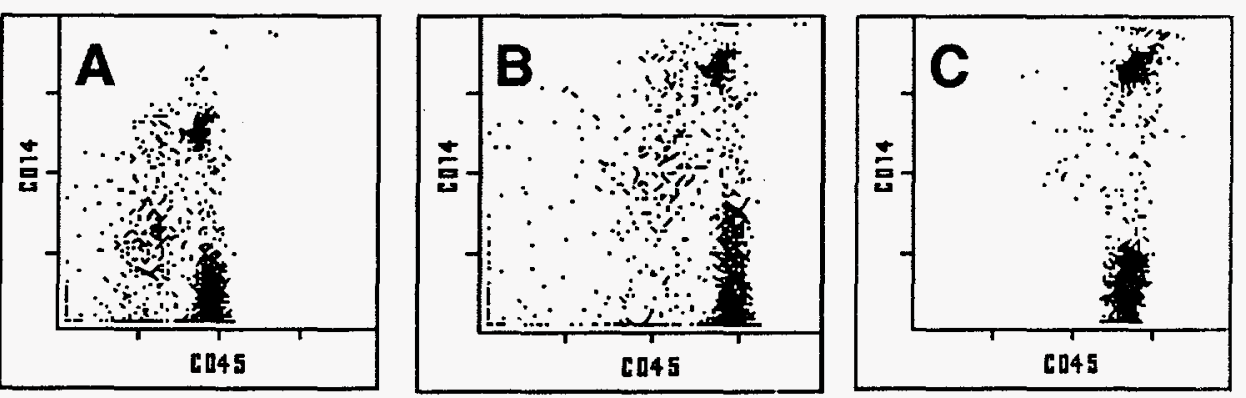

Fig. 1. Three bivariate dot plots showing CD45 vs CD14 for peripheral blood lymphocytes and monocytes. (A) Data from January 1991, in which the fluorescence intensity for both CD45 and CD14 was dim; (B) the same data as shown in (A) but normalized to match the data in (C); (C) data collected in January 1992.

*Roswell Park Cancer Institute, Buffalo, New York 


\title{
Rapid Mix Flow Cytometer (LANL)
}

\author{
Principal Investigator: L. A. Sklar
}

\section{Co-Investigators: J. P. Nolan, R. C. Habbersett, and J. C. Martin}

This project incorporates rapid sample mixing and delivery capabilities into a flow cytometer, enabling fluorescence measurements of individual cells less than $1 \mathrm{sec}$ after reagent addition. The resulting instrument extends the application of flow cytometry to hundreds of important biological molecules that interact with cellsurface receptors. In particular, the rapid mix flow cytometer makes it possible to examine the interactions of hormones, peptides, peptidomimectics, and other small molecules with receptors when binding affinities are too low to be examined by other methods. It also enables direct measurement of the earliest molecular events involved in the responses of cells to various stimuli. This device is expected to extend the usefulness of flow cytometers to new communities of biomedical and health scientists, including pharmacologists, neuroscientists, and cell biologists.

The rapid mix flow cytometer consists of a modified commercial stepper-motordriven, stopped-flow mixing system, integrated with a flow cytometer. The modifications allow a sample to be mixed rapidly (microliters $/ \mathrm{msec}$ ) and delivered to the cytometer at the appropriate rate (microliters/second), enabling measurement of fluorescent beads within $300 \mathrm{~ms}$ after mixing. Extensive testing of the instrument has verified efficient mixing and quantitative sample delivery. Currently, the rapid mix flow cytometer is being used to measure the kinetics of association and dissociation of chemotactic peptides with their cell surface receptors. This approach provides direct examination of the macromolecular interactions responsible for cell activation and will provide new insights into the regulation of cell function. Future plans include the development of more complex mixing protocols, such as two sequential reagent addition and mixing steps, which will allow analysis of the time-dependent processes that occur during the activation of living cells. 


\section{Cytometry Accomplishments}

- The lower limit for the size of DNA fragments that can be analyzed by flow cytometry has been reduced from 5.0 to $1.5 \mathrm{~kb}$. Efforts are under way to reduce the detection limit to several hundred bases.

- Fabrication of the two multilayer boards that make up the digital signal pulse processor of the digital data acquisition (DiDAC) system has begun.

- The first direct flow cytometry-based measurements of fluorescence lifetime have been made on cells labeled with cell-surface immunofluorescence probes and on cells and chromosomes stained with DNA-binding fluorochromes.

- The first phase-resolved measurements of heterogeneous (overlapping) fluorescence emission from cells have been reported. Cells were labeled with Red 613antiThy 1.2 (cell-surface antigens) and propidium iodide ("dead cells").

- A new technique for determining heterogeneous fluorescence decay lifetime in fluorochrome-labeled cells and particles has been developed, using dual-frequency, phase-sensitive flow cytometry.

- A patent has been awarded for our method of labeling chromosomes with the stains TOTO and YOYO, two new fluorochromes with very high quantum efficiencies.

- A new procedure has been developed for labeling chromosomes for bivariate flow karyotype analysis using TOTO or YOYO alone and has been excited sequentially with ultraviolet and visible wavelengths. Excellent resolution has been achieved. These results demonstrate the utility of these new and very bright cyanine dyes for analysis of human chromosomes by flow cytometry.

- Two new dyes, ethidium homodimer (EthD) 1 and EthD 2 (Molecular Probes, Inc.), have been successfully adapted to cellular DNA staining for flowcytometry measurements. The advantage of these new fluorochromes will be seen in studies where enhanced fluorescence is required. We found these dyes to be about five times brighter than propridium iodine (PI) on an equimolar basis.

- Performance testing of the rapid mix flow cytometer has been completed. Validation of quantitative reagent proportioning, efficient sample mixing, and rapid delivery have been completed, enabling measurement of fluorescent microspheres $300 \mathrm{~ms}$ after mixing.

- The binding kinetics of fluorescein isothiocyanate (FITC)-labeled formyl peptide to its receptor in intact cells has been measured with subsecond resolution, using the rapid mix flow cytometer. 


\title{
CELL GROWTH AND DIFFERENTIATION
}

\section{Optimization and Monitoring of Hollow-Fiber Bioreactors (LANL)}

\author{
Principal Investigator: J. P. Freyer

\section{Co-Investators: T. A. Zawodzinski and B. R. Mattes}

Multicomponent fluid separation modules based on hollow fiber polymer membranes are currently being used as bioreactors for culturing mammalian cells at very high densities. These bioreactors are of increasing interest to both basic researchers and to the biotechnology industry in a wide range of applications, from synthesis of genetically engineered biologicals for artificial organs in humans to realistic models of tumors for use in basic and applied cancer research. However, current hollow-fiber bioreactor designs are largely empirical, and the performance of such systems is far from optimal. In addition, techniques for monitoring the viability or productivity of cells inside these reactors are primitive. There are two primary goals of this project: (1) to develop improved bioreactors based on novel high-performance polymer membranes and advances in physical design, and (2) to develop new methodology for noninvasive, real-time assessment of bioreactor performance. We are currently working on novel bioreactor designs, using fibers previously synthesized by Dr. Jay Hennes, a consultant on this project. Work is also proceeding on establishing a facility in the Chemical Science and Technology (CST) Division for the production of custom-designed hollow fibers. Finally, we are developing advanced nuclear magnetic resonance (NMR) microimaging techniques for monitoring transport properties inside a functioning bioreactor.

\section{Regulation of Cellular Growth in Multicellular Spheroids (NIH)}

\section{Principal Investigator: J. P. Freyer}

\section{Co-Investigators: S. Vuk-Pavlovic* and L. Kunz-Schugart}

The objective of this project is to use the multicellular tumor spheroid model system to elucidate the mechanisms controlling the proliferation of malignant cells in the in vivo tumor. We are approaching this problem from several directions: (1) investigation of the regrowth kinetics of cells after removal from the spheroid microenvironment, (2) characterization of a protein growth inhibitor isolated from spheroids and tumors with extensive necrosis, (3) growth of spheroids from hormone-dependent cells in a defined medium at different hormone levels, and

(4) development and testing of new mathematical models of tumor growth regulation. The results of this research are providing some important clues as to how tumor cells

*Mayo Clinic, Rochester, Minnesota 
turn on and off the process of cellular proliferation in the stressful tumor environment. We are also clarifying the complex relationship between the regulation of cellular viability (conversely, the formation of necrosis) and the control of cellular proliferation. This project is closely related to our initiative using nuclear magnetic resonance (NMR) techniques to study necrosis and energy metabolism in spheroids. A new approach that we have begun is culturing spheroids of mixtures of different types of cells in order to investigate specific cell-to-cell interactions.

\title{
Nuclear Magnetic Resonance Spectroscopy and Imaging of Tumor Models (NIH)
}

\author{
Principal Investigator: J. P. Freyer

\section{Co-Investigator: L. Kunz-Schugart}

The objective of this project is to use state-of-the-art nuclear magnetic resonance (NMR) spectroscopy and imaging techniques to investigate the regulation of tumor cell metabolism and viability using three-dimensional in vitro tumor models. Model systems that mimic many of the properties of tumors in vivo are available; they offer the advantages of better experimental control and the ability to isolate individual experimental variables. We are currently using two complementary model systems: the multicellular spheroid and the hollow-fiber bioreactor. Multicellular spheroids are spherical clusters of tumor cells grown in suspension culture. They develop a nutrient-deprived microenvironment within the cell mass, causing the cells in different regions to adapt by ceasing proliferation and eventually undergoing a necrotic cell death. Hollow-fiber bioreactors are composed of porous fibers encased in an outer, impermeable shell, with tumor cells growing between the fibers and nutrient medium flowing through the lumen of the fibers. Spheroids have the advantages of allowing natural cell growth and permitting the assay of cells from different regions of the nutrient-stressed microenvironment.

Hollow-fiber bioreactors are more akin to the capillary supply network present in tumors and are better suited to metabolic NMR imaging. Our NMR spectroscopy efforts are focusing on developing an understanding of the mechanisms controlling the appearance of phosphorous spectra of tumors, both as a function of tumor size and of results after therapeutic treatment. The proton imaging effort is directed at elucidating the mechanisms behind image contrast in tumors, with the idea of improving the application of NMR imaging to the evaluation of tumors and their response to therapy. There is also a more basic long-term goal: to combine spectroscopy and imaging of these model systems in order to address important mechanistic questions concerning the relationship between tumor cell energy metabolism and the regulation of cellular proliferation and viability. 


\title{
Molecular Biology of Cell-Cycle-Dependent Genomic Structure (DOE)
}

\author{
Principal Investigator: J. A. D'Anna
}

Co-Investigators: H. A. Crissman and L. R. Gurley

Collaborator: J. G. Valdez.

The goal of the program is to determine the molecular mechanisms that regulate cell cycle progression and its attendant chromatin structural changes in normal and damaged/transformed cells. This includes a biochemical/structural understanding of synchronized cell populations and the development of flow-cytometric methods for rapid biochemical/structural/cell cycle analysis of individual cells within a population. Our results show that blockage of synchronized, transformed Chinese hamster ovary ( $\mathrm{CHO}$ cell line) cells near the G1/S boundary with mimosine or aphidicolin produces similar biochemical and structural changes, including depletion of histone $\mathrm{H} 1$, changes in chromatin structure, activation of cyclin-dependent kinase 2 (cdk2), phosphorylation of $\mathrm{cdk} 2$, and unbalanced growth. Mimosine prevents initiation of DNA replication, but aphidicolin does not. These results and other considerations raise the possibilities that (1) histone $\mathrm{H} 1$ is dissociated from replicons as a preparatory event for DNA replication, (2) replicons of G1/S-blocked CHO cells are biochemically and structurally poised for initiation, and (3) depletion of histone $\mathrm{H} 1$ may be driven by phosphorylation of histone $\mathrm{H} 1$ by $\mathrm{cdk} 2$, the formation of replication foci, and/or by proteins synthesized during unbalanced growth.

The near-term objectives of the program are to test this proposed model of chromatin structural changes and to investigate potential mechanisms that might regulate histone $\mathrm{H} 1$ depletion and foci formation in normal and transformed cells.

\section{Mechanisms of Pulmonary Damage (DOE)}

\section{Principal Investigator: B. E. Lehnert \\ Co-Investigator: J. A. Steinkamp}

This project concerns the elucidation of mechanisms by which human airway epithelial cells respond to ionizing radiation, especially $\alpha$-particles like those implicated in the development of lung cancer in individuals who have been exposed to radon and radon daughter products. The research considers how responses to $\alpha$-emitters may be modified by reactive oxygen species (ROS) and other conditions that likely occur in vivo along with radon and radon daughter exposure. Mechanisms that cause postexposure delays in G1 phase are of particular interest because: (1) such 
delays may provide cells with additional time to repair damaged DNA before DNA replication, and (2) escape from the G1 checkpoint or limitation of the otherwise normal duration of the G1 checkpoint in response to a given level of DNA damage hypothetically could limit the repair efficiency of damaged DNA before initiation of replication. Results from this project could provide an explanation about how genomic alterations caused by ionizing radiations may go unrepaired and become heritable. Moreover, our results concerning ROS are expected to expand our understanding of the roles ROS may play in the development of lung cancer following exposure to particles. Because the project relies heavily on flow-cytometric approaches for cell-cycle analyses concurrently with analyses of immunofluorescencelabeled proteins, an additional goal of the project is to further the development and applications of our multiparameter flow cytometer and phase-sensitive-detection flow cytometer for such measurements.

\title{
Latent Expression of Genetic Damage In Human Lung Cells Caused by $\alpha$-Particles and $\gamma$-Rays (DOE)
}

\author{
Principal Investigator: B. E. Lehnert
}

\section{Co-Investigators: $R . T$. Okinaka and M. N. Cornforth*}

Ionizing radiations with characteristics similar to those found with radon exposure have been implicated in a form of genetic instability that we term "latent expression of radiation damage" (LERD). Because genetic instability has been postulated to play a central role in radiation-induced carcinogenesis and because radiation protection standards are based on lung cancer as being the biological endpoint of ultimate concern in regard to inhaled radon, it is important to determine whether LERD indeed occurs in human lung cells after exposure to $\alpha$-particles. This problem can be addressed initially at the chromosomal level, inasmuch as it is at that level where the effects of LERD are perhaps most obvious. To date, little is known about conditions surrounding the phenomenology of LERD, and even less is known about its mechanistic basis. Using human bronchial epithelial cells as target cell populations, we are investigating conditions (i.e., radiation quality and intensity) that are likely to affect LERD at the chromosomal level. Demonstration of LERD in the lung cells will serve as a starting point to further address two related hypotheses regarding the mechanisms that are involved in the process. One hypothesis explains the progression of genomic instability in terms of unstable chromosomal junctions. The other hypothesis places a central role on a linear energy transfer (LET)-dependent induction of specific cellular transcripts whose products may affect genomic instability directly or indirectly.

*University of Texas Medical Branch, Galveston, Texas 


\section{Cell Growth and Differentiation Accomplishments}

- We have demonstrated that the fraction of proliferating cells in three-dimensional tumor models can be monitored noninvasively by phosphorous nuclear magnetic resonance (NMR) spectroscopy, suggesting that the effectiveness of therapeutic treatment could be monitored for individual patients.

- The technique for selectively dissociating cells from different locations within spheroids has been extended to two oncogene-transformed rat fibroblast cell lines, allowing charactization of metabolic properties of cells in this carcinogenesis model system.

- Our observations of a significantly decreased mitochondrial function in nonproliferating cells have been extended to the two transformed rat fibroblasts cell lines, showing that this reduction in mitochondrial function in cells that have been exposed to the stressful spheroid microenvironment is an important and general feature of nonproliferating cells in tumors.

- The forward-angle light-scatter signal (FALS) has been conclusively demonstrated to be an unreliable indicator of cell size, one that is highly influenced by the staining and manipulation of the cells during flow analysis.

- We have designed and constructed a prototype hollow-fiber bioreactor for NMR microimaging, which is only $5 \mathrm{~mm}$ in diameter and incorporates 10 fibers aligned along the central axis. This small size and precise fiber alignment will allow a significant improvement in image resolution over existing bioreactors.

- We have designed, constructed, and tested a new perfusion chamber for maintaining spheroids and other cell culture systems under constant environmental conditions inside an NMR spectrometer. These chambers are now in routine use in Life Sciences Division, as well as at several other research institutions.

- Blockage of Chinese hamster ovary (CHO) cells near the G1/S boundary with mimosine has been found to lead to time-dependent depletion of histone $\mathrm{H} 1$ from chromatin, phosphorylation of histone $\mathrm{H} 1$, cdk2 activation, and unbalanced growth.

- Although Chinese hamster ovary (CHO) cells blocked near the G1/S boundary with mimosine do not initiate DNA synthesis, they do undergo biochemical and structural changes that are characteristic of $S$ phase cells; thus, it has been demonstrated that mimosine does not prevent traverse of the G1/S boundary.

- Changes in chromatin/cellular structure produced by blockage of cells with mimosine have been found to indicate that the restriction point for unbalanced growth in $\mathrm{CHO}$ cells precedes the mimosine block point.

- It has been learned that changes in chromatin/cellular structure during mimosine blockage in CHO cells are consistent with (1) the hypothesis that dissociation of $\mathrm{H} 1$ and rearrangement of chromatin may be preparatory events for the initiation of DNA synthesis in replicons, and (2) the notion that activation of $\operatorname{cdk} 2$ is required for these preparatory structural changes. 
- We have demonstrated that tumor necrosis factor- $\alpha$, a proinflammatory cytokine produced by appropriately stimulated macrophages, is not an early mediator of the injurious effects of inhaled phosgene.

- Assessments of mechanistically based, therapeutic approaches for protecting the lung against phosgene-induced injury have revealed that postexposure intratracheal instillation of $\mathrm{H}_{2} \mathrm{O}$ markedly delays the onset of the pulmonary edematous response.

- We have demonstrated that the cytokine interleukin-4 (1) can inhibit the proliferation of alveolar macrophages in a concentration-dependent manner and (2) can biphasically regulate the production of tumor necrosis factor- $\alpha$ by alveolar macrophages stimulated with bacterial lipopolysaccharide.

- We have demonstrated that exposure to $\gamma$-rays causes human bronchial epithelial cells and human lung fibroblasts to arrest in the G1 phase of the cell cycle.

- Phase-sensitive flow cytometry has been shown to be able to resolve separately signals from cells labeled with fluorochromes that have overlapping emission spectra.

- We have shown that adverse effects of particles in the lung correlate with their surface areas and their persistency in the lung's alveolar and interstitial compartments.

- An alveolar macrophage-based model of lung clearance has been completed for future use in animal-to-human extrapolation studies and risk assessment.

- Evidence has been obtained that indicates that the proinflammatory cytokine fumor necrosis factor- $\alpha$ is not involved in mediating the early pulmonary edematous response to phosgene.

- Modeling of published data concerning the ability of $\alpha$-particles to cause sister chromatid exchanges has indicated that the cellular target substantially exceeds nuclear surface areas.

- We have demonstrated that a protein identified as xip7 (x-ray-induced protein) in a radioresistant human melanoma cell is induced by both $\mathrm{x}$-rays and $\alpha$-particles in normal human fibroblasts.

- Polymerase chain reaction (PCR) primers obtained from a $1.8 \mathrm{~kb}-\mathrm{cloned}$ cDNA fragment of the gene $x i p 7^{*}$ have been utilized to isolate five Centre $\mathrm{d}^{\prime} E$ tude du Polymorphisme Humain (CEPH)-mega yeast artificial chromosome (YAC) clones. In situ hybridization indicates that xip7 localizes to the $\mathrm{q} 35$ arm of chromosome 7. Eight xip7 positive genomic clones have been isolated from a human European Molecular Biology Laboratory (EMBL) library.

* Obtained from D. Boothman, University of Wisconsin, Madison, Wisconsin 


\title{
RADIATION BIOLOGY AND CARCINOGENESIS
}

\section{Mechanisms of Radiation and Chemical Genetic Toxicology (DOE)}

\author{
Principal Investigator: G. F. Strniste
}

Co-Investigators: M. A. MacInnes, R. T. Okinaka, M. S. Park, and R. J. Reynolds

The purpose of this program is to determine the molecular mechanisms by which ionizing and nonionizing radiations and environmental chemicals induce heritable genetic change in humans. Particular emphasis is directed toward understanding those cellular mechanisms that act to ameliorate the cytotoxic and genetic effects of these DNA-damaging agents. Recent progress includes (1) the construction of xeroderma pigmentosum complementation group $\mathrm{G}$ (XP-G) cDNA into expression vectors and the demonstration of the functionality of these constructs; (2) the identification of naturally occurring mutations in XP-G patients; (3) the examination of structural and biochemical properties of the helix-loop-helix domain of the XPG protein; and (4) the characterization of XPG protein intracellular localization. Ongoing research includes (1) the identification and characterization of additional, naturally occurring mutations in the XPG gene; (2) analysis of the HLH domain, nuclear localization region, and conserved nuclease consensus sites of the XPG gene and determination of their significance for XPG function; (3) examination of the XPG participation in conferring cellular resistance to low and high linear energy transfer (LET) ionizing radiations; and (4) characterization of XPG gene regulation and the role of this regulation in cellular resistance to ionizing and nonionizing radiations. The results of this research will contribute to our understanding of the molecular basis for xeroderma pigmentosum and Cockayne's syndrome in particular and of cellular responses to environmental carcinogens in general.

\section{Molecular Genetics of Human Radiation Repair Genes (DOE)}

\section{Principal Investigator: D. J. Chen}

Ionizing radiation induces various types of DNA damage in mammalian cells, including DNA single-strand breaks (SSBs), DNA double-strand breaks (DSBs), DNA protein crosslinks, DNA-DNA interstrand crosslinks, and altered bases. Although it is obvious that human cells can repair many of these lesions, there is little detailed knowledge as to the nature of the genes and the encoded enzymes that control these repair processes. Our objective in this program is to utilize somatic cell genetics and recombinant DNA technology to study the molecular mechanisms of ionizing radiation (IR)-specific DNA repair in human cells. Our ultimate goals are to isolate the human genes involved in repairing IR-induced DSBs and to study the expression and function of these repair genes in mammalian cells. Progress to date includes (1) characterization of two new DNA DSB repair-deficient mutants; (2) 
establishment of three new complementation groups for the human DNA DSB repair genes; (3) regional localization of three human DSB repair genes-XRCC4L, XRCC5, and the human homolog of mouse scid gene; and (4) cloning and mapping of the human and the mouse homologs of the yeast Rad52 gene. Future directions include (1) regional mapping of three DNA DSB repair genes in the human genome; (2) isolating the human DSB repair genes XRCC4L and XRCC6; and (3) determining whether or not the human homolog of the yeast Rad52 gene is involved in the repair of IR-induced DNA DSBs.

\section{Cell-Cycle Regulation After $\alpha$-Particle Exposure (NIH)}

\section{Prinicpal Investigator: D. J. Chen}

Other Investigators: H. A. Crissman, D. M. Gadbois, S. R. Peterson, W. Wharton, and P. Keng*

The purpose of this project is to understand how a cell recognizes DNA damage after high linear energy transfer (LET) $\alpha$-particle irradiation. Our hypothesis is that delays at checkpoints in either the G1 or G2 phase must occur, following DNA damage, in order for the cell efficiently to repair lesions in the DNA. Alpha particles will be used to simulate radiation exposure experiments during the decay of radon gas. Highly synchronized normal human cells will be irradiated with $\alpha$-particles at different points in the G1 or G2 phase to determine cell-cycle-specific checkpoints and cell-cycle-specific relative biological effectiveness. These checkpoints, especially in the G1 phase, have been elusive because of the lack of sensitive detection technology. Therefore, we will apply a flow-cytometric technique that measures bromodeoxyuridine incorporation into DNA that is capable of detecting subpopulations of cells that delay in various phases of the cell cycle. Since, for a given dose, $\alpha-$ particle exposure induces more severe DNA damage, compared to low LET $\gamma$ - or $x$-rays, the effects of the magnitude of DNA-damage on the length of cell-cycle delay will be determined. Finally, we will study the effects of $\alpha$-particle-induced cell-cycle delay on the expression of various cell-cycle control proteins (i.e., cyclin D1, cyclin $\mathrm{E}$, cdk2, and cdk4 in G1, and $\mathrm{p} 34^{\mathrm{cdc} 2}$ and cyclin $\mathrm{B} 1$ in G2).

\section{Molecular Cloning of a Human Radiation Repair Gene (NIH)}

\section{Principal Investigator: D. J. Chen}

The original objective of this project was to utilize recombinant DNA techniques to isolate a specific human gene (XRCC5) involved in the repair of DNA doublestrand breaks (DSBs) induced by ionizing radiation. The XRCC 5 gene has been localized in the human chromosome $2 \mathrm{q} 35$ region. This mapping information and identification of XRCC5 as DNA-binding protein Ku80. Ku protein was originally

*University of Rochester School of Medicine and Dentistry, Rochester, New' York 
found as an autoantigen in the sera of patients with scleroderma-polymyositis overlap syndrome. Subsequent analysis demonstrated that $\mathrm{Ku}$ is composed of a p70 and a p80 polypeptide. Ku protein was also found in in vitro studies to bind to free ends of DNA fragments via its $70-\mathrm{kDa}$ subunit without apparent specificity for a particular sequence or configuration. Upon binding to the DNA ends, Ku recruits a $350-\mathrm{kDa}$ catalytic unit to form a DNA-dependent protein kinase (DNA-PK). The genes for $\mathrm{ku} 70, \mathrm{Ku} 80$, and p350 have been mapped to human chromosomes 22q13, 2q33-35, and 8 , respectively. Recently, we have shown that the severe combined immunodeficiency (SCID) mouse cells are deficient in the p350 catalytic unit of the DNA-PK. Identification of XRCC5 as Ku80 and the absence of DNA end-binding activity in DNA DSB repair-deficient mutants suggests that DNA end-binding proteins and the DNA-PK complex may be one of the early radiation responses that initiate a signaling pathway induced by DNA damage, perhaps for cell-cycle arrest and recruiting DNA repair apparatus to the damage sites. Our future research goals are (1) to determine the role of the DNA-PK in the process of DNA DSB repair; (2) to analyze the expression of the $\mathrm{ku} 70, \mathrm{ku} 80$, and p350 genes in human cells; and (3) to evaluate the genetic consequences of DNA DSB repair deficiency in a transgenic mouse model system.

\section{Radiation-Induced Mutation Spectra at the Human HPRT Locus (NIH)}

\section{Principal Investigator: D. J. Chen}

The objective of this research project is to determine whether characteristic mutational spectra (types and frequencies) are induced at or proximal to the HPRT locus in normal human fibroblasts exposed to low- and high-linear energy transfer (LET) radiation. If unique mutational spectra can be demonstrated, then this can served as a molecular signature to differentiate low- and high-LET radiation-induced genetic damage from that which occurs spontaneously. Progress to date includes (1) molecular analysis of the $\gamma$-ray-induced mutations in human cells; (2) molecular analysis of $\alpha$-particle-induced mutations in human cells; and (3) comparison of radiation-induced large deletion in the HPRT locus. Our data indicated that radiation induces mostly larger deletion and there is no difference in the distribution of deletion size in high-LET $\alpha$-particle-induced mutants when compared to $\gamma$-ray-induced mutants. A future goal of this project is to determine whether the spectra of point mutations (base substitutions, frame shifts, and small deletions) induced by $\gamma$-rays and $\alpha$-particles are significantly different from those which occur spontaneously. 


\title{
Transgenic Cell and Animal Models of Human Radiation Sensitivity (DOE)
}

\author{
Principal Investigator: $M$. A. MacInnes \\ Co-Investigator: D. J. Chen \\ Collaborator: R. Pederson*
}

Other Staff: D. Ludwig, Y. Takiguchi, and P. Pardington

The objective of this research is to develop novel mouse and cellular genetic models to gain insight into the mechanisms and consequences of human inherited susceptibilities to exogenous radiations. Our specific aims include construction of mouse gene knockout $(\mathrm{KO})$ null mutations in the genes encoding the xeroderma pigmentosum, type $\mathrm{G}$ (XP-G) enzyme and in gene encoding a related enzyme, flap endonuclease-1 (FEN-1). These proteins are mammalian representatives of the RAD2 family of single-strand, DNA repair nucleases. XP-G protein is the 3'-specific damage endonuclease for chemical carcinogen and ultraviolet damages excision. The role of FEN-1 in mammalian damage recovery processes is still not clear. We will intercross these genetic mouse models to knockout mutants of other damage response pathways starting with mouse AP endonuclease (mAPE) gene. The mAPE is a critical 5 '-apurinic/apyrimidinic endonuclease related to repair of spontaneous, oxidative, and ionizing radiation-induced damages. Current progress includes the following. (1) The functional mouse XP-G gene has been characterized for its exon structure, and we have discovered XP-G promoter induction caused by exogenous DNA damages.

(2) In collaboration with Dr. Roger Pederson, we are producing homologous gene replacement with a XP-G KO construct in ES cells. (3) We have produced targeted KO mutants for mouse mAPE gene in embryonic stem (ES) cells. (4) The mAPE mutant ES cells have been introduced into mouse embryos, which have given rise to our first chimeric animals. Our approaches include the following: (1) targeting KO gene-replacement of XP-G and FEN-1 in ES cells. This approach will include double targeting to produce homozygous KO ES cells in vitro. (2) We will produce germline transmission of XP-G, FEN-1, and APendo KO mutations in the 129 mouse. (3) We will characterize mouse mutant cellular cytotoxicity and DNA repair capacities from ultraviolet radiation, ionizing radiation, and oxidative damaging agents. (4) These recessive mouse mutations will be interbred to assess their mechanistic interactions and the relevance of these repair pathways for human disease etiology. Anticipated benefits include production of novel mouse cell and animal models for evaluating the impact of these DNA repair proteins in ameliorating the risk of human carcinogenesis and of degenerative diseases.

*Laboratory of Radiobiology, University of California-San Francisco, San Francisco, California 


\title{
Chromosomal Damage in the 1-Rad Region: Cytogenetic Detection Following Ultralow Doses and Dose Rate (DOE)
}

\author{
Principal Investigator: E. H. Goodwin
}

Chromosome aberration measurements provide a sensitive indication of genetic damage induced by radiation. The objective of this research effort is to obtain quantitative data concerning induction of chromosomal damage by densely ionizing $\alpha$ particles at doses as low as $1 \mathrm{rad}$ and to monitor cellular attempts to repair that damage. It is felt that this objective represents a scientifically sound approach to the problem of improving radiological risk assessment in human populations exposed to realistic levels of radon and radon daughter products. As an experimental system, normal human fibroblast cells are exposed to $5 \mathrm{MeV} \alpha$-particles from a ${ }^{238} \mathrm{Pu}$ source. Specific aims are (1) to use premature chromosome condensation to measure radiation-induced breaks and to follow the time course of their repair; and (2) to use mitotic chromosome analysis and micronuclei measurements to quantitate unrepaired or misrepaired chromosome damage. Innovative approaches are being developed to increase the information content of these cytogenetic techniques and to allow detection of chromosome damage at lower doses than previously possible. Data obtained using these methods will lead to an accurate determination of the biological effectiveness of $\alpha$-particles. These measurements are being extended down to the dose range where single-particle effects predominate. In this low dose range, the estimated effectiveness per unit dose of $\alpha$-particle radiation is no longer a function of dose or dose rate and therefore is expected to remain constant at even lower doses characteristic of actual radon exposure levels. The $\alpha$-particle data will be compared to similar data for $\gamma$-rays, about which carcinogenic potential is thought to be better understood.

\section{Applications of Strand-Specific In-Situ Hybridization (LANL)}

\author{
Principal Investigator: E. H. Goodwin
}

\section{Co-Investigator: J. Meyne}

Fluorescence in situ hybridization (FISH) is an effective tool for mapping DNA sequences to their corresponding chromosomal locations. In the Life Sciences Division of LANL, a variation of FISH was developed that makes in situ hybridization strandspecific. The advantage of this process is that, in addition to location, the relative orientation of two or more target sequences on the same chromosome can be determined. The new procedure has been named "chromosomal orientation FISH" (CO-FISH). Using CO-FISH, we have observed that the tandemly repeated units of many, but not all, satellite DNA sequences are arranged head to tail, whereas dispersed repeats show no preferential orientation at the level of light microscopy. The TTAGGG telomeric repeats are known to have a 5'-to-3' direction pointing toward the end of the chromosome. Therefore, the absolute direction of any other sequence can be learned from its orientation with respect to telomeres. The objective of this research effort is to expand the range 
of applications of strand-specific in situ hybridization. We intend to develop CO-FISHbased methods to examine altered gene expression, investigate mechanisms of gene amplification, and facilitate genomic mapping.

\section{Repair of Bifilar DNA Damage Induced by Radiation (NIH)}

\section{Principal Investigator: $R$. J. Reynolds}

The bifilar nature of closely opposed cyclobutyl pyrimidine dimers complicates their elimination from cellular DNA by normal enzymatic repair mechanisms. As a result of these complications, it is believed that the induction of dimers at closely opposed positions may have greater biologic significance than the induction of dimers at relatively isolated positions. The overall objectives of this proposal are to examine factors affecting the induction of closely opposed pyrimidine dimers, to determine the mechanisms by which they are repaired and the consequences of their induction and repair in eukaryotic cells. Sensitive enzymatic assays, developed in this laboratory, have facilitated the detection and quantification of closely opposed dimers and have been used to characterize partially the cellular functions necessary for their repair. Current studies are concerned with the replication of DNA past closely opposed dimers, the effects of DNA sequence on the induction of closely opposed dimers, and the role of closely-opposed dimers in the induction of genetic recombination by ultraviolet radiation.

\section{Radiation Responses of S-Phase Cells (DOE)}

Principal Investigator: J. A. D'Anna

\section{Co-Investigator: L. R. Gurley}

\section{Collaborators: H. A. Crissman and J. G. Valdez}

The goal of this project is to determine the molecular mechanisms that regulate DNA replication in response to ionizing radiation. The investigations are focused on cyclin-dependent kinases (cdks), their substrates, and their role in regulating DNA replication in response to DNA damage during $S$ phase. The rhodopsin replicon in cells of Chinese hamster ovary $(\mathrm{CHO})$ cell line is being used to understand the regulation of replication in specific regions of the genome. Our recent results support the hypotheses that (1) the regulation of radiation delay during $S$ phase precedes or prevents the activation of cdk2 activity and/or preparatory structural changes required for initiation within sets of replication foci or (2) cdk2 activity may be inhibited throughout the S-phase nucleus. The near-term objective of the project is to test these concepts and to clarify the kinetics, mechanisms, and limitations regarding $\gamma$-radiation-induced delay of DNA replication in normal human fibroblasts and CHO cells. The results will clarify a confusing area of radiation biology so that attention can be focused on actual participants in regulation. 


\title{
Development of an Ultrasensitive and Rapid DNA Repair Assay (DOE, LANL)
}

\author{
Principal Investigator: M. S. Park
}

The objective of this study is to develop an ultrasensitive and rapid DNA repair assay. This assay will enable us to screen individuals with higher risks of skin cancer, to identify potential environmental mutagens, and to aid in the purification and characterization of DNA excision repair proteins. The assay is based upon the experimental observation that the quantity of full-size in vitro transcripts synthesized from DNA templates decreases as a function of chemical- or radiation-induced damage in the DNA due to inhibition of transcription beyond these damaged sites. If the DNA damage is repaired, the amount of the synthesized full-size transcripts increases proportionately. The goals of the project are (1) to optimize the incorporation kinetics of nonradioisotopic ribonucleotide analogs in the in vitro transcription reaction; and (2) to refine this assay in a form that can be readily converted into a DNA repair assay kit in cooperation with an industrial partner. In addition, the development of this assay has an immediate application in the purification and characterization of biological functions of the human DNA repair protein ERCC5/XPGC.

\section{Competency Development in Antibody Production for Cancer Cell Biology (DOE, LANL)}

\author{
Principal Investigator: M. S. Park
}

Co-Investigators: M. R. Altherr, J. A. D'Anna, H. A. Crissman, B. L. Marrone, and B. E. Lehnert

Modern cell biology requires the use of antibodies developed against specific cellassociated proteins in order to investigate the roles played by the proteins in complex biological processes. Cell biologists in Life Sciences Division recently evaluated our current research strengths in the context of our long-term research objectives; and we have identified modern antibody capabilities as a competency that is urgently needed for the identification, purification, and functional analyses of new gene products that are being investigated in our newly formulated Cancer Risk Assessment Program. This program additionally requires expertise in cancer cell genetics. With regard to our specific needs, antibodies are critical for identifying and monitoring the expression of proteins involved in the rate-limiting steps of DNA repair, cell-cycle checkpoints, and the regulation of cell division. Moreover, antibodies undoubtedly will be indispensable for our future development of "user-friendly" bioassay kits that will be commercialized and used to screen individuals for cancer risk. In addition to satisfying the needs of cell biologists in Life Sciences Division, the production of antibodies at Los Alamos National Laboratory will also be important to future developments in the Human Genome Project and the Structural Biology Program, and high-quality antibodies are required to meet the specific aims of several projects in other divisions as well. Accordingly, we propose (1) to develop here at LANL the technical capabilities for producing high-quality antibodies, 
and (2) to strengthen and broaden our scientific expertise in bioscience and biotechnology, in general, and in Cancer Risk Assessment, in particular.

\title{
Karyotype Instability and Neoplasia (DOE, LANL)
}

\author{
Principal Investigator: $P$. M. Kraemer
}

\section{Collaborators: S. R. Peterson and H. Ozer*}

A concerted effort is being made to isolate a gene or genes tentatively localized on the long arm of human chromosome 6 that are involved in the immortalization step of carcinogenesis. The human fibroblast-large $\mathrm{T}$ antigen model of carcinogenesis has special features that permit it to be exploited for investigations of this immortalization step. Human fibroblasts transfected with the large $\mathrm{T}$ antigen are not directly immortalized; rather they show an extended life span but then enter "crisis" and, with rare exceptions, all the cells die without being blocked in G1 as they would have, had they become senescent. Rare cells that survived this process have been expanded and shown to be serially clonogenic, that is, immortal and capable of passage as permanent cell lines. We now have a large set of independently immortalized cell populations, cryopreserved as "newly immortalized" cells. These cells require further genetic changes before they will become transformed or tumorigenic; thus, they constitute appropriate experimental material for focused investigations on the abrogation of cellular senescence. Recently, we have shown that at this early stage, newly immortalized cells do not form normal quartenary complexes of the cyclin-dependent kinases. These complexes are thought to be important in normal cell cycle control.

We have completed detailed cytogenetic analyses of these newly immortalized cell populations. These analyses include a combination of G-banded karyotyping, fluorescence in situ hybridization (FISH) with whole chromosome painting probes, and molecular analyses for losses of heterozygosity. Eleven independently immortalized cell populations were studied, and several clonal cytogenetic changes were commonly found. The most common findings were those of deletions and of other lesions involving the long arm of chromosome 6 . So far, three cases were found in which the inactivation of the putative gene at $6 \mathrm{q} 21$ apparently occurred by breakage and translocation of the locus to two or more derivative chromosomes. Our plan is to exploit these cases by isolating and characterizing these breakpoints.

For this purpose we have (with the collaboration of Genome Center personnel) mapped clones from the Centre d'Etude du Polymorphisme Humain (CEPH) mega-yeast artificial chromosome (YAC) library on normal and marker chromosomes using FISH techniques. Clones that span the $6 \mathrm{q} 21$ breakpoint on the marker chromosomes, that is, clones that give a signal at the breakpoint on both marker chromosomes, will be identified. Such YAC clones will then be used to isolate chromosome 6 cosmid clones that form the smallest contig that also spans the breakpoint. The molecular characterization of the region will then be done with this cosmid contig.

*University of Medicine and Dentistry of New Jersey, Newark, New Jersey 


\section{Radiation Biology and Carcinogenesis Accomplishments}

- We overexpressed and purified a functionally active recombinant XPG protein. We found the protein to possess a structure-specific endonuclease activity. We made mutant XPG proteins in order to identify the catalytic domain of XPG protein. It was observed that the helix-loop-helix (HLH) motif has lost the flap-endonuclease activity. One of the XPG mutant proteins, which lacks the C-terminal nuclear localization signal, still possessed the flap endonuclease activity.

- Circular dichroism studies on the HLH motif of XPG protein confirmed the helical propensity of the motif. The conditions for the labeling of the recombinant HLH peptide with stable isotopes $(15 \mathrm{~N}, 13 \mathrm{C}$ ) have been established, and $5 \mathrm{mg}$ of labeled peptide was produced for multidimensional nuclear magnetic resonance (NMR) spectroscopy studies.

- We identified within the XPG protein regions that are responsible for nuclear localization and ultraviolet response. We observed that XPG protein responds to ultraviolet irradiation and dissociates and reassociates within defined foci after such exposure. By using a reporter system, we identified a nuclear retention signal in XPG protein, which is responsible for association and dissociation of XPG protein with the perinucleolar region in HeLa cells after they were exposed to ultraviolet radiation.

- We isolated cDNA and genomic clones of human flap-endonuclease (FEN-1) gene. We also mapped the FEN-1 on human chromosome 11q13. A wild-type and a mutant FEN-1 protein were overexpressed in bacteria for structure/function studies.

- We used a mammalian expression construct to test the effect of overexpression of RAD52 protein in intrachromosomal homologous recombination in mammalian cells. We observed that the overexpression of RAD52 confers a resistance to ionizing radiation and induces homologous recombination in monkey cells. A recombinant RAD52 protein was produced in bacteria and purified to apparent homogeneity for biochemical and structural studies.

- A recombinant RAD51 protein was produced for biochemical studies including strand exchange and homologous pairing in vitro.

- The molecular nature of mutations occurring in the XPG gene is being characterized in three patients. The pedigree analysis of a single patient has revealed that a nonsense mutation in exon 1 was paternally inherited, while two apparent genetic polymorphisms were maternally inherited.

- We have identified another potentially inactivating mutation in the XPG gene of a xeroderma pigmentosum patient. The mutation is located within the conserved $\mathrm{B}$ domain (yeast and humans) at cDNA base pair position 792 and results in the conversion of an alanine to a valine. 
- We accumulated additional data suggesting that XPG alleles in two patients may be inactivated by loss of gene function at the transcription level. The precise mechanisms by which this occurs is currently under investigation.

- In an effort to produce a "null" mutant genetic background for XPG in transformed human lymphoblastoid cells, we have constructed a cosmid library from a cell line that is functionally hemizygous for XPG. The normal allele of the XPG gene will be modified to construct a knockout (KO) XPG gene targeting vector. A complete $\mathrm{KO}$ of functional XPG gene expression is expected from homologous recombination of the targeting vector with the normal genomic XPG allele.

- A gene-targeted KO DNA construct has been completed for the mouse XPG gene. It will be used to produce targeted XPG gene inactivation by homologous recombination in mouse embryonic stem (ES) cells in collaboration with Dr. Roger Pederson of the University of California-San Francisco (UCSF). The mutant ES cells then will be bred to germline transmission of homozygous XPG null mutation in the mouse.

- The mouse XPG promoter, when fused into a luciferase reporter gene, is induced threefold in mouse $\mathrm{L}$ cells by ultraviolet light and by the chemical genotoxin mitomycin $\mathrm{C}$.

- We have isolated both mouse and human homologs of the yeast Rad52 genes, using degenerated polymerase chain reaction (PCR) primers designed from the yeast Rad52 sequences. The human Rad52 gene also was mapped on the human chromosome 12 by cDNA fluorescence in situ hybridization (FISH) analysis.

- We have developed a suitable DNA template for an ultrasensitive and rapid DNA repair assay.

- We have identified a biotinylated-UTP and digoxigenin-UTP as nonradioactive substitutes for the in vitro transcription steps in the rapid DNA repair assay.

- We tested two nonradioactive NTP analogs for incorporation efficiency during in vitro transcription. The biotinylated UTP (bio-UTP) and digoxigenin-UTP (dig-UTP) were substituted for radioactive ${ }^{32} \mathrm{P}-\mathrm{UTP}$ for in vitro transcription. Both analogs showed a level of incorporation equivalent to that of ${ }^{32} \mathrm{P}-\mathrm{UTP}$.

- Advances were made in detection of a nonradioactive signal. The original protocol, which uses dig-UTP, provides few advantages, such as larger signal-to-noise ratio, by incorporating more dig-UTP per each full-size transcript over the modified primer approach that introduces only one molecule of digoxigenin per transcript. We tested two different enzyme-conjugated anti-digoxigenin antibodies: one with AP and another with HRP. In combination of the relevant colorimetric substrates, such as 5bromo-4-chloro-3-indoyl phosphate (BCIP)/nitroblue tetrazolium (NBT) or 
diamino benzidine (DAB) for alkaline phosphatase or horseradish peroxidae, respectively, we found that $\mathrm{AP}-\mathrm{BCIP} / \mathrm{NBT}$ is superior than the HRP-DAB combination.

- We have determined that mammalian cell transfection efficiency can be significantly increased by incubation of the target cells with m-AMSA, an inhibitor of topoisomerase II.

- We found that the topoisomerase II inhibitor m-AMSA reduces single-strand annealing during cotransfection of Chinese hamster ovary (CHO) cells with plasmids that share homology.

- We found that irradiation of CHO UV135 cells with ultraviolet radiation stimulates the efficiency of stable transfection. These CHO UV135 cells are deficient in nucleotide excision repair and have increased sensitivity to ultraviolet radiation, but normal sensitivity to ionizing radiation. This stimulation is much greater than that observed in normal, excision-proficient $\mathrm{CHO}$ cells.

- We have determined that the ultraviolet radiation-sensitive mutant CHO UV135 does not exhibit increased sensitivity to ${ }^{137} \mathrm{Cs} \gamma$-rays or to the topoisomerase inhibitor m-AMSA.

- Our measurements of histone $\mathrm{H} 1$ content, histone phosphorylation, and cdk2 levels/activities indicate that CHO cells blocked near the G1/S boundary with mimosine are biochemically and structurally poised for initiation, as suggested by others to explain an absence of radiation delay in the early replicating replicons of the mimosine-blocked cells.

- Since radiation delay is abolished in the early replicating replicons of synchronized cells, in which cdk 2 is activated and the early replicating replicons are putatively poised for initiation, these results indicate that the regulation of DNA replication in response to ionizing radiation must precede the localized activation of cdk 2 and/or the preparatory structural changes required for initiation in replicons.

- A gene or genes that appear to be involved in the immortalization step of carcinogenesis have tentatively been localized on the long arm of chromosome 6 . Yeast artificial chromosome (YAC) clones that span the suspect region (6q21) have been identified.

- Normal human cells form protein complexes containing cyclin and cyclindependent kinases that are involved in cell-cycle regulation. When such cells are immortalized by SV40 large T antigen, some of these complexes, presumably related to cellular senescence, are rearranged and thereby fail to inhibit the cell cycle. 

Facilities and Support Services 


\title{
NATIONAL FLOW CYTOMETRY RESOURCE
}

\author{
J. H. Jett, L. S. Cram, G. C. Salzman, J. C. Martin, L. A. Sklar,* \\ J. A. Steinkamp, and.H. A. Crissman
}

The National Flow Cytometry Resource (NFCR) was established to make stateof-the-art flow-cytometric instrumentation available to the biomedical research community. The NFCR is supported by the Biomedical Research Technology Program, the National Center for Research Resources of the National Institutes of Health (NIH), and the Office of Health and Environmental Research (OHER) of the Department of Energy (DOE). The focus of the NFCR is to provide an active and dynamic program of collaborative research, develop new instrumentation capabilities and biological techniques based on identified user need, train scientists in the use of flow cytometry, and serve as an interface between the academic, private, and government sectors. To this end, the Resource has the following five major goals:

- Technological Research and Development. Develop and make available advanced flow-cytometric instrumentation and relevant methodology in response to specific needs of the biomedical community, collaborators, and service users. Identify new investigative and clinical uses for flow cytometry.

- Collaborative Research. Establish, between NFCR staff and scientists at other institutions, research projects that enhance and enlarge the frontiers of flow cytometry for answering significant biomedical questions.

- Service Projects. Provide, to the user community, support for short-term projects that will help facilitate the availability of general flow-cytometric techniques and technology.

- Training. Train students, postdoctoral appointees, and scientists in the operation and application of flow instruments and in related technologies.

- Dissemination. Disseminate information about the availability of the NFCR and its activities, using the Flow Systems Newsletter, postdoctoral training, brochures, and transfer of technology to other institutions.

Unique capabilities either exist or are being established in the following areas: chromosome analysis and sorting, high-resolution analysis, super high-speed sorting, phase-sensitive detection cytometry, and multilaser excitation systems. Techniques include analysis of fluorescence polarization, kinetic measurements, correlated data analysis procedures, high-resolution DNA studies, staining protocol development, fluorescence distribution analysis, and multiparameter procedures. Research fields include cellular and molecular biology, tumor biology, infectious disease, parasitology, genetics, and radiobiology. Biomedical research investigators from other U. S. locations are involved in the use and management of this designated user facility.

*University of New Mexico School of Medicine, Albuquerque, New Mexico 


\title{
MULTIPLE-UNIT $\gamma$-RAY IRRADIATION FACILITY
}

\author{
G. F. Strniste
}

Three $\gamma$-ray irradiators located within the Health Research Laboratory (HRL-1) provide LANL research personnel with ionizing radiation beams that have a dynamic range of dose rates of $>500,000$-fold. Our facility consists of three irradiators. (1) A high-dose-rate Mark I ${ }^{137} \mathrm{Cs}$ irradiator, manufactured by J. L. Shepherd and Associates of San Fernando, California, contains $\sim 6900 \mathrm{Ci}{ }^{137} \mathrm{Cs}$ and provides sample irradiation with $0.66 \mathrm{MeV} \gamma$-rays at dose rates up to $17.5 \mathrm{~Gy} / \mathrm{min}$. (2) A dualsource irradiator contains at present (December 1994) $8.5 \mathrm{Ci}$ and $850 \mathrm{Ci}{ }^{137} \mathrm{Cs}$ sources. This unit is a specially designed model 81-12 irradiator, also manufactured by J. L. Shepherd and Associates. It produces fluxes of $0.66 \mathrm{MeV} \gamma$-rays between 0.2 and $200 \mathrm{cGy} / \mathrm{h}$., dependent on the source used and position of built-in attenuators. (3) $\mathrm{A}^{60} \mathrm{Co}$ irradiator (a modified Picker radiotherapy unit), at present contains $3,900 \mathrm{Ci}{ }^{60} \mathrm{Co}$ and produces fluxes of $1.17 \mathrm{MeV} \gamma$-rays at dose rates between 0.67 and $2.7 \mathrm{~Gy} / \mathrm{min}$. The radiation facility is used extensively by radiobiologists in the Life Sciences Division in both molecular and cellular experimentation. In addition, source time has been provided to other LANL personnel in studies concerning radiation physics and dosimetry, radiation chemistry, and plant biology.

\section{IMAGE MICROSCOPY}

\section{B. L. Marrone}

The image microscopy facility is a laboratory resource for digital image acquisition, analysis, processing, and hard-copy output. Two microscope systems are available for image acquisition. The Zeiss Axiophot microscope is fitted with a Photometrics (Tucson, Arizona) slow-scan cooled charge coupled device (CCD) camera containing a $1 \mathrm{~K} \times 1 \mathrm{~K}$ Kodak KAF-1400 Grade 1 chip. The camera is interfaced via a VME bus-to-S-bus adapter to a Sun Sparc $2 \mathrm{GX}$ computer running Inovision dsp/os/ISee software for image acquisition and microscope control (Inovision Corporation, Research Triangle Park, North Carolina). This microscope also is equipped with a motorized excitation filter wheel, for multicolor imaging, and a motorized $\mathrm{x}, \mathrm{y}, \mathrm{z}$ stage. A Zeiss LSM-10 laser scanning confocal microscope is equipped with a $10 \mathrm{~mW}$ argon laser $(488 \mathrm{~nm}, 514 \mathrm{~nm}$ excitation) and a HeNe laser. The computers controlling image acquisition are part of an ethernet network dedicated to image processing. Image processing is performed with the image processing software package KHOROS ( ${ }^{\circ}$ by University of New Mexico). For image analysis, images are stored on a Sun Sparc 1 file server and accessed by a Macintosh computer over the network via NFS/Share (Intercon, Herndon, Virginia). The Macintosh has a 24-bit video card and a 20-in Supermatch color monitor for highest resolution image display. Other image processing and analysis software includes IP Lab Spectrum, NIH Image, and Adobe Photoshop. A Hewlett-Packard (HP) laserjet printer, and a Tektronix color printer are also on the network to provide high-quality printed image output. 


\section{ANIMAL COLONY RESOURCE}

\section{J. S. Wilson}

The Animal Colony Resource provides animal model experimentation for diverse research projects in an accredited facility under scrutiny of an Institutional Animal Care and Use Committee (IACUC). The resources of the facility include housing and care for rodents; experimental areas and equipment; veterinary consultation; accreditation of care and use by an independent oversight organization, the American Association for the Accreditation of Laboratory Animal Care (AAALAC); and assurance of care and use to the DOE and to the National Institutes of Health (NIH). An Animal Users Group oversees research interests and allocation of financial responsibility for the Resource. This group has members representing the LANL divisions of Life Sciences (LS); Physics (P); Environment, Safety, and Health (ESH); and Theoretical research $(\mathrm{T})$. While the Animal Colony Resource is currently quite limited in its space and housing capability, the need for in vivo experimentation is driving the maintenance of this minimal, but quality, research.

Included in current LANL animal research projects are the Environmental Park studies of animal populations in and around Los Alamos conducted by ESH Division, genomic perturbations resulting from the introduction of exogenous DNA into rodent embryos conducted by LS Division, and production of "designer" antibodies performed by T Division. Using the LANL Animal Colony Resource, researchers have successfully produced transgenic mice from both pronuclear- and embryonic stem (ES) cell-injection strategies. Unique antigen moieties have been introduced into mice and the resulting highly specific ("designer") antibodies have been retrieved. Mice and rats have provided tissue-specific cells for elucidating cellular responses to physical and chemical agents. Although cultured cells can and are being used to investigate some aspects of these research interests, whole animal experimentation remains a unique way to study complex living systems. 



\section{Organization}




\section{LIFE SCIENCES DIVISION}

ORGANIZATION CHART

E. Morton Bradbury
Division Director

\section{Funding Distribution}

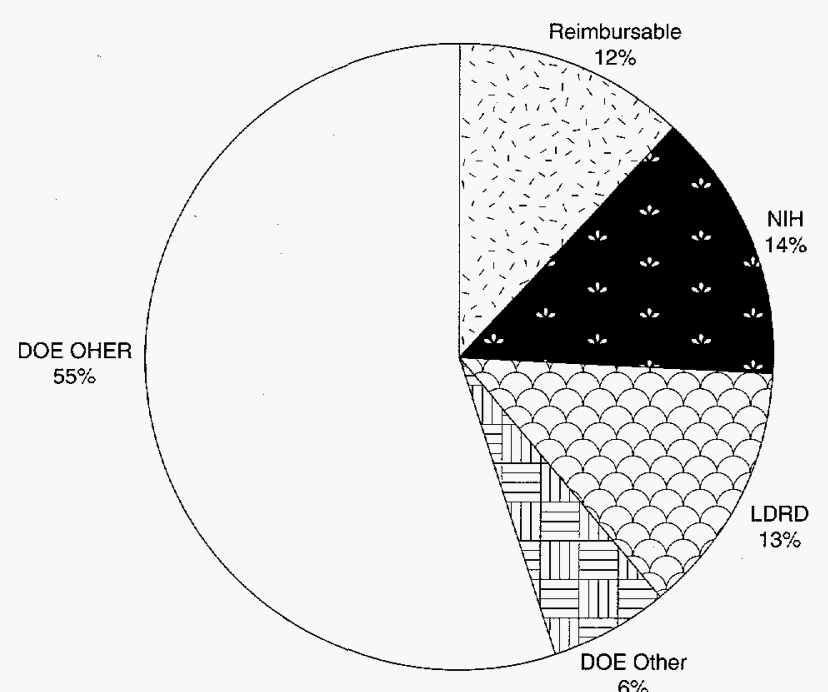

$6 \%$ 


\section{LIFE SCIENCES DIVISION}

\section{E. Morton Bradbury, Division Director}

L. Scott Cram, Deputy Division Director

Carolyn Stafford, Staff Assistant

Gary F. Strniste, Group Leader, LS-1

Thomas W. Whaley, Group Leader, LS-2

Russell Durrer, Facility Manager

Fawn Gore, Division Office Administator

John Horne, Building Manager

Cheryl Straub, Budget Fiscal Specialist, BUS-8

Kathy Montoya, Secretary

Belinda Teller, Secretary

Scott Downing, Waste Management Coordinator

Toby Trujillo, Property Administrator, BUS-6*

Lori Wolfe, Property Administrator, BUS-6*

Laboratory Associate

Donald F. Petersen

\section{CENTER FOR HUMAN GENOME STUDIES}

Robert K. Moyzis, Center Leader

Larry L. Deaven, Deputy Center Leader

Monica H. Fink, Administative Assistant

Lynn M. Clark, Technical Administrator

*Business Operations Division, Property and Transportation Group 


\title{
CELL GROWTH, DAMAGE, AND REPAIR GROUP (LS-1)
}

\author{
Gary F. Strniste, Group Leader \\ James H. Jett, Program Manager \\ Bruce E. Lehnert, Program Coordinator \\ Richard J. Reynolds, Program Coordinator \\ Ruby R. Archuleta, Group Office Administrator \\ Dusty Deaguero, Secretary
}

STAFF MEMBERS

E. Campbell

D. Chen

H. Crissman

J. Freyer

E. Goodwin

P. Kramer

B. Lehnert

M. MacInnes

B. Marrone

J. Martin

R. Okinaka

M. Park

F. Ray*

R. Reynolds

G. Salzman

L. Sklar

M. Smyth*

J. Steinkamp

W. Wharton

M. Wilder

Y. Yamada

\section{TECHNICAL STAFF}

S. Bailey

C. Bell-Prince

L. Bustos

M. Campbell

J. Fawcett

R. Habbersett

P. Jewett

N. Lehnert

A. Martinez

P. Pardington

J. Parson

P. Schor

K. Shera

Y. Valdez

M. Waltman

\section{POSTDOCTORAL FELLOWS}

S. Amundson

C. Deka

M. Englen

D. Gadbois

L. Kunz-Schugart

D. Ludwig

J. Nolan

M. Roslaniec

B. Shen

Z. Shen

M. Stackhouse

Y. Takiguchi

C. Wistrom**

\section{STUDENTS AND ASSISTANTS}

B. Anderson

N. Ballew

F. Chen

K. Cloud

J. Comeaux

A. Deshpande

J. Francis

J. Fulwyler

J. Gonzales

H. Henderson

C. Lin

S. Minter

M. Naivar

A. Nastasi

S. Pendergrass

A. Pierce

C. Potter

D. Quigley

S. Rose

J. Rudnick

D. Scott

A. Seña

L. Smith

R. Svensson

S. Tan

S. Wang

D. Zastro

* Leave of Absence

**Current Address: University of California-Riverside, Riverside, California 


\section{GENOMICS AND STRUCTURAL BIOLOGY GROUP (LS-2)}

STAFF MEMBERS

M. Altherr

J. D'Anna

N. Doggett

J. Gatewood

D. Grady

L. Hersman

E. Hildebrand*

B. Imai

P. Jackson

C. Kuske

J. Longmire

J. Meyne

B. Schoenborn

T. Terwilliger

J. Wilson

\section{GRADUATE RESEARCH ASSOCIATES}

D. Adair

K. Banton

L. Beauchamp

J. Busch

L. Chasteen

J. Houts

H. Hue

J. Liu

M. Lowenstein

K. Richmond

W. Sawhill

Q. Simmons

S. Story

R. Tagett

C. Tape

F. Whitsitt
Thomas W. Whaley, Group Leader Tricia Lewis, Group Office Administrator Josie Gutierrez, Volt Contract Employee
TECHNICIANS
N. Brown
D. Bruce
J. Buckingham
K. Denison
A. Ford
L. Goodwin
K. Hill
M. Jones
C. Lemanski
R. Lehndorf
R. Lobb
T. Lucero
L. Meincke
C. Munk
C. Naranjo
D. Robinson
E. Saunders
N. Sherlock
J. Tesmer
S. Thompson
K. Umbarger*
J. Valdez

D. Leschnitzer

A. Perez

E. Peterson

S. Peterson

M. Skinner

T. Wright

\section{LAB ASSOCIATES}

M. Brooks
L. Gurley
R. Ratliff

\section{AFFILIATES}

\section{UNDERGRADUATE}

M. Valdez
EDUCATION R. Wagner

COOPERATIVE

PROGRAM

SPECIAL PROGRAMS

H. Blair

S. Clark

M. Culumber

\footnotetext{
* Leave of Absence
} 


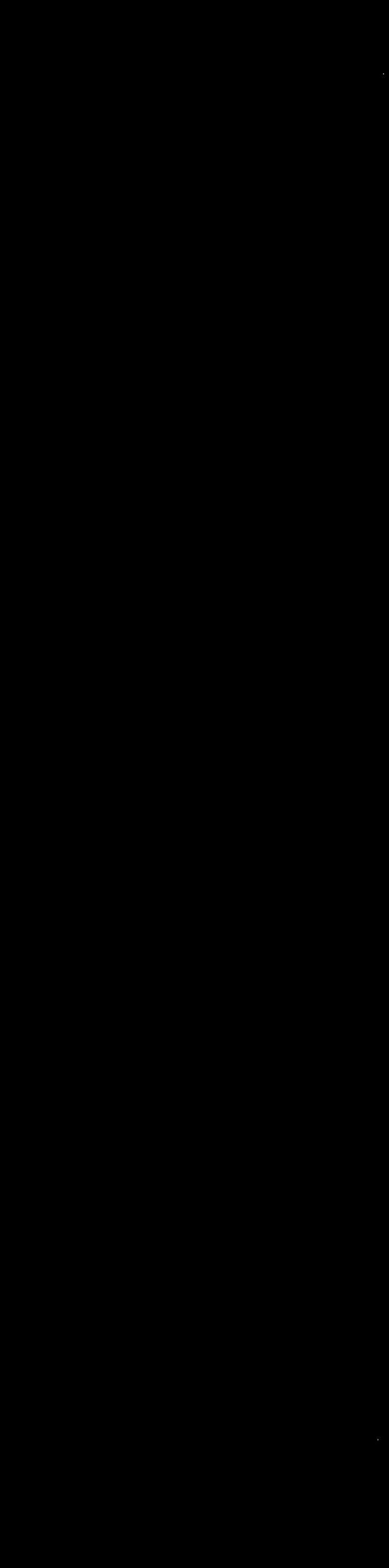




\section{Communications}




\section{PUBLICATIONS}

\section{Center for Human Genome Studies (CHGS)}

\section{Papers}

Brayton, K. A., Z. Chen, G. Zhou, P. L. Nagy, A. Gavalas, J. M. Trent, L. L. Deaven, J. E. Dixon, and H. Zalkin, Two genes for de novo purine nucleotide synthesis on human chromosome 4 are closely linked and divergently transcribed, J. Biol. Chem. 269, 5313-5321 (1994).

Kouprina, N., M. Eldarov, R. K. Moyzis, M. Resnick, and V. Larionov, A model system to assess the integrity of mammalian YACs during transformation and propagation in yeast, Genomics $\mathbf{2 1}$, 7-17 (1994).

\section{LS-1}

\section{Papers}

Ambrose, W. P., P. M. Goodwin, J. C. Martin, and R. A. Keller, Alterations of single molecule fluorescence lifetime in near-field optical microscopy, Science 265, 364 (1994).

Ambrose, W. P., P. M. Goodwin, J. C. Martin, and R. A. Keller, Single molecule detection and photochemistry on a surface using near-field optical excitation, Phys. Rev. Lett. 72, 160 (1994).

Campbell, M. L., R. K. Moyzis, L. L. Deaven, and M. K. McCormick, Use of Gelase TM in construction of chromosome-specific yeast artificial chromosome (YAC) libraries, Epicentre Forum 1(3), 1-2 (1994).

Chen, D. J., T. Nguyen, M. A. Stackhouse, B. L. Marrone, Y. Zhao, and M. J. Siciliano, Regional assignment of a human radiation gene (XRCC5) to $2 \mathrm{q} 35$ by x-ray hybrid mapping, Genomics 21 , 423-427 (1994).

Chen, D. J., K. Tsuboi, T. T. Nguyen, and T. C. Yang, Charged-particle mutagenesis II: mutagenic effects of high-energy charged particles in normal human fibroblasts, Adv. Space Res. 14(10), 347-354 (1994).

Deka, C., L. A. Sklar, and J. A. Steinkamp, Fluorescence lifetime measurements in a flow cytometer by amplitude demodulation using digital data acquisition technique, Cytometry 17, 94101 (1994).

Fay, S. P., R. Posner, M. Domalewski, E. Pierson, R. Freer, J. Whitaker, R. Haugland, R. C. Habbersett, and L. A. Sklar, Multiparameter flow-cytometric analysis of a pH-sensitive formyl peptide with application to receptor structure and processing kinetics, Cytometry 15, 148-153 (1994). 
Freyer, J. P., Rates of oxygen consumption for proliferating and quiescent cells isolated from multicellular tumor spheroids, Adv. Exper. Med. Bio. 345, 335-342 (1994).

Goodwin, E. H., E. A. Blakely, and C. Tobias, Chromosomal damage and repair in $\mathrm{G}_{1}$-phase Chinese hamster ovary cells exposed to charged-particle beams, Radiat. Res. 138, 343-351 (1994).

Goodwin, E. H., and M. N. Cornforth, RBE: mechanisms inferred from cytogenetics, Adv. Space Res. 14, 249-255 (1994).

Hirons, G. T., J. J. Fawcett, and H. A. Crissman, TOTO and YOYO: new ultrasensitive fluorochromes for DNA content analyses by flow cytometry, Cytometry 15, 129-140 (1994).

Jamaluddin, M., M. Molnar, B. L. Marrone, and F. Hertelendy, Signal transduction in avian granulosa cells: effects of protein kinase C inhibitors, Gen. Comp. Endocrinol. 93, 471-479 (1994).

Laubscher, K., L. Lai, R. H. Glew, T. J. Gribble, and R. T. Okinaka, DGGE analysis of mutations causing Gaucher Disease, Hum. Mutat. 3, 411-415 (1994).

Lehnert, B. E., D. C. Archuleta, T. Ellis, W. S. Session, N. M. Lehnert, L. R. Gurley, and D. M. Stavert, Lung injury following exposure of rats to relatively high-mass concentrations of nitrogen dioxide, Toxicology 89, 239-277 (1994).

Lehnert, B. E., Y. E. Valdez, N. M. Lehnert, M. S. Park, M. D. Englen, Stimulation of rat and murine alveolar macrophage proliferation by lung fibroblasts, Am. J. Respir. Cell Mol. Biol. 11, 375-385 (1994).

Lynam, E., S. I. Simon, Y. P. Rochon, and L. A. Sklar, Lipopolysaccharide enhances CD11b/ CD18 function but inhibits neutrophil aggregation, Blood 83, 3303-331 (1994).

Marrone, B. L., E. W. Campbell, S. L. Anzick, K. Shera, M. Campbell, T. M. Yoshida, M. K. McCormick, and L. L. Deaven, Mapping of low-frequency chimeric yeast artificial chromosomes 16 and 21 by fluoresence in situ hybridization and quantitative image analysis, Genomics 21, 202-207 (1994).

Marusic, M., Z. Bajzer, J. P. Freyer, and S. Vuk-Pavlovic, Analysis of growth of multicellular tumor spheroids by mathematical models, Cell Prolif. 27, 73-94 (1994).

Marusic, M., Z. Bajzer, S. Vuk-Pavlovic, and J. P. Freyer, Tumor growth in vivo and as multicellular spheroids compared by mathematical models, Math. Biosci. 56(4), 617-631 (1994).

Oberdörster, G., J. Ferin, and B. E. Lehnert, Correlation between particle size, in vivo particle persistence, and lung injury, Environ. Health Persp. 102, 173-179 (1994).

Posner, R. G., S. P. Fay, M. D. Domalewski, and L. A. Sklar, Continuous spectrofluorometric analysis of ternary complex dynamics: formyl-peptide receptor, Mol. Pharmacol. 45, 65-73 (1994). 
Rochon, Y., S. Simon, E. Lynam, and L. A. Sklar, A role for lectin-like interactions during human neutrophil aggregation, J. Immunol. 52, 1385-1393 (1994).

Stackhouse, M. A., J. B. Ortiz, K. Sato, and D. J. Chen, Functional complementation of the radiation-sensitive mutant M10 cells line by human chromosome 5, Mutat. Res. Lett. 323, 47-59 (1994).

Stone, B. L., and W. R. Wharton, Targeted RNA fingerprinting: the cloning of differentially expressed cDNA fragments enriched for members of the zinc finger gene family, Nucl. Acid $R$. 22, 2612-2618 (1994).

Takiguchi, Y., and D. J. Chen, Genomic structure of the mouse apurinic/apyrimidinic endonuclease (APE) gene, Mamm. Genome 5, 717-722 (1994).

Tellinghuisen, J., P. M. Goodwin, W. P. Ambrose, J. C. Martin, and R. A. Keller, Analysis of fluorescence lifetime data for single rhodamine molecules in flowing sample streams, Anal. Chem. 66, 64 (1994).

Th'ng, J. P. H., X. Guo, R. A. Swank, H. A. Crissman, and E. M. Bradbury, Inhibition of histone phosphorylation by staurosporine leads to chromosome decondensation, J. Biol.Chem. 269, 9568-9573 (1994).

\section{Abstracts}

Ambrose, W. P., P. M. Goodwin, J. A. Schecker, J. C. Martin, and R. A. Keller, Near-field fluorescence imaging of DNA, XVII Congress of the International Society for Analytical Cytology, Lake Placid, New York, October 16-21, 1994.

Amundson, S. A., and D. J. Chen, Dose-rate effect for mutation induction by ionizing radiation in human lymphoblasts, 42nd Annual Meeting of the Radiation Research Society, Nashville, Tennessee, April 29-May 4, 1994.

Amundson, S. A., and D. J. Chen, Ionizing radiation-induced mutation of human cells with different DNA repair capacities, 30th Meeting of the International Committee on Space Research, Hamburg, Germany, July 11-30, 1994.

Aurell-Wistom, C., G. M. Jones, P. S. Tobias, and L. A. Sklar, Bacterial endotoxin topology and structure examined by fluorescence resonance energy transfer, Rocky Mountain Cytometry Meeting, Angel Fire, New Mexico, May 27-29, 1994.

Aurell-Wistrom, C., G. M. Jones, P. S. Tobias, and L. A. Sklar, Bacterial endotoxin topology and surface structure examined by fluorescence resonance energy transfer, 6th Annual Structural Biology Symposium, Santa Fe, New Mexico, May 13, 1994.

Bailey, S. M., E. H. Goodwin, and M. N. Cornforth, Mitotic anomalies induced by alpha particle irradiation, 42nd Annual Meeting of the Radiation Research Society, Nashville, Tennessee, April 29-May 4, 1994. 
Bell-Prince, C., J. H. Jett, and L. A. Sklar, The National Flow Cytometry Resource, XVII Congress of the International Society for Analytical Cytology, Lake Placid, New York, October 16-21, 1994.

Bennett, T. A., E. B. Lynam, C. M. G. Schammel, D. A. Guyer, A. L. Hall, and L. A. Sklar, Sufficiency of MAC-1 and L-selectin in PMN homotypic aggregation, Rocky Mountain Cytometry Conference, Angel Fire, New Mexico, May 27-29, 1994.

Chen, D. J., D. M. Gadbois, S. R. Peterson, H. A. Crissman, and B. E. Lehnert, Cell cycle regulation after alpha particle exposure, Charged-Particle Microbeam Application Workshop, Richland, Washington, October 10-13, 1994.

Chen, F., P. E. Purtymun, N. A. Doggett, and D. J. Chen, Isolation of YAC clones from human chromosome 2Q35, where the human radiation repair gene XRCC5 is mapped, 42nd Annual Meeting of the Radiation Research Society, Nashville, Tennessee, April 29-May 4, 1994.

Cloud, K. G., and M. S. Park, Overexpression and characterization of the ERCC5/XPGC protein produced in insect cells by recombinant baculovirus expression technology, 42nd Annual Meeting of the Radiation Research Society, Nashville, Tennessee, April 29-May 4, 1994.

Crissman, H. A., New stains for DNA analysis and their utility for chromosome analysis, The Flow Cytometry Forum of the Cancer Therapy Research Center, San Antonio, Texas, December 6-7, 1994.

Crissman, H. A., Quantitation of proliferation markers, 3rd Conference of the European Society for Analytical Cellular Pathology, Grenoble, France, May 15-20, 1994.

Crissman, H. A., L. D. Bustos, J. A. Dickson, S. Y. Minter, D. M. Gadbois, P. M. Kraemer, and E. M. Bradbury, Flow cytometric studies on differences in cell-cycle regulation and growth of normal and malignant cell populations, Association de Cytometrie en Flux Cercle Francais de Microscopie Quantitative Meeting, Grenoble, France, May 15-20, 1994.

Crissman, H. A., J. A. Dickson, and L. D. Bustos, Cell-cycle and chromosome analysis by flow cytometry using new fluorochromes, Cell Kinetics Meeting, Louisville, Kentucky, March 24-27, 1994.

Crissman, H. A., J. A. Dickson, L. D. Bustos, and J. A. Steinkamp, Analysis of cells and chromosomes with new DNA fluorochromes, XVII Congress of the International Society for Analytical Cytology, Lake Placid, New York, October 16-21, 1994.

Deka, C., L. A. Sklar, and J. A. Steinkamp, An advanced multi-harmonic frequency phasesensitive flow cytometer using pulsed excitation, XVII Congress of the International Society for Analytical Cytology, Lake Placid, New York, October 16-21, 1994.

Deka, C., J. A. Steinkamp, and L. A. Sklar, Phase-sensitive detection in flow cytometry, Rocky Mountain Cytometry Conference, Angel Fire, New Mexico, May 27-29, 1994.

Dickson, J. A., L. D. Bustos, J. A. Steinkamp, and H. A. Crissman, Flow cytometric analysis of cells and chromosomes with new DNA fluorochromes, Rocky Mountain Cytometry Conference, Angel Fire, New Mexico, May 27-29, 1994. 
Domalewski, M. D., D. A. Guyer, and L. A. Sklar, Receptor/G-protein association can be regulated by GTP(s) in the absence of ligand in the human neutrophil, Rocky Mountain Cytometry Conference, Angel Fire, New Mexico, May 27-29, 1994.

Englen, M. D., N. M. Lehnert, Y. E. Valdez, and B. E. Lehnert, Silica particles fail to stimulate murine alveolar macrophages to release tumor necrosis factor, FASEB Experimental Biology ' 94 , Anaheim, California, April 24-28, 1994, FASEB 8, A840.

Freyer, J. P., Decreased mitochondrial function in quiescent cells isolated from multicellular tumor spheroids, 42nd Annual Meeting of the Radiation Research Society, Nashville, Tennessee, April 29-May 4, 1994.

Freyer, J. P., and R. C. Habbersett, Mitochondrial function in cells isolated from multicellular spheroids, XVII Congress of the International Society for Analytical Cytology, Lake Placid, New York, October 16-21, 1994.

Freyer, J. P., H. Lindford, V. Lovejoy, and G. J. Moore, Correlation between alterations in phosphomonoesters and cellular proliferation during recovery from quiescence in a tumor model, 2nd Meeting of the Society of Magnetic Resonance, San Francisco, California, August 6-12, 1994.

Goodwin, E. H., and S. M. Bailey, Scoring micronuclei in daughter cell pairs: a viable alternative to the cytochalasin assay, 42nd Annual Meeting of the Radiation Research Society, Nashville, Tennessee, April 29-May 4, 1994.

Goodwin, E. H., S. M. Bailey, and D. J. Chen, The effect of track structure on chromatin breaks, survival and HPRT mutation, 5th Annual Space Radiation Health Investigators Workshop, Houston, Texas, April 26-28, 1994, and 30th Meeting of the International Committee on Space Research, Hamburg, Germany, July 11-30, 1994.

Guyer, D. A., Y. P. Rochon, and L. A. Sklar, The use of fixed cells as targets to study homotypic neutrophil aggregation, Rocky Mountain Cytometry Conference, Angel Fire, New Mexico, May 27-29, 1994.

Habbersett, R. C., Embedded control of fluidic/pneumatic systems on flow cytometers, XVII Congress of the International Society for Analytical Cytology, Lake Placid, New York, October 16-21, 1994.

Habbersett, R. C., IDLYK-A program for flow cytometry data display \& analysis written in IDL, Rocky Mountain Cytometry Conference, Angel Fire, New Mexico, May 27-29, 1994.

Habbersett, R. C., and J. H. Jett, Display your data, as you never have before, in 15 minutes or less, International Cytometry Symposium, San Francisco, California, January 18-21, 1994.

Hall, L. L., J. P. H. Th'ng, H. A. Crissman, X. W. Guo, R. L. Tepliz, and E. M. Bradbury, Induction of polyploidy in mouse cells with staurosporine, American Society for Cell Biology Meeting, San Francisco, California, December 10-14, 1994. 
Jett, J. H., Flow cytometry: A powerful technique for application to biomarker measurements, DOE Biomarkers Meeting, Santa Fe, New Mexico, April 27-29, 1994.

Jett, J. H., J. D. Parson, and J. C. Martin, A simple Macintosh computer-based data acquisition system for flow cytometry that uses Labview, XVII Congress of the International Society for Analytical Cytology, Lake Placid, New York, October 16-21, 1994.

Knauf, J. A., M. S. Park, and M. A. MacInnes, Identification of the NLS sequence in the ERCC5/ XP-G protein, 42nd Annual Meeting of the Radiation Research Society, Nashville, Tennessee, April 29-May 4, 1994.

Kunz-Schughart, L. A., W. Mueller-Klieser, and J. P. Freyer, Tumorigenic conversion of rat embryo fibroblasts by T24HA-RAS transection is associated with systematic changes in cellular metabolism in vitro, 42nd Annual Meeting of the Radiation Research Society, Nashville, Tennessee, April 29-May 4, 1994.

Lehnert, B. E., D. C. Archuleta, A. Despande, N. M. Lehnert, and Y. E. Valdez, Tumor necrosis factor- $\alpha$ production by alveolar macrophages during the early development of phosgene-induced lung injury, 33rd Annual Meeting of the Society of Toxicology, Dallas, Texas, March 13-17, 1994; The Toxicologist 14, A752 (1994).

Lehnert, B. E., Y. E. Valdez, N. M. Lehnert, and M. D. Englen, Inhibition of alveolar macrophage proliferation and tumor necrosis factor- $\alpha$ production by interleukin-4, Am. Rev. Resp. Dis. 149, A1101 (1994).

Lynam, E. B., S. I. Simon, Y. P. Rochon, and L. A. Sklar, Lipopolysaccharide enhances CD11b/ CD18 function while inhibiting homotypic neutrophil aggregation, Rocky Mountain Cytometry Conference, Angel Fire, New Mexico, May 27-29, 1994.

Marrone, B. L., G. C. Salzman, S. H. Pendergrass, and J. A. Gonzales, Development of image cytometry methods for chromosome and gene mapping, Clinical Cytometry Meeting, Charleston, South Carolina, September 9-12, 1994.

Minter, S. Y., L. D. Bustos, J. A. Dickson, and H. A. Crissman, Phosphorylations in S and G2 regulate cycle progression in post-mitotic G1 phase, Cell Kinetics Meeting, Louisville, Kentucky, March 24-27, 1994.

Nolan, J. P., R. A. Posner, R. C. Habbersett, J. C. Martin, and L. A. Sklar, Development of a rapid kinetics flow cytometer, Rocky Mountain Cytometry Conference, Angel Fire, New Mexico, May 27-29, 1994.

Nolan, J. P., R. A. Posner, R. C. Habbersett, J. C. Martin, and L. A. Sklar, Rapid kinetics flow cytometry, XVII Congress of the International Society for Analytical Cytology, Lake Placid, New York, October 16-21, 1994.

Okinaka, R. T., Application of denaturing gradient gel electrophoresis and single-strand conformation polymorphism techniques in mutation detection, 42nd Annual Meeting of the Radiation Research Society, Nashville, Tennessee, April 29-May 4, 1994. 
Okinaka, R. T., S. L. Anzick, G. F. Strniste, and W. G. Thilly, Denaturing gradient gel analysis of mutations induced in human cells by long-term, low dose-rate exposure to gamma rays, 30th Meeting of the International Committee on Space Research, Hamburg, Germany, July 11-30, 1994.

Parson, J. D., C. Deka, R. C. Habbersett, J. C. Martin, M. A. Naivar, J. A. Steinkamp, M. E. Wilder, and J. H. Jett, Digital processing of phase-sensitive flow cytometry signals, XVII Congress of the International Society for Analytical Cytology, Lake Placid, New York, October 16-21, 1994.

Reynolds, R. J., The induction and repair of closely opposed cyclobutyl pyrimidine dimers, 22nd Annual Meeting of the American Society for Photobiology, Scottsdale, Arizona, June 25-29, 1994.

Reynolds, R. J., Translesion synthesis at closely opposed dimers, The M. D. Anderson Cancer Center Cell Cycle Workshop: Mechanisms of Genome Instability and Genetic Toxicity, Smithville, Texas, March 11, 1994.

Rhein, A. P., K. P. Gilbertz, D. Van Bueningen, Analysis of early changes in cell-cycle kinetics after low-dose irradiation, Rocky Mountain Cytometry Conference, Angel Fire, New Mexico, May 27-29, 1994.

Roslaniec, M. C., J. C. Martin, R. J. Reynolds, and L. S. Cram, Development of a high-speed optical chromosome sorter based on photoinduced cross-linking of DNA with psoralens, XVII Congress of the International Society for Analytical Cytology, Lake Placid, New York, October 16-21, 1994.

Salzman, G. C., R. J. Beckman, S. J. Stewart, and C. C. Stewart, Software for leukemia immunophenotyping, Clinical Applications of Cytometry Meeting, Charleston, South Carolina, September 9-12, 1994.

Salzman, G. C., and C. C. Stewart, Normalization of clinical immunophenotyping data, Rocky Mountain Cytometry Conference, Angel Fire, New Mexico, May 27-29, 1994.

Salzman, G. C., S. J. Stewart, and C. C. Stewart, Normalization of immunophenotyping data, XVII Congress of the International Society for Analytical Cytology, Lake Placid, New York, October 16-21, 1994.

Sebring, R. J., D. C. Archuleta, A. Deshpande, and B. E. Lehnert, Light and electron microscopic changes during the course of development of phosgene-induced lung injury, 33rd Annual Meeting of the Society of Toxicology, Dallas, Texas, March 13-17, 1994; The Toxicologist 14, A1200, 1994.

Shera, K. A., S. L. Anzick, E. W. Campbell, B. L. Marrone, M. K. McCormick, R. K. Moyzis, and L. L. Deaven, Down's syndrome-specific probe generated by inter-ALU PCR of a yeast artificial chromosome library clone, 1st Annual Imagenetics-Sponsored Lecture Series on Genetics and Human Health, Lake Tahoe, California, February 8-11, 1994. 
Simon, S. I., E. Lynam, L. A. Sklar, and C. W. Smith, L-Selectin is a co-signal for $b_{2}$-integrin dependent adhesion, Rocky Mountain Cytometry Conference, Angel Fire, New Mexico, May 27-29, 1994.

Sklar, L. A., M. Domalewski, T. Gilbert-Houghton, R. Posner, and R. Freer, A model for ligandreceptor dynamics and neutrophil signal transduction, Rocky Mountain Cytometry Conference, Angel Fire, New Mexico, May 27-29, 1994.

Stackhouse, M. A., B. L. Marrone, and D. J. Chen, Refined chromosomal mapping of the human radiation repair gene XRCC4L to chromosome 5Q13-Q14, 42nd Annual Meeting of the Radiation Research Society, Nashville, Tennessee, April 29-May 4, 1994.

Steinkamp, J. A., C. Deka, B. E. Lehnert, and H. A. Crissman, Phase-sensitive flow cytometry, XVII Congress of the International Society for Analytical Cytology, Lake Placid, New York, October 16-21, 1994.

Takiguchi, Y., and D. J. Chen, Genomic structure of the mouse apurinic/apyrimidic endonuclease gene, American Association for Cancer Research, San Francisco, California, April 10-13, 1994.

Takiguchi, Y., and D. J. Chen, Structure of the mouse apurinic/apyrimidic endonuclease gene and its possible pseudogenes, 42nd Annual Meeting of the Radiation Research Society, Nashville, Tennessee, April 29-May 4, 1994.

Yamada, Y., and D. J. Chen, Molecular analysis of radiation-induced large deletions containing the HPRT locus in normal human fibroblasts, 42nd Annual Meeting of the Radiation Research Society, Nashville, Tennessee, April 29-May 4, 1994.

\section{Conference Proceedings and Reports}

Deka, C., J. A. Steinkamp, and L. A. Sklar, Fluorescence lifetime measurements in a flow cytometer by amplitude demodulation using digital data acquisition technique, Proceedings of the Optical Society of America Conference on Laser Applications to Chemical Analysis (Jackson Hole, Wyoming 1994), Technical Digest Series 5, pp. 143-146.

Jett, J. H., Flow Cytometry: A powerful technology for measuring biomarkers, Proceedings of the DOE Biomarkers Symposium, Santa Fe, New Mexico, April 27, 1994, p. 14.

Kim, J. M., D. C. Archuleta, N. M. Lehnert, H. A. Crissman, L. R. Gurley, E. M. Bradbury, and B. E. Lehnert, In vivo and in vitro effects of staurosporine on the DNA distributions in and proliferation of various rodent cell populations, Los Alamos National Laboratory report LA12812-MS, UC-408 (August 1994).

Lehnert, B. E., R. J. Sebring, and G. Oberdörster, Pulmonary macrophages: Phenomena associated with the particle "overload" condition, Proceedings of the 4th International Inhalation Symposium: Toxic and Carcinogenic Effects of Solid Particles in the Respiratory Tract, U. Mohr, Ed. (International Life Sciences Institute, Washington, D.C., 1994), pp. 159-176. 
Nickoloff, J. A., W. P. Deng, E. M. Miller, and F. A. Ray, Site-directed mutagenesis of doublestranded plasmids, domain substitution, and marker rescue by comutagenesis of restriction sites, Contemporary Nucleic Acid Protocols Methods in Molecular Biology (A. Harwood, Humana Press, Totowa, New Jersey, 1994), Vol. 38, p. 127.

Pendergrass, D., Y. E. Valdez, and B. E. Lehnert, Proliferation of rat alveolar macrophages stimulated by granulocyte/macrophage colony stimulating factor and the effects of differing cellular burdens of particles on the proliferative response, Proceedings of the 4th International Inhalation Symposium on Toxic and Carcinogenic Effects of Solid Particles in the Respiratory Tract, U. Mohr, Ed. (International Life Sciences Institute, Washington, D.C., 1994), pp. 553-563.

Sklar, L. A., G. Jones, and T. Houghton, Cellular and biological applications of laser-induced fluorescence, Proceedings of the Optical Society of America Conference on Laser Applications to Chemical Analysis (Jackson Hole, Wyoming, 1994), Technical Digest Series 5, pp. 188-191.

Steinkamp, J. A., Phase-sensitive flow cytometry: new technology for analyzing biochemical, functional, and structural features in fluorochrome-labeled cells/particles, Proceedings of the Optical Society of America Conference on Laser Applications to Chemical Analysis (Jackson Hole, Wyoming, 1994), Technical Digest Series 5, p. 86.

\section{Review Articles}

Crissman, H. A., and G. T. Hirons, Staining of DNA in live and fixed cells, in Methods in Cell Biology: Flow Cytometry, Z. Darzynkiewicz, J. P. Robinson, and H. A. Crissman, Eds. (Academic Press, New York, 1994), pp. 195-209.

Crissman, H. A., N. Oishi, and R. C. Habbersett, Detection of BrdUrd-labeled cells by differential fluorescence analysis of DNA fluorochromes: pulse-chase and continuous labeling methods, in Methods in Cell Biology: Flow Cytometry, Z. Darzynkiewicz, J. P. Robinson, and H. A. Crissman, Eds. (Academic Press, New York, 1994), Vol. 41, pp. 341-349.

Crissman H. A., and J. A. Steinkamp, Cellular protein content measurements, in Methods in Cell Biology: Flow Cytometry, Z. Darzynkiewicz, J. P. Robinson, and H. A. Crissman, Eds. (Academic Press, New York, 1994), Vol. 41, pp. 175-183.

Fawcett, J. J., J. L. Longmire, J. C. Martin, L. L. Deaven, and L. S. Cram, Large-scale chromosome sorting, in Methods in Cell Biology: Flow Cytometry, 2nd ed., Z. Darzynkiewicz, J. Robinson, and H. A. Crissman, Eds. (Academic Press, New York, 1994), Vol. 42, pp. 319-326.

Lehnert, B. E., Physiological and biochemical endpoints in inhalation toxicology, in Respiratory Toxicology and Risk Assessment (WHO/International Life Sciences Institute, Washington, D. C., 1994), pp. 175-205.

Lehnert, B. E., J. B. Ortiz, J. A. Steinkamp, G. L. Tietjen, R. J. Sebring, and G. Oberdorster, Mechanisms underlying the redistribution of particles among the lung's alveolar macrophages during alveolar phase clearance, in Inhaled Particles VII, Annals Occupational Hygiene, (Elsevier Science, Inc., United Kingdom, 1994), pp. 215-224. 
Okinaka, R. T., S. L. Anzick, and W. G. Thilly, DGGE analysis of specific exons in x-ray of the HPRT gene from x-ray-induced mutant populations, in Molecular Mechansims in Radiation Mutagenesis and Carcinogenesis, K. Chadwick, Ed. (Luxembourgh, Belgium, 1994), pp. 151156.

Steinkamp, J. A., Phase-sensitive detection methods for resolving fluorescence emission signals and quantifying lifetime directly, in Methods in Cell Biology: Flow Cytometry Series, 2nd ed., Z. Darzynkiewicz, J. Robinson, and H. A. Crissman, Eds. (Academic Press, New York, 1994),Vol. 42, pp. 627-640.

\section{LS-2}

\section{Papers}

Brughes, A. H., S. E. Ingraham, M. McLean, T. G. Thompson, J. D. Mcpherson, Z. Kote-Jarai, J. D. Carpten, C. J. Didonato, J. E. Ikeda, L. Surh, B. Writh, C. A. Sargent, M. A. Ferguson-Smith, P. Fuerst, R. K. Moyzis, D. L. Grady, A. MacKenzie, and J. J. Wasmuth, A multicopy dinucleotide marker that maps close to the spinal muscular atrophy gene, Genomics 21:394 (May 1994).

Catasti, P., G. Gupta, A. E. Garcia, R. L. Ratliff, L. Hong, P. Yau, R. K. Moyzis, and E. M. Bradbury, Unusual structures of the tandem repetitive DNA sequences located at human centromeres, Biochemistry 33, 3819-3830 (1994).

D’Anna, J. A., J. G. Valdez, S. Peterson, and H. A. Crissman, Replicons May Be Poised For Initiation In Mimosine-Blocked CHO Cells, Mol. Biol. of the Cell 5:S, 13a (1994).

Dooley, T. P., H. M. Mitchison, P. B. Munroe, P. Probst, M. Neal, M. J. Siciliano, N. A. Doggett, D. F. Callen, R. M. Gardiner, and S. E. Mole, Mapping of two phenol sulphotransferase genes, STP and STM, to chromosome 16p: candidate genes for Batten Disease, Biochem. Biophys. Res. Commun. 205, 482-489 (1994).

Dooley, T. P., P. Probst, P. B. Munroe, S. E. Mole, Z. Liu, and N. A. Doggett, Genomic organization of the human catecholamine-sulfating phenol sulfotransferase gene (STM), Biochem.

Biophys. Res. Comm. 205, 1325-1332 (1994).

Goodart, S. A., A. D. Simmons, D. L. Grady, K. Rojas, R. K. Moyzia, M. Lovett, J. Overhauser, A yeast artificial chromosome contig of the critical region for cri du chat syndrome, Genomics 24, 63-68 (1994).

L. R. Gurley, K. O. Umbarger, J. M. Kim, E. M. Bradbury, and B. E. Lehnert, Staurosporine analysis and its pharmacokinetics in the blood of rats, Los Alamos National Laboratory Report LA-12788-MS, (July 1994).

Meyne J., E. H. Goodwin, and R. K. Moyzis, Chromosomal localization and organization of the simple sequence repeat of human satellite I, Chromosoma 103, 99-103 (1994).

Nancarrow, J. K., E. Kremer, E. Baker, K. Holman, H. Eyre, N. A. Doggett, D. Le Paslier, D. F. 
Callen, G. R. Sutherland, and R. I. Richards, Implications of FRA16A structure for the mechanism of chromosomal fragile site genesis, Science 264, 1938-1941 (1994).

Okumura, K., R. L. Stallings, N. A. Doggett, and D. C. Ward, In situ hybridization mapping of human chromosome 16: evidence for a high frequency of repetitive DNA sequences, Cytogen. Cell Gene. 67, 61-67 (1994).

Shen, Y., H. M. Kozman, A. Thompson, H. A. Phillips, K. Holman, J. Nancarrow, S. Lane, Z. L. Chen, S. Apostolou, N. A. Doggett, D. F. Callen, J. C. Mulley, G. R. Sutherland, and R. I. Richards, A PCR-based genetic linkage map of human chromosome 16, Genomics 22, 68-76 (1994).

Skinner, M. M., H. Zhang, D. H. Leschnitzer, H. Bellamy, R. M. Sweet, C. M. Gray, R. N. H. Konings, A. H. J. Wang, and T. C. Terwilliger, Structure of the gene V protein of bacteriophage $\mathrm{fl}$ determined by multiwavelength $\mathrm{x}$-ray diffraction on the selenomethionyl protein, Proc. Natl. Acad. Sci. U.S.A. 91, 2071-2075 (1994).

Terwilliger, T. C., MAD phasing: Bayesian estimates of Fa, Acta Cryst. D50, 11-16 (1994).

Terwilliger, T. C., MAD phasing: treatment of dispersive differences as isomorphous replacement information, Acta Cryst. D50, 17-23 (1994).

Terwilliger, T. C., H. B. Zabin, M. P. Horvath, W. S. Sandberg, and P. M. Schlunk, In vivo characterization of mutants of the bacteriophage $\mathrm{f1}$ gene $\mathrm{V}$ protein from ff phage suggest possible protein-protein interactions in The GVP-ssDNA Complex, Biochemistry 33, 7768-7778 (1994).

Ward, O. G., R. L. Miller, E. H. Johnson, J. N. Lucas, J. Meyne, Identification of trisomy in Macaca fascicularis by fluorescence in situ hybridization with a human chromosome 13 DNA library, Hum. Genet. 94, 247-251 (1994).

Weber, B. H. F., H. Stohr, I. Siedlaczck, J. L. Longmire, L. L. Deaven, A. M. V. Duncan, and O. Riess, Characterization of a cosmid library from flow-sorted chromosome 11, Chromosome Res. 2, 201-207 (1994).

Weiffenbach, B., J. Dubois, S. Manning, N. S. Ma, B. C. Schutte, S. T. Winokur, M. R. Altherr, S. J. Jacobsen, V. P. Stanton, Jr., K. Yokoyama, and D. Moir, YAC contigs for $4 \mathrm{q} 35$ in the region of the facioscapulohumeral muscular dystrophy (FSHD) gene, Genomics 19:532-541 (1994).

\section{Book Chapters}

Doggett, N. A., and D. F. Callen, Report of the genetic constituency of chromosome 16, in Human Gene Mapping 1993: A Compendium, A. J. Cuticchia, and P. L. Pearson, Eds. (The Johns Hopkins University Press, Baltimore, Maryland, 1994), pp. 506-528.

Doggett, N. A., D. L. Grady, J. L. Longmire, and L. L. Deaven, Generation and mapping of chromosome-specific sequence-tagged sites, in Automated DNA Sequencing and Analysis, M. D. Adams, C. Fields, and J. C. Venter, Eds. (Academic Press, London, 1994), pp. 96-100.

Meyne, J., and E. H. Goodwin, Strand-specific fluorescence in situ hybridization for determining 
orientation and direction of DNA sequences, in Methods in Molecular Biology: In Situ Hybridization Protocols, K. H. A. Choo, Ed. (Humana Press, Totowa, New Jersey, 1994), Vol. 33, pp. 141145.

Meyne, J., and R. K. Moyzis, In Situ hybridization using synthetic oligomers as probes for centromere and telomere repeats, in Methods in Molecular Biology: In Situ Hybridization Protocols, K. H. A. Choo, Ed. (Humana Press, Totowa, New Jersey, 1994), Vol. 33, pp. 63-94.

Rappaport, B., J. Gatewood, C. Fields, and N. A. Doggett, Software tools for primer site prediction and sequence similarity searches, in Automated DNA Sequencing and Analysis, M. D. Adams, C. Fields, and J. C. Venter, Eds. (Academic Press Limited, London, 1994), pp. 289-293.

Stallings, R. L., N. A. Doggett, A. Ford, J. Longmire, C. E, Hildebrand, L. L. Deaven, and R. K. Moyzis, Applications of cosmid libraries in genome mapping and sequencing efforts, in Automated DNA Sequencing and Analysis, M. D. Adams, C. Fields, and J. C. Venter, Eds. (Academic Press, London, 1994), pp. 83-88.

\section{Abstracts and Meeting Presentations}

Aksentijevich, I., X. Chen, J. E. Barlow, E. Levy, E. Pras, D. Gardner, M. Pras, N. FischelGodsian, A. Kupelian, M. Shoat, J. I. Rotter, Y. Shen, R. I. Richards, D. F. Calken, N. A. Doggett, P. Liu, T. Blacke, D. Shelton, D. Gumucio, and D. F. Kastner, Refined localization of the gene causing famalial Mediterranean fever, Third International Workshop on Human Chromosome 16 (Pittsburgh, Pennsylvania, 1994), p.1.

Aksentijevich, I., X. Chen, E. Levy, J. E. Balow, D. Gardner, E. Pras, M. Prạs, N. FischelGhodsian, A. Kupelian, M. Shohat, J. I. Rotter, Y. Shen, R. I. Richards, D. F. Callen, N. A. Doggett, P. Liu, T. Blake, D. Shelton, D. Gumucio, and D. L. Kastner, Genetic and physical localization of the gene causing familial Mediterranean fever, Am. J. Hum. Genet. 55, Suppl:1480 (1994).

Altherr, M. R., A. A. Ford, C. Naranjo, J. M. Buckingham, A. C. Munk, and R. K. Moyzis, Using expressed sequences as nucleation points for genomic sequencing, DOE Contractors Meeting, Santa Fe, New Mexico (1994).

Balding, D. J., D. C. Bruce, W. L. Bruno, N. A. Doggett, E. Knill, D. C. Torney, and C. C. Whittaker, Efficient pooling of YAC libraries, Cold Spring Harbor Meeting on Genome Mapping and Sequencing (New York, 1994), p.17.

Bengtsson, U., M. R. Altherr, J. J. Wasmuth, and S. T. Winokur, High-resolution fluorescence in situ hybridization to linearly extended DNA visually maps a tandem repeat associated with facioscapulohumeral muscular dystrophy immediately adjacent to the telomere of $4 \mathrm{q}, \mathrm{Hum}$. Mol. Genet. 10, 1801-1805 (1994).

Callen, D. F., N. A. Doggett, S. Apostolou, G. Dolman, S. A. Lane, S. A. Whitmore, and G. R. Sutherland, Use of a high-resolution hybrid cell panel for physical mapping of chromosome 16 , Third International Workshop on Human Chromosome 16 (Pittsburgh, Pennsylvania, 1994), p. 5.

Chen, X., I. Aksentijevich, E. Levy, E. Pras, J. E. Barlow, D. Gardner, M. Pras, D. F. Kastner, N. 
Fischel-Godsian, A. Kupelian, M. Shoat, J. I. Rotter, Y. Shen, R. I. Richards, D. F. Callen, N. A. Doggett, P. Liu, T. Blacke, D. Shelton, and D. Gumucio, Refined localization of the gene causing famalial Mediterranean Fever, Cold Spring Harbor Meeting on Genome Mapping and Sequencing (New York, 1994), p. 42.

Cobo, M., J. G. Valdez, and L. R. Gurley, Inhibition of mitotic-specific histone phosphorylation by sodium arsenite, 8th International Workshop on In Vitro Toxicology (Kartause Ittingen, Switzerland, 1994), p. 22.

Deaven, L. L., M. K. McCormick, D. L. Grady, D. L. Robinson, J. M. Buckingham, N. C. Brown, E. W. Campbell, M. L. Campbell, J. J. Fawcett, P. Jewett, J. L. Longmire, A. Martinez, L. J. Meincke, P. L. Schor, and R. K. Moyzis, Construction of DNA libraries from flow-sorted human chromosomes, Cold Spring Harbor Meeting on Genome Mapping and Sequencing (New York, 1994), p. 51.

Doggett, N. A., D. F. Callen, L. A. Duesing, J. G. Tesmer, L. J. Meincke, D. C. Bruce, M. R. Altherr, A. A. Ford, D. C. Torney, R. D. Sutherland, M. G. Lowenstein, M. O. Mundt, W. J. Bruno, E. H. Knill, L. L. Deaven, G. R. Sutherland, R. I. Richards, and R. K. Sutherland, An integrated physical/genetic/cytogenetic map of human chromsome 16, Am. J. Hum. Genet. 55, Suppl:1505 (1994).

Doggett, N. A., D. F. Callen, L. A. Duesing, J. G. Tesmer, L. J. Meincke, D. C. Bruce, M. R. Altherr, A. A. Ford,'D. C. Torney, R. D. Sutherland, M. G. Lowenstein, M. O. Mundt, W. J. Bruno, E. H. Knill, L. L. Deaven, G. R. Sutherland, R. I. Richards, and R. K. Moyzis, An integrated map of human chromosome 16, Cold Spring Harbor Meeting on Genome Mapping and Sequencing (New York, 1994), p. 59.

Doggett, N. A., D. F. Callen, L. A. Duesing, J. G. Tesmer, L. J. Meincke, D. C. Bruce, M. R. Altherr, A. A. Ford, D. C. Torney, R. D. Sutherland, M. G. Lowenstein, M. O. Mundt, W. J. Bruno, E. H. Knill, L. L. Deaven, G. R. Sutherland, R. I. Richards, and R. K. Moyzis, An integrated map of human chromosome 16, Third International Workshop on Human Chromosome 16 (Pittsburgh, Pennsylvania, 1994), p. 9.

Goodart, S. A., A. Simmons, D. L. Grady, K. Rojas, R. K. Moyzis, M. Lovett, and J. Overhauser, A yeast artifical chromosome contig of the critical region for cri du chat syndrome, Third International Chromosome 5 Workshop, Irvine, California, 1994.

Grady, D. L., J. D. McPherson, D. L. Robinson, L. L. Deaven, J. J. Wasmuth, J. Overhauser, J. Feder, E. Nickerson, and R. K. Moyzis, The generation of a framework STS map for human chromosome 5, Third International Chromosome 5 Workshop, Irvine, California, 1994.

Grady, D. L., D. L. Robinson, J. Overhauser, M. Feder, J. D. McPherson, E. Nickerson, J. J. Wasmuth, L. L. Deaven, and R. K. Moyzis, The generation of a framework STS map for human chromosome 5, Cold Spring Harbor Meeting on Genome Mapping and Sequencing (New York, 1994), p. 76.

Hersman, L., T. Lloyd, and G. Sposito, Iron uptake by microorganisms from iron oxides, $A b$ stracts: Annual Meeting of the American Society for Microbiology (Las Vegas, Nevada, May 2327, 1994), p. 319.

Hersman, L., T. Lloyd, and G. Sposito, Microbial-enhanced mineral dissolution, Abstrasts: 
Annual Meeting of the American Chemical Society (San Diego, California, March 13-17, 1994), GEOC-O 123 .

Johnson, V. P., M. R. Altherr, J. M. Blake, and L. D. Keppen, FISH detection of Wolf-Hirschhorn Syndrome: exclusion of D4F26 as critical site, Am. J. Med. Genet. 52, 70-74 (1994).

Kaiser, U. B., H. Dushkin, M. R. Altherr, D. R. Bier, and W. W. Chin, Chromosomal localization of the gonadotropin-releasing hormone receptor gene to human chromosome 4q13.1-21.1 and mouse chromosome 5, Genomics 20, 506-508 (1994).

Landes, G., W. Dackowski, T. Burn, T. Connors, L. Petry, H. Shukla, R. Hakim, N. A. Doggett, and K. Klinger, Transcriptional Map of the PKD1 Locus, Am. J. Hum. Genet. 55, Suppl:1535 (1994).

Landes, G., L. R. Petry, W. R. Dackowski, R. Hakim, N. A. Doggett, and K. W. Klinger, Chromosome 16p13.3: Enrichment of Kindey cDNAs, Third International Workshop on Human Chromosome 16, (Pittsburgh, Pennsylvania, 1994), p. 16.

Lerner, T. J., L. Kenneth, L. D'Arigo, J. L. Haines, N. A. Doggett, and A. Buckler, Isolation of transcribed sequences from the Batten candidate region using exon amplification, Third International Workshop on Human Chromosome 16 (Pittsburgh, Pennsylvania, 1994), p. 17.

Lovett, M., A. Buckler, G. Clines, R. Del Mastro, G. Dolganvov, T. Gallardo, S. Goodart, D. L. Grady, C. Hillard, E. Wang Jabs, X. Li, R. K. Moyzis, J. Overhauser, K. Rojas, Q. R. Simmons, A. Stotler, L. Wang, and C. Wise, Physical and transcription mapping across four regions of human chromosome 5, Third International Chromosome 5 Workshop, Irvine, California, 1994.

Medvick, P. A., T. J. Beugelsdijk, J. T. Chen, B. K. Den Hartog, L. A. Stovall, M. R. Altherr, D. C. Bruce, N. A. Doggett, L. L. Deaven, and R. K. Moyzis, System integration for automation of genomic research, Cold Spring Harbor Meeting on Genome Mapping and Sequencing (New York, 1994), p. 167.

Meyne, J., and E. H. Goodwin, Strand-specific FISH: determination of orientation and direction of repetitive DNA sequences in mammalian chromosomes, Rocky Mountain Cytometry Conference, Angel Fire, New Mexico (1994).

Meyne, J., E. H. Goodwin, S. M. Bailey, L. R. Smith, D. I. Quigley, and R. K. Moyzis, Strandspecific in situ hybridization: application of the method, 4th DOE Genome Program ContractorGrantee Meeting, Santa Fe, New Mexico (1994).

Meyne, J., E. H. Goodwin, and R. K. Moyzis, Strand-specific FISH: a new method for analysis of pericentromeric heterochromatin in mammalian chromosomes, 4th European Workshop on Cytogenetics and Molecular Genetics of Human Solid Tumors, Noordwijkerhout, The Netherlands (1994).

Richards, R. I., J. K. Nancarrow, M. Mangelsdorf, E. Kremer, K. Holman, H. Eyre, N. A. Doggett, D. Le Paslier, T. Hori, D. F. Callen, and G. R. Sutherland, Chromosomal fragile site, FRA16A: implications for fragile site genesis, Am. J. Hum. Genet. 55, 52 (1994).

Spritz, R. A., K. M. Strunk, S. T. Lee, J. M. Lu-Kuo, D. C. Ward, D. LePaslier, M. R. Altherr, T. 
E. Dorman, and D. T. Moir, A YAC contig spanning a cluster of human type III receptor protein tyrosine kinase genes (PDGFRA-KIT-KDR) in chromosome segment 4q12, Genomics 22, 431-436 (1994).

Sutherland, R. D., R. M. Pecherer, L. A. Duesing, and N. A. Doggett, Analysis of genethon YAC data and incorporation into an existing genomic database, Third International Workshop on Human Chromosome 16 (Pittsburgh, Pennsylvania, 1994), p. 20.

Sutherland, R. D., R. M. Pecherer, L. A. Duesing, and N. A. Doggett, Analysis of genethon YAC data and incorporation into an existing genomic database, Cold Spring Harbor Meeting on Genome Mapping and Sequencing (New York, 1994), p. 17.

Winokur, S. T., U. Bengtsson, J. Feddersen, K. D. Matthews, B. Weiffenbach, H. Bailey, R. P. Markovich, J. C. Murray, J. J. Wasmuth, M. R. Altherr, and B. C. Schutte, The DNA rearrangement associated with facioscapulohumeral muscular dystrophy involves a heterochromatin associated repetitive element: implications for a role for chromatin structure in the pathogenesis of the disease, Chromosome Res. 2, 225-234 (1994).

\section{Invited Lectures}

Terwilliger, T. C., Heavy: origin-removed Patterson Refinement of heavy atom parameters, American Crystallographic Association Annual Meeting, Atlanta, Georgia (June 1994).

Terwilliger, T. C., Difference refinement: a method for obtaining estimates of differences between closely related structure, American Crystallographic Association Annual Meeting, Atlanta, Georgia (June 1994).

Terwilliger, T. C., Gene V protein structure and cooperativity of nucleic acid binding, Gordon Research Conference on Biomolecular Recognition and Immobilization (August 1994).

\section{Thesis}

Shu, F., "Solvent Structure in Predeuterated Recombinant Myoglobin," Ph.D. thesis, State University of New York at Stony Brook (1994). 


\title{
AWARDS, HONORS, AND PATENTS \\ Center for Human Genome Studies
}

\author{
L. L. Deaven Elected Member, Human Genome Organization \\ R. K. Moyzis NIH/DOE Steering Committee, Human Genome Organization \\ Elected Member, Human Genome Organization \\ Adjunct Professor of Cell Biology, University of New Mexico \\ Recipient, E. O. Lawrence Award
}

\section{Life Sciences Division}

M. R. Altherr

E. M. Bradbury

Member, NIH C Study Section-Neurology

Section Member, Scientific Advisory Board, Huntington's Disease Society of America

Assistant Researcher, University of California at Irvine

Member, Science Advisory Board for the Advanced Light Source, Lawrence Berkeley Laboratory

Chairman, X-ray Microscopy Advisory Committee, Lawrence Berkeley Laboratory

Member, Health and Environmental Research Advisory Committee

Member, Joint NIH/DOE Committee on the Evaluation of Biotechnology Research, Japan 1992-1993

Editorial Board, Critical Reviews in Eukaryotic Gene Expression

Editorial Board, Biochemistry

Adjunct Professor, Department of Cell Biology, University of New Mexico School of Medicine

L. S. Cram

Adjunct Associate Professor, University of New Mexico School of Medicine

Chairman, Technical Area Coordinating Team for Defense Technology Transfer Program

Chairman, NIH Special Study Section, Cytometry Instrumentation Editorial Board, Cytometry

H. A. Crissman Editorial Board, European Journal of Histochemistry

Editorial Board, Cytometry

Councilor, International Society for Analytical Cytology

R\&D 100 Award, Phase-Sensitive Flow Cytometer

Adjunct Professor, University of New Mexico

N. A. Doggett Editorial Committee, Genome Database Chromosome 16, International Human Gene Mapping Workshop

J. P. Freyer

Associate Editor, International Joumal of Radiation Oncology, Biology, and Physics 
S. B. Goldbard Isolation of trophoblasts, Eur. Patent \# WO 9419487, Issued 9/94

P. J. Jackson Adjunct Professor, Department of Biological Science, Northern Arizona University

Adjunct Associate Professor, Department of Cell Biology, University of New Mexico

Adjunct Professor, Department of Agronomy and Soil Sciences, New Mexico State University

LANL Representative, Steering Committee, Southwest Consortium for Plant Genetics and Water Resources

LANL Representative, University of California, Systemwide Biotechnology Research and Education Program

J. H. Jett

Adjunct Professor, Department of Cell Biology, University of New Mexico Scientific Staff, University of New Mexico Cancer Center

P. M. Kraemer

Adjunct Associate Professor, Department of Cell Biology, University of New Mexico

B. E. Lehnert Adjunct Professor, Department of Biology, Jackson State University

Editorial Board, Joumal of Leukocyte Biology

M. A. MacInnes

Adjunct Professor, Department of Science and Technology, New Mexico Highlands University

B. L. Marrone

Isolation of trophoblasts, Eur. Patent \#WO 9419487, Issued 9/94

C. E. Hildebrand Adjunct Professor, Department of Cell Biology, University of New Mexico

Elected Member, Department of Human Genome Organization

R. T. Okinaka Adjunct Professor, Department of Cell Biology, University of New Mexico

G. C. Salzman Editorial Board, Cell Biophysics

Councilor, International Society of Analytical Cytology

B. P. Schoenborn Recipient, E. O. Lawrence Award

Adjunct Professor, State University of New York at Stony Brook

Adjunct Professor, Columbia University

L. A. Sklar Mentor for Student Finalist, Society of Leukocyte Biology

Editor, Biological Signals

Editor, Journal of Fluorescence

Isolation of trophoblasts, Eur. Patent \#WO 9419487, Issued 9/94

J. A. Steinkamp R\&D 100 Award, Phase-Sensitive Flow Cytometer 
G. F. Strniste Adjunct Professor, Department of Cell Biology, University of New Mexico Southwest Regional Spaceport Science Advisory Committee, New Mexico State University, Physical Sciences Laboratory

Japanese Government Research Award for Foreign Specialists, Science and Technology Agency-Japan, National Institute of Radiological Sciences, Chiba, Japan (March 1994)

W. R. Wharton Scientific Staff, University of New Mexico Cancer Center

Adjunct Associate Professor, Department of Pathology, University of New Mexico

Adjunct Associate Professor, Department of Cell Biology, University of New Mexico

Adjunct Fellow, Eleanor Roosevelt Institute for Cancer Research

T. W. Whaley Adjunct Professor, Department of Chemistry, University of New Mexico Executive Committee, University of California Systemwide Biotechnology Research and Education Program 
US GPO 1995 673-213/33016 
This report has been reproduced directly from the best available copy.

It is available to DOE and DOE contractors from the Office of Scientific and Technical Information,

P.O. Box 62,

Oak Ridge, TN 37831.

Prices are available from

(615) 576-8401.

It is available to the public from the

National Technical Information Service,

U.S. Department of Commerce,

5285 Port Royal Rd.

Springfield, VA 22161. 


\section{Los Alamos \\ NATIONAL LABORATORY}

Los Alamos, New Mexico 87545 